UNIVERSIDADE DE SÃO PAULO

INSTITUTO DE GEOCIÊNCIAS

\title{
AVALIAÇÃO DE PORTE DE UM SISTEMA ENTRELAÇADO NA FORMAÇÃO MARIZAL (APTIANO, BACIA DO TUCANO) A PARTIR DE ANÁLISES DE PALEOSINUOSIDADE E PALEOHIDRÁULICA
}

Maria Paula Ramos Clavijo

Orientador: Prof. Dr. Renato Paes de Almeida

DISSERTAÇÃO DE MESTRADO

Programa de Pós-Graduação em Geoquímica e Geotectônica

SÃO PAULO 
Nome: Maria Paula Ramos Clavijo

\section{AVALIAÇÃO DE PORTE DE UM SISTEMA ENTRELAÇADO NA FORMAÇÃO MARIZAL (APTIANO, BACIA DO TUCANO) A PARTIR DE ANÁLISES DE PALEOSINUOSIDADE E PALEOHIDRÁULICA}

Dissertação apresentada ao Instituto de Geociências da Universidade de são Paulo, como parte dos requisitos para obtenção do grau de Mestre em Geociências.

Área de concentração: Geotectônica

Orientador: Prof. Dr. Renato Paes de Almeida

SÃO PAULO 
Autorizo a reprodução e divulgação total ou parcial deste trabalho, por qualquer meio convencional ou eletrônico, para fins de estudo e pesquisa, desde que citada a fonte.

\footnotetext{
Ficha catalográfica preparada pelo Serviço de Biblioteca e Documentação do Instituto de Geociências da Universidade de São Paulo
}

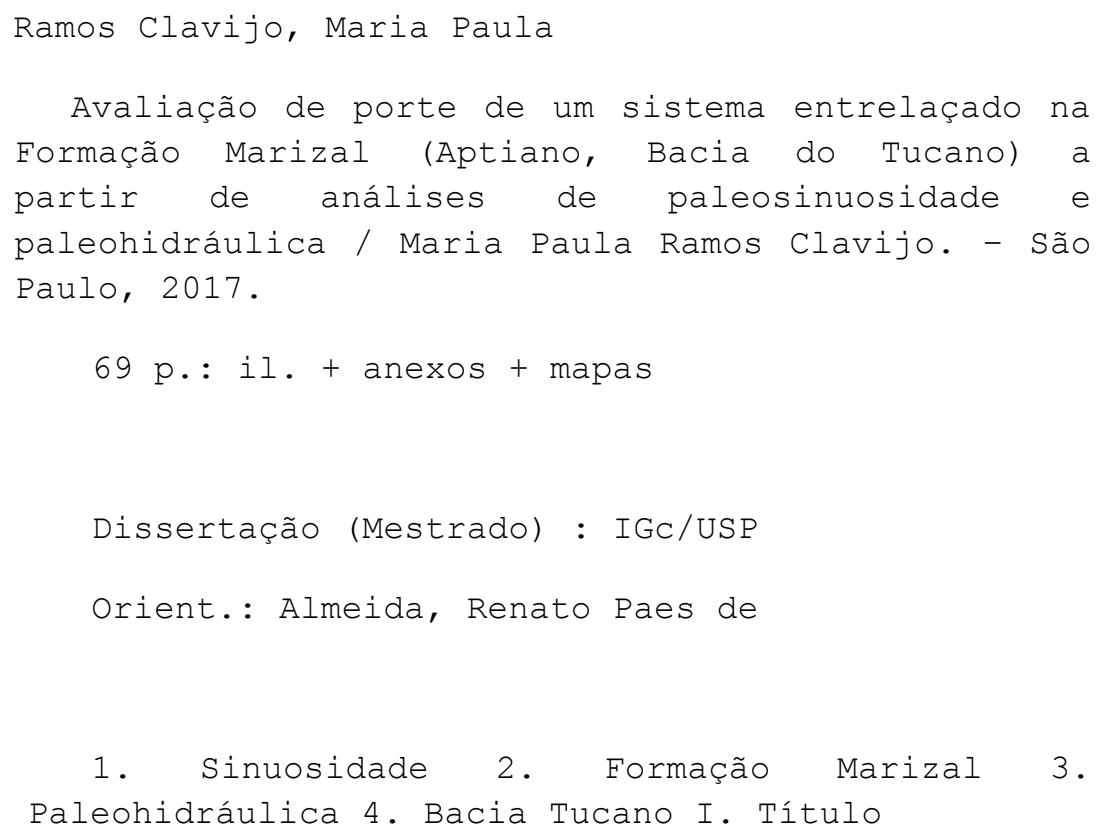


Título: AVALIAÇÃO DE PORTE DE UM SISTEMA ENTRELAÇADO NA FORMAÇÃO MARIZAL (APTIANO, BACIA DO TUCANO) A PARTIR DE ANÁLISES DE PALEOSINUOSIDADE E PALEOHIDRÁULICA

Dissertação apresentada ao Instituto de Geociências da Universidade de são Paulo, como parte dos requisitos para obtenção do grau de Mestre em Geociências.

Área de concentração: Geotectônica

Orientador: Prof. Dr. Renato Paes de Almeida

Aprovado em:

\section{Banca Examinadora}

Prof. Dr.

Instituição:

Julgamento:

Prof. Dr.

Instituição:

Julgamento:

Prof. Dr.

Instituição:

Julgamento: 
Para mi família 


\section{AGRADECIMENTOS}

Agradeço,

Primeiramente, ao Prof. Renato por conceder-me a oportunidade de fazer parte do grupo de pesquisa, por estar presente nesses dois anos de trabalho fornecendo apoio em todos os âmbitos, especialmente durante o trabalho de campo, pelo entusiasmo dos resultados e no encaminhamento das discussões. E, finalmente, por ser um exemplo de força de trabalho e liderança.

Ao Grupo Mocó, a Natalia, o Heitor, o Xupim e a Bia pela ajuda na coleta de dados o longo dos trabalhos de campo. À Lari pela companhia nas aulas e pelo apoio nos relatórios e prestações de contas. À Prof. Liliana pelo apoio e pelas discussões em campo. E especialmente ao Cristiano pela ajuda incondicional ao longo desses dois anos: nas aulas, nas discussões em campo, na revisão e no apoio para a culminação deste trabalho.

Ao Carlos pela disposição em me ensinar os programas de edições de mapas, e pelas criticas às imagens do trabalho.

Aos órgãos de fomento, à Fapesp pelo auxilio à pesquisa sob a forma do processo 2014/16739-8, 2016/03091-5, e ao $\mathrm{PRH}-241$ pelo auxilio através de bolsa.

Por fim, às pessoas que fizeram parte desta linda experiência e que tive o prazer de conhecer. Ao Santiago e ao Andrés por mostrarme un camino más relajado, pelo apoio, carinho e amizade. Ao Cleber pelas longas conversas e desabafos. Aos colombianos pelo apoio fora de casa. Ao Adrian pela boa companhia. À equipe de rugby Tsunami pela oportunidade de sentir-me em casa. À Mari, pela ajuda e a paciência nesta última parte do mestrado. Ao Cris, Lari, Dori, Fer, Naza, Helena, Julio, Pedro, e Marcelo pelo apoio para que esta etapa fosse terminada.

Aos professores e funcionários do IGc. 


\section{RESUMO}

Uma das principais questões da geologia sedimentar fluvial é a identificação do porte dos depósitos fluviais no registro geológico. O seguinte trabalho desenvolveu um método para determinação de um indicador de escala do sistema fluvial independente das medidas de espessura de séries, com base na relação empírica entre o porte do sistema fluvial e o comprimento de onda da sinuosidade de seu canal principal.

A Formação Marizal é interpretada como depósitos fluviais de rio entrelaçado do Aptiano, no município de Banzaê (Bahia-Brasil) as excelentes exposições e a continuidade lateral do Membro Banzaê permitiram a análise da distribuição espacial dos dados de paleocorrentes. Análise de 592 pares de estratificação cruzada e limite de séries permitiram reconhecer $\circ$ predomínio de acréscimo frontal em barras arenosas, corroborando a interpretação de depósitos de rios entrelaçados. Para uma área de 250 $\mathrm{Km}^{2}$, em 40 localidades tomaram-se 1264 medidas de estratificações cruzadas, permitindo a elaboração de mapas de paleocorrentes de três níveis estratigráficos de 10 a $15 \mathrm{~m}$ de espessura. Para cada estação pontual de medidas, foi possível estabelecer um erro em graus, com 95\% de confiança, determinado pela análise de uma grande amostra (938 medidas em uma única estação) tomada como representativa da distribuição típica. Essa abordagem permitiu reconhecer a variação nos sentidos de paleocorrentes em uma malha de afloramentos e reconstituir a padrões de sinuosidade do sistema, dando como resultado $9 \mathrm{~km}$ de comprimento de onda da sinuosidade preservada no registro sedimentar. Novas medidas de espessura de séries de estratificação cruzada $(n=2051)$ corroboram trabalhos anteriores, indicando média entre 21 e $23 \mathrm{~cm}$ para o Membro Banzaê, o que sugere canais com profundidade na escala de rios entrelaçados modernos de grande porte.

A análise de rios entrelaçados ativos com vazão conhecida mostra que o comprimento de onda da sinuosidade está diretamente relacionado à vazão média anual. A comparação do comprimento de onda dos rios ativos com o obtido no registro geológico para a unidade estudada permite concluir que o rio responsável pela deposição do Membro Banzaê da Fm. Marizal foi de grande porte, equiparável a rios de bacia de drenagem regional, como o Irrawaddy (Mianmar) e o Brahmaputra (Índia-Bangladesh). 


\section{ABSTRACT}

One of the main questions in fluvial sedimentary geology is the recognition of the scale of past fluvial systems in the rock record. This work proposes a method for the assessment of fluvial system scale independent of cross-strata set thickness measurements, based on the empirical relation between the size of the fluvial system and the wavelength of the sinuosity in its main channel.

The Marizal Formation is interpreted as deposits of an Aptian braided river. The excellent exposures of the Banzaê Member, in Banzaê municipality (Bahia State - Northeastern Brazil) and their lateral continuity, enabled an analysis of the spatial distribution of paleocurrent data. The analysis of 592 pairs of cross-strata set surfaces and cross-strata set bounding surfaces reveal the prevalence of downstream accretion in sandy bars, thus corroborating previous interpretations of a braided river. For an area of $250 \mathrm{Km}^{2}$, in 40 outcrops 1264 cross-strata set surfaces were measured, leading to paleocurrent maps for three 10 to $15 \mathrm{~m}$ thick stratigraphic levels. An error in degrees, with $95 \%$ of confidence, was attributed for each individual station, calculated based on the analysis of a large sample (938 measurements in one individual station) taken as representative of the typical distribution. This aproach enabled the recognition of the variability in local paleocurrent

directions, leading to the reconstruction of the sinuosity patterns of the system, pointing to a $9 \mathrm{~km}$ wavelength for the preserved sinuosity. New cross-strata set thickness measurements ( $n=2051$ ) corroborate previous works, with and mean thickness between 21 e $23 \mathrm{~cm}$ for the Banzaê Member, suggesting channel depths in the same scale of modern day large scale braided rivers.

The analysis of active braided rivers with known discharge reveals that the sinuosity wavelength is directly correlated to the mean annual dischage. Comparison of modern day rivers sinuosity wavelengths with the results obtained for the studied unit in the rock record indicates that the river responsible for the deposition of the Banzaê Member of the Marizal Formation was one of large dimensions, comparable to rivers of regional-scale drainage basins such as the Irrawaddy (Mianmar) and the Brahmaputra (India-Bangladesh). 


\section{SUMÁRIO}

Capítulo 1 - Considerações iniciais

1.1 Introdução

1.2 Justificativa

1.3 Objetivo

1.4 Localização e acessos das áreas de estudo

Capítulo 2 - Fundamentação Bibliográfica

2.1 Contexto Geológico

2.1.1 Estratigrafia

2.1.2 Formação Marizal

2.2 Sinuosidade no registro

Capítulo 3 - Metodologia

3.1 Análises de fácies e elementos arquiteturais $\quad 14$

3.2 Análise de sinuosidade $\quad 15$

3.2.1 Paleocorrentes 15

3.2.2 Comprimento de onda da sinuosidade em rios atuais $\quad 17$

$\begin{array}{ll}3.3 \text { Análise de profundidade } & 18\end{array}$

$\begin{array}{ll}\text { 3.3.1 Paleohidráulica } & 18\end{array}$

$\begin{array}{ll}\text { 3.3.2 Espessura de preenchimento } & 18\end{array}$

3.4 Processamento computacional $\quad 19$

Capítulo 4 - Resultados $\quad 20$

4.1 Arquitetura Deposicional 20

4.1.1 Caracterização de Fácies $\quad 20$

4.1.2 Caracterização das associações de fácies e elementos arquiteturais 22

4.2 Análises de Paleocorrentes $\quad 24$

4.2.1 Escala hectométrica - Área Ravina de Curralinho 24

4.2.2 Escala quilométrica - Área de Banzaê 28

4.2.3 Escala da Bacia do Tucano 35

4.3 Análises de Paleohidráulica 38

4.3.1 Área Ravina de Curralinho 38

4.3.2 Área de Banzaê $\quad 41$

4.3.3 Comparação com dados anteriores Bacia do Tucano 45

4.4 Comparações entre os dados de paleocorrente e paleohidráulica 45 
$\begin{array}{ll}5.1 \text { Sinuosidade } & 47\end{array}$

5.1.1 Sinuosidade do canal em escala quilométrica na região de Banzaê $\quad 47$

5.1.2 Comparação com sistemas ativos $\quad 48$

$\begin{array}{ll}5.2 \text { Profundidade } & 51\end{array}$

5.2.1 Paleohidráulica: espessuras de série $\quad 51$

5.2.2 Comparação com sistemas fluviais ativos $\quad 51$

Capítulo 6 - Conclusões $\quad 55$

$\begin{array}{ll}\text { Referências } & 57\end{array}$

$\begin{array}{ll}\text { Anexos } & 63\end{array}$

Anexo 1. Resultado gráfico das análises de reconstrução de superfícies barra.

Curralinho 64

Anexo 2. Resultado gráfico das análises de reconstrução de superfícies barra, Banzaê , mapa $A$.

Anexo 3. Resultado gráfico das análises de reconstrução de superfícies barra, Banzaê , mapa $B$.

Anexo 4. Resultado gráfico das análises de reconstrução de superfícies barra, Banzaê , mapa C. 


\section{ÍNDICE DE FIGURAS}

Figura 1. Mapas da localização da área de estudo. A. Mapa da Bacia de Tucano. B. Afloramento Ravina de Curralinho. C. Afloramentos da área de Banzaê. ............................ 4

Figura 2. Mapa geológico simplificado das bacias do Recôncavo, Tucano e Jatobá (extraído de Magnativa et al., 2003).

Figura 3. Carta estratigráfica atualizada e aspectos tectono-deposicionais da Bacia do Tucano na área estudada (extraído de Santos et al., 2010)......................................... 10

Figura 4. Coluna estratigráfica da Formação Marizal (extraído de Santos et al., 2010). ....12

Figura 5. Hierarquia de formas de leito e respectivas variabilidades de paleocorrentes (extraído de Miall, 1974).

Figura 6. Rio Rakaia (Nova Zelândia) com medições do comprimento de onda da sinuosidade do canal.

Figura 7. Fotos das fácies sedimentares presentes nos afloramentos. A. Arenito com estratificação cruzada tabular (At). B. Arenito com estratificação cruzada de baixo ângulo $(\mathrm{Ab})$. C. Conglomerado com estratificação cruzada (Ce). D. Fácies dos Arenito com estratificação cruzada acanalada $(\mathrm{Aa})$.

Figura 8. Fotos dos elementos arquiteturais nos afloramentos. A-D Estratificações cruzada de grande porte na Ravina de Curralinho. E. Estratificações cruzadas afloramento da área Banzaê. F. Estratificação cruzadas de médio porte na área de Banzaê.

Figura 9. A. Panorâmica em direção Norte -Sul da área Ravina de Curralinho e localidade geográfica dos grupos 1, 2 e 3. B. Panorâmica da quarta seção estratigráfica. 26

Figura 10. Parte superior, mapa com o vetor médio das paleocorrentes e reconstruções de superfícies nas seções estratigráficas da Ravina de Curralinho. Parte inferior, mapa com as distribuições das paleocorrente em rosetas de cada seção... 27

Figura 11. Expressões geomorfológicas dos afloramentos da área de Banzaê. 29

Figura 12. Expressões geomorfológicas e fácies dos afloramentos da área de Banzaê. A e B. Fotografia resaltando a direção entre as seções estratigráficas intermédiaria $B$ e superior C (linha azul) e estratificações cruzada (linhas roxas). D Fotografia que detalhada de estratificação cruzada tabular. 30

Figura 13. Mapa de paleocorrentes da seção estratigráfica $A$ na área de Banzaê. A. Mapa com o vetor médio das paleocorrentes e reconstruções de superfícies. B. Mapa com as distribuições das paleocorrente em gráficas de rosetas.

Figura 14. Mapa de paleocorrentes da seção estratigráfica B na área de Banzaê. A. Mapa com o vetor médio das paleocorrentes e reconstruções de superfícies. B. Mapa com as distribuições das paleocorrente em gráficas de rosetas. 
Figura 15. Mapa de paleocorrentes da seção estratigráfica $C$ na área de Banzaê. A. Mapa com o vetor médio das paleocorrentes e reconstruções de superfícies. B. Mapa com as distribuições das paleocorrente em gráficas de rosetas. 34

Figura 16. Mapas de paleocorrentes dos três níveis estratigráficos na área de Banzaê....36

Figura 17. Mapa de paleocorrentes do Membro Banzaê. (Modificado de Abdala, 2014 e Freitas, 2014).

Figura 18. Diagramas de caixas das espessuras de séries das seções estratigráficas da Ravina de Curralinho. 39

Figura 19. Diagramas de caixas da espessura de séries nas seções estratigráficas divididas e organizadas de Norte a Sul em cada localidade da Ravina de Curralinho. ...... 40

Figura 20. Diagramas de caixas das espessuras de séries das seções estratigráficas da área de Banzaê.

Figura 21. Mapa de distribuição da média das espessuras de serie nas três seções estratigráficas da área de Banzaê.

Figura 22. Mapa de distribuição das espessuras de séries máximas nas três seções estratigráficas da área de Banzaê.

Figura 23. Mapa da relação de paleocorrente e espessuras de séries máximas nas três seções estratigráficas da área de Banzaê.

Figura 24. Mapa das interpretações da sinuosidade nas três seções da área Banzaê. ..... 48

Figura 25. Gráfico da relação do comprimento de onda da sinuosidade com a vazão de sete rios atuais.

Figura 26. Imagens satélites do Brahmaputra, Ghaghara, Kosi, Irrawaddy, Waitaki, Rakaia e Karakash, associadas a histogramas com o comprimento de onda da sinuosidade do canal.

Figura 27. Diagramas de caixas das espessuras de séries da Rabina de Curralinho e Banzaê (dados do presente trabalho) e o Membro Banzaê (compilados de Abdala, 2014). 


\section{INDICE DE TABELAS}

Tabela 1. Tabela de erros para cada número de medidas 16

Tabela 2. Compilação das medidas de estadística descritiva da Ravina de Curralinho. ...39

Tabela 3. Compilações das médias de cada grupo em cada seção estratigráfica da Ravina de Curralinho 40

Tabela 4. Estimativas de profundidade das seções estratigráficas da Ravina de Curralinho. Sm (Média da espessura da série), H (altura da duna), D1 (profundidade do canal seis vezes maior a $\mathrm{H}$ ) e D2 (profundidade do canal dez vezes maior a $\mathrm{H}$ ).

Tabela 5. Recopilação das medidas de estadística descritiva das seções estratigráficas da área de Banzaê.

Tabela 6. Recopilação das estimações de profundidade das seções estratigráficas da Ravina de Curralinho, Banzaê e Membro Banzaê (Abdala, 2014). Sm (Média da espessura da série), SM (Máximo da espessura de serie), H (altura da duna), D1 (profundidade do canal seis vezes maior a $\mathrm{H}$ ) e D2 (profundidade do canal dez vezes maior a $\mathrm{H}$ ). 53 


\section{Capítulo 1 - Considerações iniciais}

\subsection{Introdução}

Rios de grande porte são um dos principais elementos dos sistemas de transporte e deposição sedimentar no planeta (e.g. Tandon \& Sinha, 2007), e a identificação de grandes rios no registro sedimentar antigo é uma das principais questões da geologia sedimentar atual (e.g. Miall, 2006; Ashworth \& Lewin, 2012; Lewin \& Ashworth, 2014), porém critérios seguros para o reconhecimento de grandes rios no registro são ainda escassos. Nesse contexto o presente trabalho aborda a questão do reconhecimento do porte de paleorios com base em seus depósitos preservados em bacias sedimentares de uma forma alternativa às tradicionais análises de espessura de séries de estratos cruzados, propondo um método baseado no reconhecimento do comprimento de onda da sinuosidade de paleocanais, comparado ao de sistemas ativos com estilo de canal semelhante.

A Formação Marizal tem sido interpretada como um depósito de um sistema fluvial entrelaçado de rio grande (e.g. Freitas 2014). Localizada na Bacia do Tucano, no topo de uma sucessão de rifte do Cretáceo associado à abertura do Atlântico Sul (e.g. Magnavita, 1994; Cesero, 1997).

Trabalhos recentes desenvolvidos na Bacia do Tucano foram voltados à coleta sistemática de grande quantidade de dados de paleocorrentes e de espessuras de série (e.g. Freitas, 2014; Abdala, 2014). Nesses trabalhos, os dados de paleocorrentes foram utilizados principalmente para estimar direção geral do fluxo no contexto da bacia, enquanto os dados de espessura de série foram usados para estimar profundidade do canal.

Esse trabalho, por meio de um volume robusto de dados de paleocorrentes e de espessuras de séries, distribuídos em malha por uma área de $250 \mathrm{~km}^{2}$, apresenta novos dados para avaliar o porte do rio que depositou a Fm. Marizal. A distribuição de dados de paleocorrentes permitiu desenvolver um método inovador de estimativa do comprimento de onda da sinuosidade em grande escala para depósitos fluviais, a partir do qual é possível comparar depósitos antigos com rios atuais de diferente dimensões. As espessuras de série foram utilizadas para obter estimativas de profundidade do paleocanal. 
Os dados de sinuosidade e profundidade obtidos foram complementados com estimativas de profundidade de trabalhos prévios (e.g. Freitas, 2014; Abdala, 2014) e comparados com as características de sinuosidade e profundidade de rios ativos, a fim de estimar, por meio de análogos, o porte do sistema fluvial que existiu na época de deposição da Formação Marizal.

\subsection{Justificativa}

A Formação Marizal caracteriza-se por afloramentos com altura de dezenas de metros e continuidade lateral de quilômetros, além de fácil acessibilidade, assim constitui alvo ideal para o desenvolvimento de métodos de estudo de afloramentos de sistemas fluviais (e.g. Almeida et al., 2016; Figueiredo et al., 2016). Este trabalho apresenta dados importantes para as reconstruções e interpretações paleogeográficas especificamente na evolução espaço temporal do tamanho e sinuosidade de paleorios.

\subsection{Objetivo}

O objetivo desse trabalho é testar a possibilidade de estimar o porte de depósitos de rios antigos com base no comprimento de onda registrado como variação espacial de paleocorrentes.

Para isso é preciso:

1. Obter medidas de paleocorrentes em malha de pontos com espaçamento ideal para reconhecer a sinuosidade.

2. Medir espessuras de séries de estratos cruzados para avaliar o porte do rio com base em métodos de paleohidráulica.

3. Reconhecer a espessura preservada de depósitos de canal.

4. Interpretar o estilo dos canais e comparar com rios ativos para os quais pode-se conhecer a vazão e medir o comprimento de onda da sinuosidade.

O presente trabalho procura desenvolver método para determinação de um indicador de escala do sistema fluvial independente das medidas de espessura de séries, com base na relação empírica entre o porte do sistema fluvial e o comprimento de onda da 
sinuosidade de seu canal principal (Leclair \& Bridge, 2001 e Paola \& Borgman, 1991) na escala do rank 3 de Miall (1974). Assim, com base em grande volume de dados de paleocorrentes e estimativa de erro para o rumo de paleocorrentes obtido em cada localidade, foram elaborados mapas de paleocorrentes para três diferentes níveis estratigráficos na área tipo da Formação Banzaê, permitindo a reconstituição tentativa da sinuosidade do sistema.

\subsection{Localização e acessos das áreas de estudo}

A área do presente trabalho está localizada no nordeste do Brasil, no Estado da Bahia. Geologicamente, encontra-se na Bacia de Tucano, que faz parte do Rifte Recôncavo - Tucano - Jatobá (RTJ). A Bacia de Tucano estende-se em direção Norte-Sul $330 \mathrm{Km}$ e Leste-Oeste $40 \mathrm{Km}$, aproximadamente (Figura 1).

Foram estudadas duas áreas para obtenção de dados: a primeira encontra-se a norte do município de Banzaê, em local denominado de Ravina de Curralinho, enquanto a segunda área tem escala quilométrica, sendo constituída por uma série de afloramentos distribuídos a noroeste do povoado Banzaê. Estas áreas são caracterizadas pela ocorrência de paredões com espessuras que alcançam dezenas de metros, e continuidade lateral de centenas de metros até quilômetros que permitiu um estudo detalhado de cada localidade.

O percurso para chegar à Ravina de Curralinho envolve o uso de estradas secundárias, sendo necessário um veículo de dupla tração para o percurso. $O$ trajeto a partir do município de Banzaê se dá pela rodovia BA-388 em direção norte (sentido Ribeirão do Pombal) até o povoado de São João de Fortaleza, continuando por $10 \mathrm{~km}$ em direção norte na rodovia BA-220 (sentido Euclídes da Cunha). Neste ponto, há uma bifurcação para uma estrada de terra, e continua-se nessa estrada, caracterizada por diversas outras bifurcações, da seguinte forma: percorre-se por $8 \mathrm{~km}$ em direção a nortenoroeste, $11 \mathrm{~km}$ a norte, $12 \mathrm{~km}$ a noroeste e terminado com $4 \mathrm{~km}$ a norte-nordeste. 


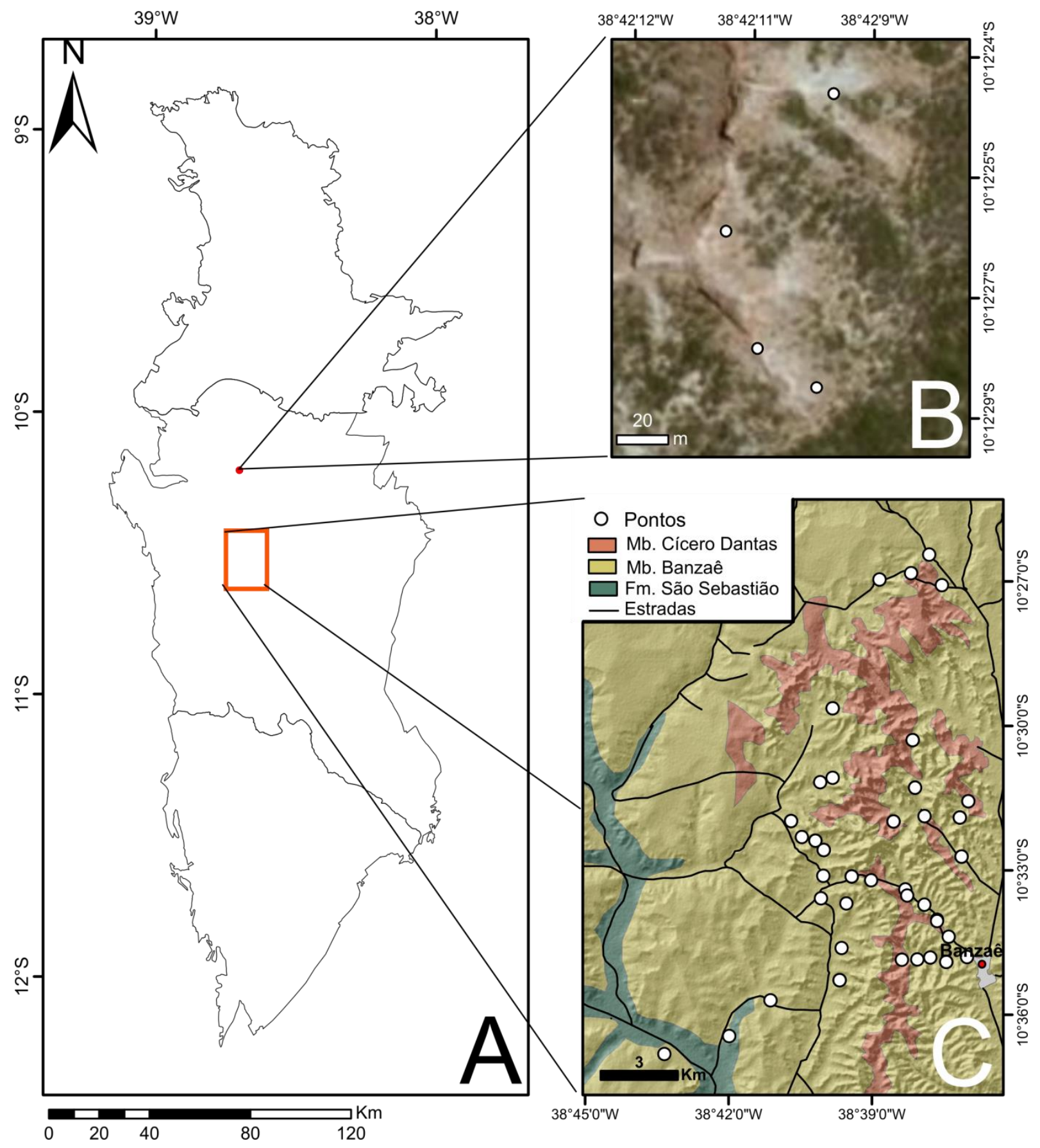

Figura 1. Mapas da localização da área de estudo. A. Mapa da Bacia de Tucano. B. Afloramento Ravina de Curralinho. C. Afloramentos da área de Banzaê. 


\section{Capítulo 2 - Fundamentação Bibliográfica}

\subsection{Contexto Geológico}

O sistema de Rifte Recôncavo-Tucano-Jatobá (RTJ) localiza-se na região nordeste do Brasil, ocupando uma área de aproximadamente $45.000 \mathrm{~km}^{2}$ (Bizzi et al., 2003) com direção NE-SW e N-S. A origem do rifte está relacionada à extensão crustal no Cretáceo Inferior que fragmentou o Supercontinente Gondwana, dando origem ao Oceano Atlântico. (Cesero \& Ponte, 1997; Costa et al., 2007a,b; Magnavita et al., 1994) e definindo os contornos das placas Sul-Americana e Africana (Milani et al., 2007). No trabalho de Ponte (1978) o sistema RTJ foi interpretado como um rifte abortado na plataforma continental brasileira.

A configuração estrutural das bacias reflete a atuação dos esforços distensivos (Magnavita \& Cupertino, 1987). Ao longo dos anos, tem-se apresentado diferentes modelos tectônicos sobre a evolução da Bacia RTJ como: o modelo de microplaca (Milani \& Davison, 1988; Milani et al., 1988), o modelo de riftemento duplo (Magnavita, 1992), o modelo de descolamento (Ussami et al.,1986); entre outros trabalhos que desenvolvem estudos estruturais e estratigráficos específicos de cada bacias ou de todo o sistema RTJ (e.g. Caixeta et al., 1994; Costa et al., 2007a,b; Costa et al., 2005, 2003; Cupertino, 1990; Cupertino \& Bueno, 2005; Destro et al., 2003a,b; Kuchle \& Dos Santos Scherer, 2010).

A Bacia do Tucano é a maior bacia do sistema RTJ. O limite geográfico com a Bacia do Recôncavo é o Alto Aporá e com a Bacia Jatobá, é o Rio São Francisco (Magnavita et al., 2003). A bacia, subdivida nas sub-bacias de Tucano Sul, Tucano Central e Tucano Norte, estruturalmente apresenta-se como semi-grabens assimétricos, com depocentros isolados por falhas transferência (Magnavita \& Cupertino, 1987) que compõe os altos estruturais de Itapicuru e Vaza-Barris. A assimetria é gerada por uma falha de borda principal (Magnavita et al., 2003) (Figura 2).

Na Sub-bacia de Tucano Sul e Tucano Central a falha de borda está ao leste e o mergulho regional das camadas é para sudeste, acomodado, em padrão dominó, por falhas normais planares, sintética em relação à falha de borda. Na Sub-bacia de Tucano Norte a falha de borda está a oeste, assim como o mergulho das camadas (Costa et al., 2007a,b; Magnavita \& Cupertino, 1987). 


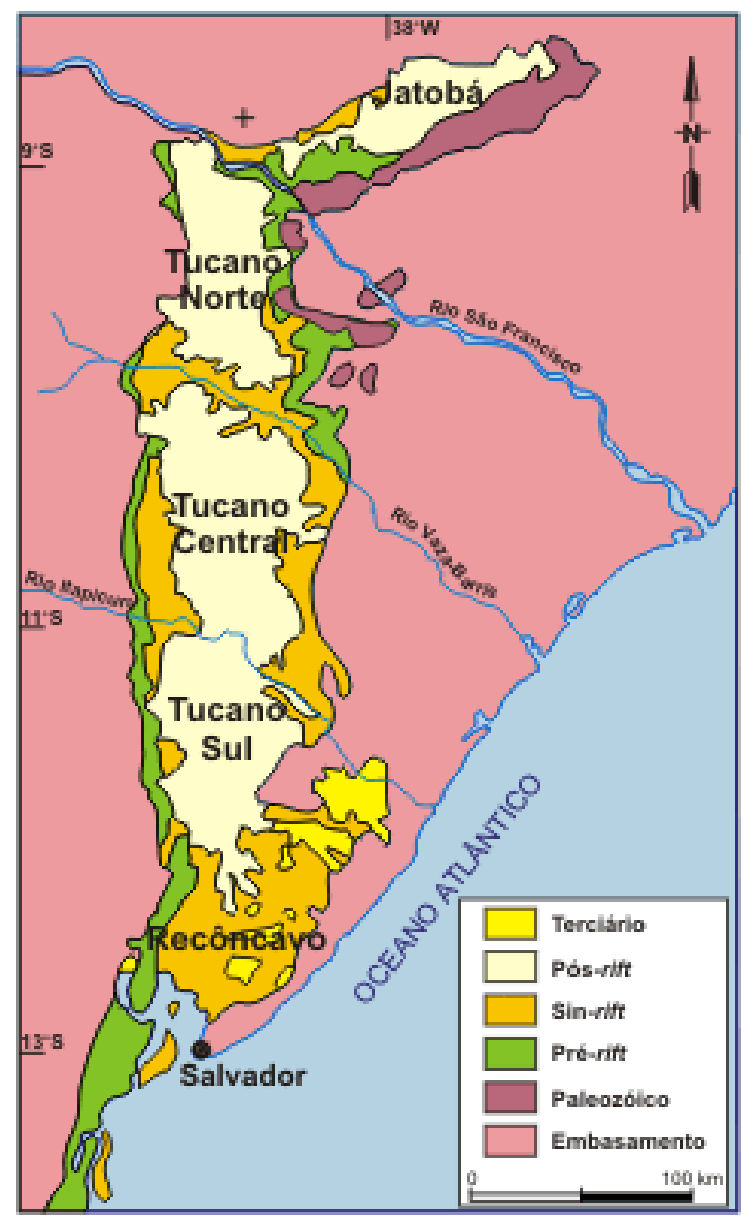

Figura 2. Mapa geológico simplificado das bacias do Recôncavo, Tucano e Jatobá (extraído de Magnativa et al., 2003).

O Tucano Sul ocupa aproximadamente $7.000 \mathrm{~km}^{2}$ em área. Seus limites são determinados pela falha de Inhambupe, a leste; pelo embasamento cristalino, a oeste; pelo Alto de Aporá, a sul; pela zona de acomodação do rio Itapicuru, a norte. A sub-bacia tornase mais profunda para nordeste, atingindo mais de 7.000 metros de espessura sedimentar no Baixo de Inhambupe (Costa et al., 2007 a; Magnavita et al., 2003).

O Tucano Central ocupa aproximadamente $14.700 \mathrm{~km}^{2}$ em área, constituindo a maior sub-bacia da região. Seus limites são determinados pela falha de Adustina, a leste; pelo embasamento cristalino, a oeste; pela zona de acomodação do rio Itapicuru, a sul; pela zona de acomodação do Vaza-Barris, a norte. A falha de Adustina é falha de borda principal, arquitetura estrutural é caracterizada por falhas de direção geral N-S, mergulhando para oeste, resultando em um estilo dominó. No baixo de Cícero Dantas a bacia tem uma espessura de mais de 10.000 metros (Costa et al., 2007a; Magnavita et al., 2003).

O Tucano Norte ocupa uma área de cerca de $8.800 \mathrm{~km}^{2}$. Seus limites são determinados pelo embasamento cristalino, a leste; pela falha São Saité, a oeste; pela zona de acomodação do Vaza-Barris, a sul; pela falha do rio São Francisco, a norte. (Costa, et al., 2007 b; Magnavita et al., 2003). No limite entre as bacias de Tucano Central 
e Tucano Norte, além do Alto do Vaza-Barris, ocorrem falhas de transferência de Caritá e de Jeremoabo que constituem uma zona de acomodação determinante da inversão da assimetria dos semi-grabens. Esta inversão está bem caracterizada pelo padrão geométrico da falha de Caritá, a qual inverte o sentido do mergulho (Caixeta et al., 1994; Cupertino, 1990; Magnavita et al., 2003) No Baixo de Salgado do Melão estima-se a profundidade de mais de 7.000 metros (Magnavita et al., 2003).

O Sistema Rifte RTJ instalou-se na região limítrofe das províncias São Francisco e Borborema, cujas estruturas controlaram sua abertura. As sub-bacias de Tucano Sul e Central tem como embasamento o Cinturão Bahia Oriental (nordeste da Província São Francisco) constituído por blocos/microplacas arqueanos, compostos por ortognaisses granulíticos e/ou migmatíticos (Serrinha, Itabuna-Curaçá) amalgamados e intensamente deformados no Paleoproterozoico (Kosin, 2008).

A Sub-bacia de Tucano Norte instala-se no limite da Província São Francisco com a Subprovíncia Meridional da Província Borborema. A Subprovíncia Meridional está dividida nos terrenos Pernambuco-Alagoas e Canindé-Marancó, constituídos por complexos ortognáissicos e sequências metavulcanossedimentares, e na Faixa de Dobramentos Sergipana, que compreende rochas metassedimentares siliciclásticas e carbonáticas (Kosin, 2008).

\subsubsection{Estratigrafia}

A revisão histórica da estratigrafia das bacias de Recôncavo e Tucano de Viana et al.,(1971) apresenta uma nova proposta estratigráfica baseada no Código de Nomenclatura Estratigráfica America de 1966. Assim, este trabalho converteu-se na base dos estudos estratigráficos do rifte RTJ. (e.g. Caixeta et al., 1994; Cupertino, 1990; Magnavita et al., 2005)

Segundo Magnavita et al. (2005), a sucessão estratigráfica do Rifte do RTJ contém estratos com idades do Paleozoico ao Cenozoico. O autor apresenta uma coluna estratigráfica da Bacia do Recôncavo relacionando-a à evolução tectôno-estratigráfica do rifte (fases pré-, sin- e pós-rifte), estendendo as unidades definidas na bacia para todo 0 Rifte RJT. Porém, aclara a necessidade de ter uma coluna estratigráfica para cada bacia ou sub-bacia (Figura 3). 
Os depósitos de idade Paleozoica estão preservados nas bordas leste e sudeste das bacias do Tucano Norte e Jatobá e constituem remanescentes de ciclos sedimentares, sendo correlacionados aos depósitos da Bacia do Parnaíba. A Formação Afligidos, de idade Permiana ou Triássica, para sua porção superior (Magnavita et al., 2005).

Os depósitos de idade Mesozoicos são o resultado da própria evolução tectônica da bacia, das etapas Pre-Rifte, Sin-Rifte e Pós-Rifte. O preenchimento da bacia nesse período inclui depósitos de um sistema fluvio-deltáico progradante de norte para o sul (Magnavita \& Cupertino, 1987).

A seção Pre-Rifte estende-se temporalmente do Tithoniano ao Berriasiano e compreende rochas do Grupo Brotas (Formação Aliança e Sergi), representado por folhelhos avermelhados e arenitos sobrepostos por arenitos fluviais e eólicos, respectivamente. Sucedidos pelo Grupo Santo Amaro (Formação Itaparica e Água Grande) representado por depósitos fluviais e lacustres sobrepostos por arenitos fluviais e eólicos, respectivamente (Costa et al., 2007a; Magnavita et al., 2005).

A porção Sin-Rifte engloba idades do Berrasiano inferior ao Aptiano inferior, abrangendo um intervalo de tempo de 24 milhões de anos, no qual a bacia foi preenchida por dois sistemas deposicionais progradantes, o longitudinal (flúvio-deltáico-lacustre) e o transversal (leques conglomeráticos). Tradicionalmente, o inicio desta fase era marcado no primeiro aparecimento da espessa cunha de conglomerados sintectônicos da Fm. Salvador. Mas os conglomerados só indicam a existência de uma elevação topográfica. $O$ inicio desta se representa quando a taxa de subsidência é maior do que a taxa sedimentação, registrada nos folhelhos escuros do Membro Tauá da Formação Candeias (Costa et al., 2007a ; Magnavita et al., 2005).

O sistema fluvio-deltáico-lacustre compreende rochas da Fm. Candeias, representada por turbiditos, folhelhos lacustres e arenitos laminados e maciços. Essas rochas são sucedidas pelo Grupo llhas, pela Fm. Marfil representada por arenitos siltitos, folhelhos e ocasionais carbonatos, pelo Fm. Pojuca/Trapique representada arenitos, folhelhos, siltitos e calcários intercalados (Viana et al., 1971). Estratigraficamente acima, encontra-se o Grupo Massacará, composto Fm. São Sebastião, representada por arenitos fluviais deltaicos (Costa et al., 2007a ; Magnavita et al., 2005), e pela Fm. Poço Verde, representada por folhelhos e alguns calcários.

A seção Pós-Rifte foi depositada do Aptiano ao Albiano Inferior. Esse período é representado por conglomerados, arenitos, folhelhos e calcários da Fm. Marizal em ambientes deltaicos. (Costa et al., 2007a ; Magnavita et al., 2005). 
Os depósitos do Neógeno são representados exclusivamente pelos depósitos aluviais da Fm. Barreiras (Costa et al., 2007a).

Em função das similaridades de seu arcabouço estrutural e registro sedimentar, as sub-bacias de Tucano Sul e Central podem ser representadas através de uma única carta estratigráfica, enquanto a sub-bacia de Tucano Norte tem maiores afinidades com a bacia de Jatobá. (Costa et al., 2007a b).

\subsubsection{Formação Marizal}

A Fm. Marizal ocupa $75 \%$ da área superficial do Rifte RTJ. Apresenta espessura média em torno de 150 m, com máximo de 300 m no centro de Tucano. Sobrepõe-se em discordância angular ao Grupo Massacará e está sotoposta em discordância homogênea à Fm. Barreiras. A formação tem idade aptiana, por estudos baseados em palinomorfos (Magnavita, 1992).

Um dos primeiros trabalhos onde se registra a Formação Marizal se descreve uma sequência de arenitos micáceos de areia média até cascalhos com algumas estratificações cruzadas exposta na Serra do Marizal ao Leste da cidade de Tucano. Na base da formação há uma discordância com as unidades do Cretáceo. Interpretou-se como um deposito eólico e deltaico. Suprajacente a ela se ocorre a Fm. Cícero Dantas como sedimentos vermelhados, arenitos folhelhos, argilas e siltitos.

Segundo Viana et al. (1971), a dificuldade para diferenciar as formações Marizal e Cícero Dantas levou a juntá-las em uma única unidade. Nesse trabalho se faz referência a Campos (1960) pela divisão informal da formação em três membros (Viana et al., 1971), a Santos (1962) pelo mapeamento da formação no sudeste da bacia e aos trabalhados de Weber (1964), Muller (1966) e Brain (1961) pela menção da formação na revisão da evolução cronoestratigrafica.

Tendo em vista estes trabalhos e o de Santos et al. (2010), descreve-se a Fm. Marizal sendo formada por arenitos e conglomerados, siltitos, folhelhos e calcários. Os arenitos são mal selecionados, finos a grossos apresentam tonalidades cinzaesbranquiçados e amarelo-avermelhados, sub-angulares a sub-arredondados, de composição quartzososa, feldspáticas, pouco micáceos, argilosos, caulínicos; com estratificações cruzadas frequentes. Os conglomerados são policompostos, seixos de arenitos vermelhos, calcários e quartzos, em uma matriz arenosa. Os folhelhos contêm 


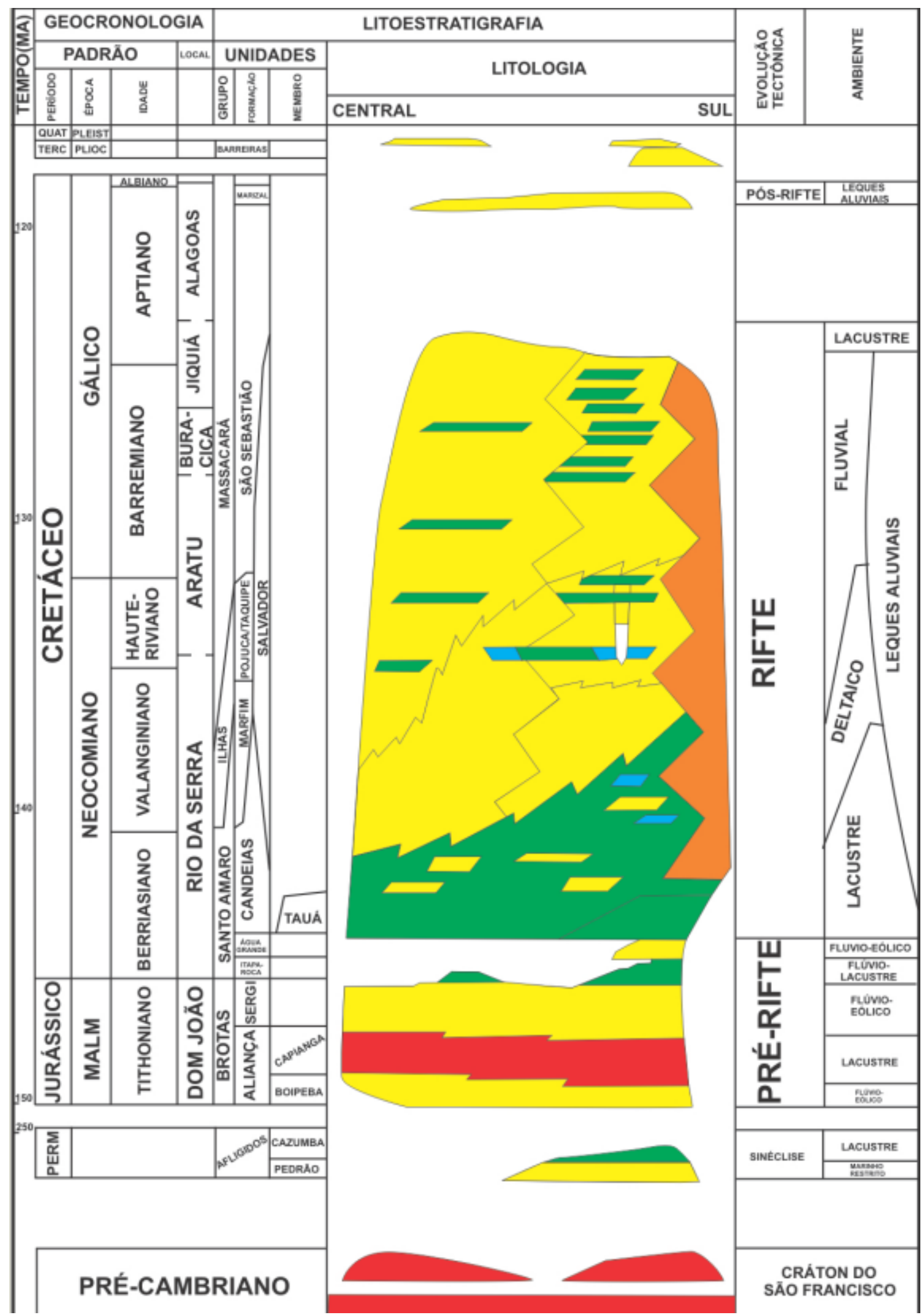

Figura 3. Carta estratigráfica atualizada e aspectos tectono-deposicionais da Bacia do Tucano na área estudada (extraído de Santos et al., 2010). 
lâminas de gipsita e barita de tons cinza, róseos e amarelados. Os siltitos micáceos têm tons róseos e amarelo-avermelhados (Figura 4).

Muitos dos peixes fósseis estudados no oeste do Gondwana no Cretáceo Temprano pertencem a uma fauna endêmica, sendo uma potencial ferramenta para as reconstruções biogeográficas. (Maisey, 2000) Os dados paleontológicos coletados na Formação Marizal reforçam a hipótese de que durante o Aptiano-Albiano houve uma conexão do mar Carriben Tetys com o sistema de rifte de Gondwana Ocidental formando um mar epicontinetal ou um 'seaway' (e.g. Brito \& Alvarado-Ortega, 2008; Maisey, 2000). Outros autores também apresentam a influência do Mediterrâneo Tethys no rifte em questão (Amaral \& Brito, 2012). As interpretações paleográficas do 'seaway' não se referem como uma única, continua e amplia conexão marinha; refletem eventos tectônicos locais incluindo às vezes faunas localmente distintivas (Brito \& Alvarado-Ortega, 2008). A camada Amargosa entre os Membros Banzaê e Cicero Dantas é interpretada como depósito destas incursões marinhas (Freitas, 2014). O registro do mar epicontinental estaria também presente em outras bacias ao longo da margem continental, e.g. bacias de São Luís, Parnaíba, Araripe, Sergipe e Camamu (Arai, 2014).

A formação Marizal recentemente foi dividida em dois membros, com uma unidade inferior, denominada de Membro Banzaê, caracterizada por depósitos de canais amalgamados, e uma unidade superior, denominada de Membro Cícero Dantas, caracterizada por depósitos de canais isolados em meio a depósitos de planície de inundação (Freitas, 2014).

Esta formação tem sido o objetivo de numerosos trabalhos de caracterização de sistemas deposicionais fluviais (e.g. Carrera, 2015: Freitas, 2014; Lima \& Boas, 1994). Os trabalhos de paleocorrente têm se desenvolvido em escalas maiores do que as apresentadas no presente trabalho. Essas pesquisas prévias, mostram a predominância do paleofluxo para SSW (Santos et al., 2010), sendo interpretada como um sistema de rio tronco fluindo para o sul, paralelo à bacia, junto à borda oeste, com padrões transversais associados a sistemas fluviais tributários, na borda leste (Abdala, 2014; Carrera, 2015; Freitas, 2014). 


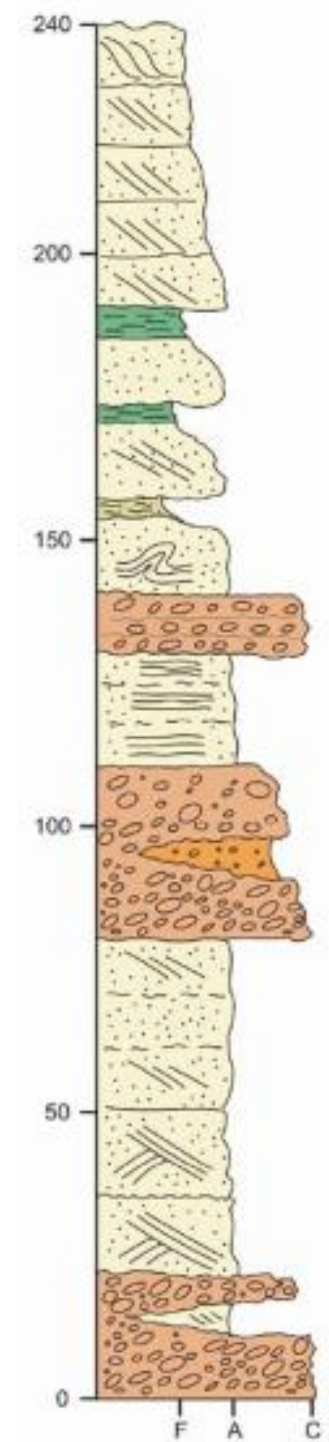

Alternância de arenitos e siltitos/folhelhos em ciclos granodecrescentes. Estratificação cruzada tabular e evidèncias de fluidizaçằo nos arenitos.

Conglomerado em barras com seixos achatados de pequeno dialmetro.

Barras de arenito com estratificaçăo plano-paralela.

Conglomerado suportado pela matriz com clastos de diammetro variavel até $50 \mathrm{~cm}$. Os clastos sao de quartzo. gnaisse. pegmatito, milonito, subangulosos e com boa esfericidade. Canal de geometria lenticular intercalado, preenchido por arenito seixoso.

Arenito bege de granulaçăo média a grossa, com matriz caulinitica estratificaçằ cruzada tabular de grande porte.

Conglomerado suportado pelos clastos, bem arredondados, de composiçāo vulcánica, gnaissica, pegmatítica e milonitica, com diâmetro até $50 \mathrm{~cm}$. Diâmetro medio $15 \mathrm{~cm}$. Paleocorrente para $160^{\circ}$.

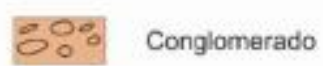

Arenito conglomerático

$\because \because \because \because \quad$ Arenito

Folhelho

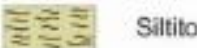

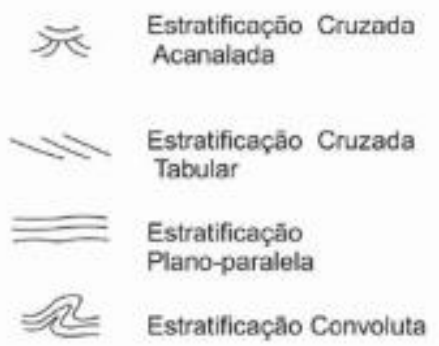

Figura 4. Coluna estratigráfica da Formação Marizal (extraído de Santos et al., 2010).

\subsection{Sinuosidade no registro}

A análise de paleocorrentes se apresenta como ferramenta de interpretações paleogeográficas e sinuosidade (e.g. Potter \& Pettijohn,1977; Selley, 1982). A análise de paleocorrentes permite saber a direção do fluxo no momento em que o sedimento foi depositado e, integrada com os dados de análises de fácies e proveniência, permite fazer reconstruções paleogeográficas regionais (e.g. Assine, 1994; Bradley \& Hanson, 2002; Bill et al., 1987; Freitas, 2014; Carrera, 2015).

Segundo Allen (1966), as informações trazidas pelos dados de paleocorrente variam de acordo com a escala da área estudada. $O$ autor, ao propor uma hierarquização de estruturas sedimentares de acordo com a escala de observação (variando da primeira ordem, que envolve um trecho de um canal, à quarta ordem, composta por ripples de pequena escala), denota que a variabilidade da direção de vetor aumenta quando a escala 
de estrutura sedimentar diminui. O trabalho de Miall (1974) retoma os conceitos de Allen (1966) e caracteriza a hierarquização em seis escalas, que incluem (1) um sistema fluvial inteiro, (2) canais dentro de um delta, (3) canal individual, (4) barras, (5) estratificação cruz margeando a frente da barra e (6) a crista de uma ripple. Para determinação de sinuosidade, a escala de interesse é representada pela variação em planta da direção do canal correspondente o rank 3 de Miall (1974), em uma área condizente com o tamanho do canal estudado (Figura 5).

No registro geológico, interpretações do grau sinuosidade, alto ou baixo, foram estimadas a partir de análises de paleocorrentes (e.g. Barrett \& Fitzgerald, 1985; Miall, 1988; Payenberg et al., 2003). Recentemente, foi confirmada a possibilidade de usar dados de paleocorrente como indicadores de sinuosidade em trabalhos que mostram geometria de depósitos fluviais antigos em planta por meio de imagens de satélite. Estas imagens mostram uma grande quantidade de "scroll bars" com variações das paleocorrentes ao longo destas, concordantes as geometrias encontradas (e.g. Wu et al., 2015; Bhattacharyya et al., 2015).
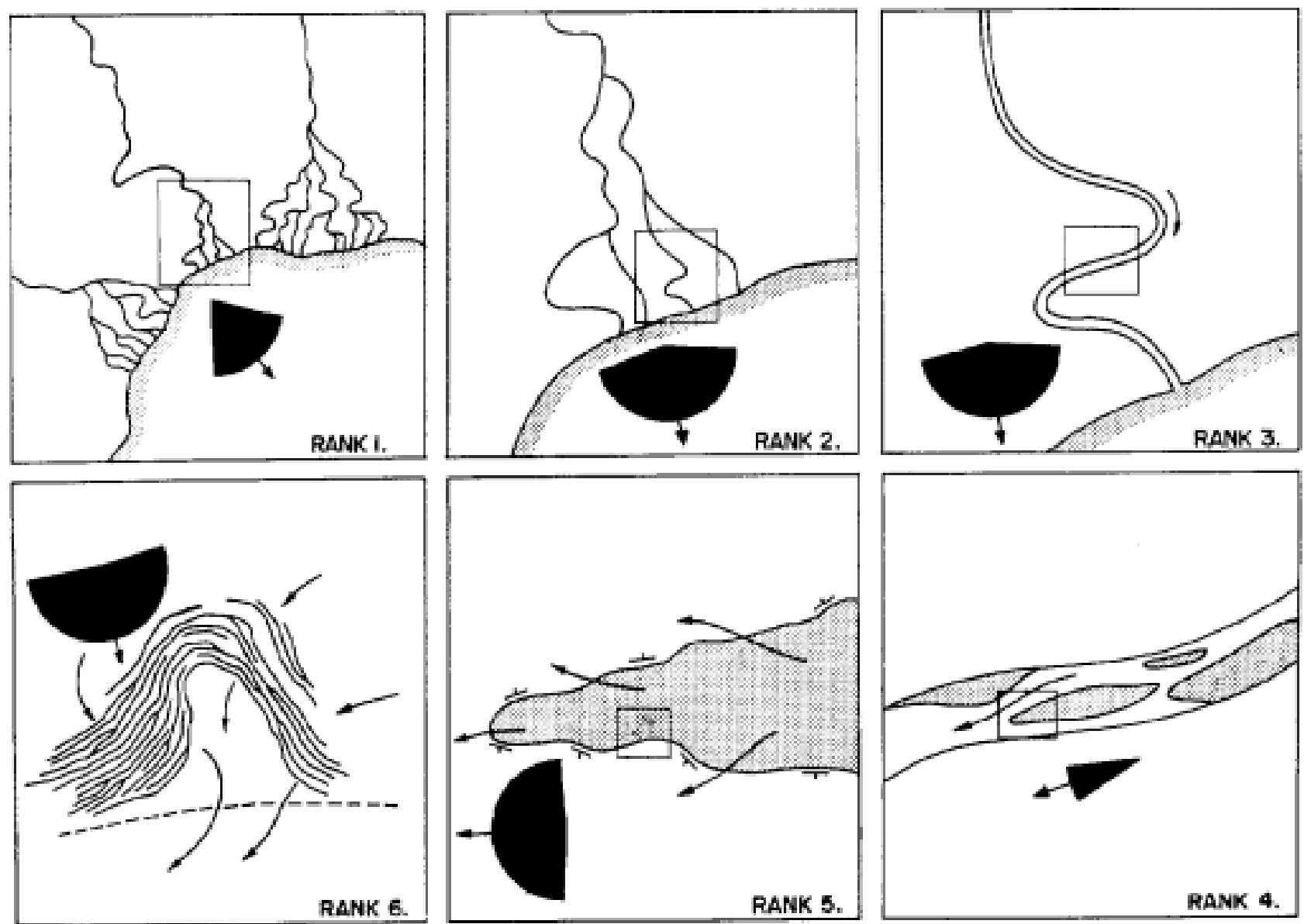

Figura 5. Hierarquia de formas de leito e respectivas variabilidades de paleocorrentes (extraído de Miall, 1974). 


\section{Capítulo 3 - Metodologia}

Com a finalidade de estimar a sinuosidade e profundidade do canal que formou os depósitos do Membro Banzaê, Fm. Marizal, na Bacia do Tucano, o trabalho aqui proposto fundamentou-se em levantamentos sistemáticos de colunas estratigráficas em detalhe, com (i) análise de fácies, (ii) aquisição de dados de paleocorrente e atitude dos respectivos limites de série e (iii) espessura de séries nos afloramentos estudados. Os dados foram adquiridos diretamente em campo nos meses de novembro de 2015 e agosto de 2016.

\subsection{Análises de fácies e elementos arquiteturais}

A análise de fácies consiste na caracterização de depósitos sedimentares a partir da identificação da textura, composição, estruturas sedimentares, geometria, conteúdo paleontológico e cor. Assim, um intervalo é distinto dos depósitos adjacentes por meio de um conjunto de características próprias, com o objetivo de interpretar o ambiente deposicional com base nas descrições e metodologias de diversos autores (e.g. Miall, 2000; Reading, 1986; Walker, 1992). A caracterização das fácies foi feita a partir da descrição e de levantamentos de colunas estratigráficas nos afloramentos estudados, apresentando um registro fotográfico de cada uma delas.

A análise dos elementos arquiteturais consiste em inferir as relações hierárquicas das fácies descritas anteriormente a partir das relações espaciais entre elas. Estas relações geométricas foram descritas em campo e comparadas com formas geométricas do sistema deposicional, conforme apresentado nos trabalhos de Allen (1983) e Miall (1985). As descrições e a nomenclatura dos depósitos foram baseadas no trabalho de Bridge (1993), no qual o autor criticou a classificação de Miall $(1985,1996)$ que evidencia a complexidade dos sistemas fluviais ativos. Em seu trabalho, o autor propôs uma observação de detalhes e de características não esperadas e interpretação de depósitos fluviais com enfoque na escala das barras. 


\subsection{Análise de sinuosidade}

\subsubsection{Paleocorrentes}

A análise de paleocorrentes consiste na determinação da direção e sentido do fluxo de um depósito sedimentar através da medição sistemática das estruturas preservadas nas rochas, cuja origem tem relação direta com o paleofluxo (Miall, 1974; Potter \& Pettijohn, 1977; Selley, 1982). As medidas são apresentadas graficamente por uma roseta que representa um histograma em formato de círculo (Selley, 1982).

A estratificação cruzada tabular é a estrutura sedimentar mais comum nas áreas de estudo relacionada ao paleofluxo. As análises para calcular os parâmetros estatísticos das estratificações cruzadas foram baseadas nos métodos propostos por Potter \& Pettijohn (1977) e Selley (1982).

$\mathrm{Na}$ equação a seguir, tem-se que o vetor médio ( $\mathrm{x}$ ) e $\mathrm{o}$ fator de consistência (f.c.) foram calculados a partir dos azimutes medidos (a) e do número de medidas realizadas (n) com as seguintes equações:

$$
\begin{aligned}
x & =\arctan \left(\sum \operatorname{sen} a / \sum \cos a\right) \\
\text { f.c. } & =\sqrt{ }\left[\left(\sum \operatorname{sen} a\right)^{2}+\left(\sum \cos a\right)^{2}\right] n^{-1}
\end{aligned}
$$

Foram estimadas 30 medidas como número de medidas mínimo em cada localidade, aumentando em 5 medidas a metodologia do trabalho de Selley (1982), no qual o autor estima um erro máximo de $\pm 30^{\circ}$ com um mínimo de 25 medidas. No entanto, por limitações de exposição, algumas localidades não cumprem com todas as medições. Nesse trabalho, foi coletado um total de 3193 medidas, principalmente com a utilização do programa Clino (Midland Valley) em iPad mini 2, com precisão verificada por medições com bússola Brunton. Para as análises em escala de bacia, compilaram-se os dados de paleocorrente e espessura de série de Abdala (2014) e Freitas (2014), e os dados adquiridos em escalas menores apresentados neste trabalho.

Foi possível interpretar a direção de acreção das barras seguindo a metodologia proposta na aquisição de dados e o processamento com os códigos em MatLab apresentados no trabalho de Almeida et al. (2016), no qual as superfícies das barras são reconstruídas a partir de medições de pares de estratificação cruzada e limite de série. $O$ método apresenta a possibilidade de reconstituição de superfícies de barra a partir de limites de séries e estratos cruzados, permitindo um grande número de medidas que não 
seria possível se apenas superfícies de incremento (3a ordem, sensu Miall, 1974) fossem medidas.

Apesar do reconhecimento de bandas de deformação e falhas afetando a unidade, os mergulhos tectônicos nas camadas da Formação Marizal nas áreas estudadas limitamse a frações de grau (Freitas, 2014). Desta forma não foi necessária a correção das medidas para basculamento tectônico.

Os intervalos de erro foram estimados a partir de novo método desenvolvido para tanto. O princípio é a coleta de um grande conjunto de dados em uma única localidade, de forma a obter-se uma amostra representativa da distribuição de medidas em estruturas geradas sob um único rumo paleocorrente local. Neste estudo, foram coletadas 938 medidas em uma área de 100 por 150 metros na localidade de Curralinho. Uma rotina gerada em Matlab foi então utilizada para extrair aleatoriamente 200 subamostras para cada número de medidas possível. Assim, para cada um dado número de medidas foi possível calcular 200 valores diferentes de paleocorrentes com diferentes subamostras. Comparando-se os 95\% centrais dessa dispersão com o rumo calculado para a amostra total de 938 medidas, foi possível estabelecer o erro, com 95\% de confiança, de amostras menores com relação à amostra total. Deve-se salientar que este é um erro mínimo, pois mesmo a amostra maior apresenta erro com relação à população real, porém, dado o grande número de medidas, a estimativa é válida para comparação entre diferentes estações.

De posse da tabela 1 de erros para cada número de medidas e considerando-se que localidades diferentes apresentam distribuição idêntica à da amostra de Curralinho para diferentes rumos de paleocorrente local, foi possível atribuir erro a cada medida, permitindo maior rigor na interpretação dos padrões de sinuosidade do sistema estudado.

\begin{tabular}{|c|c|c|c|c|c|c|c|}
\hline No. de dados & Erro & No. de dados & Erro & No. de dados & Erro & No. de dados & Erro \\
\hline 6 & 117.25 & 16 & 65.97 & 26 & 49.63 & 40 & 38.55 \\
\hline 7 & 107.12 & 17 & 63.67 & 27 & 48.54 & 45 & 35.98 \\
\hline 8 & 99.05 & 18 & 61.57 & 28 & 47.52 & 50 & 33.82 \\
\hline 9 & 92.44 & 19 & 59.65 & 29 & 46.55 & 55 & 31.98 \\
\hline 10 & 86.90 & 20 & 57.88 & 30 & 45.63 & 60 & 30.39 \\
\hline 11 & 82.18 & 21 & 56.25 & 31 & 44.76 & 65 & 29.00 \\
\hline 12 & 78.09 & 22 & 54.73 & 32 & 43.94 & 70 & 27.77 \\
\hline 13 & 74.51 & 23 & 53.33 & 33 & 43.15 & 75 & 26.67 \\
\hline 14 & 71.34 & 24 & 52.01 & 34 & 42.40 & 80 & 25.68 \\
\hline 15 & 68.52 & 25 & 50.78 & 35 & 41.69 & 85 & 24.78 \\
\hline
\end{tabular}

Tabela 1. Tabela de erros para cada número de medidas 


\subsubsection{Comprimento de onda da sinuosidade em rios atuais}

Para a análise de comprimento de onda da sinuosidade em rios ativos, foram selecionados 7 rios entrelaçados: o rio Brahmaputra, de Bangladesh, os rios Ghaghara e Kosi, da India, o rio Irrawaddy, de Myanmar, os rios Waitaki e Rakaia, da Nova Zelândia, e o rio Karakash, da China os quais apresentam diferentes vazões. O comprimento de onda foi calculado pelo comprimento de uma linha traçada entre os vales ou cristas das curvas dos rios. Para cada rio, foram tomadas 29 medições do comprimento de onda do canal com imagens satélites de Google Earth, foram estimas as médias do comprimento para cada rio. A figura 6 mostra um trecho do rio Rakaia com 4 medidas do comprimento de onda do canal.

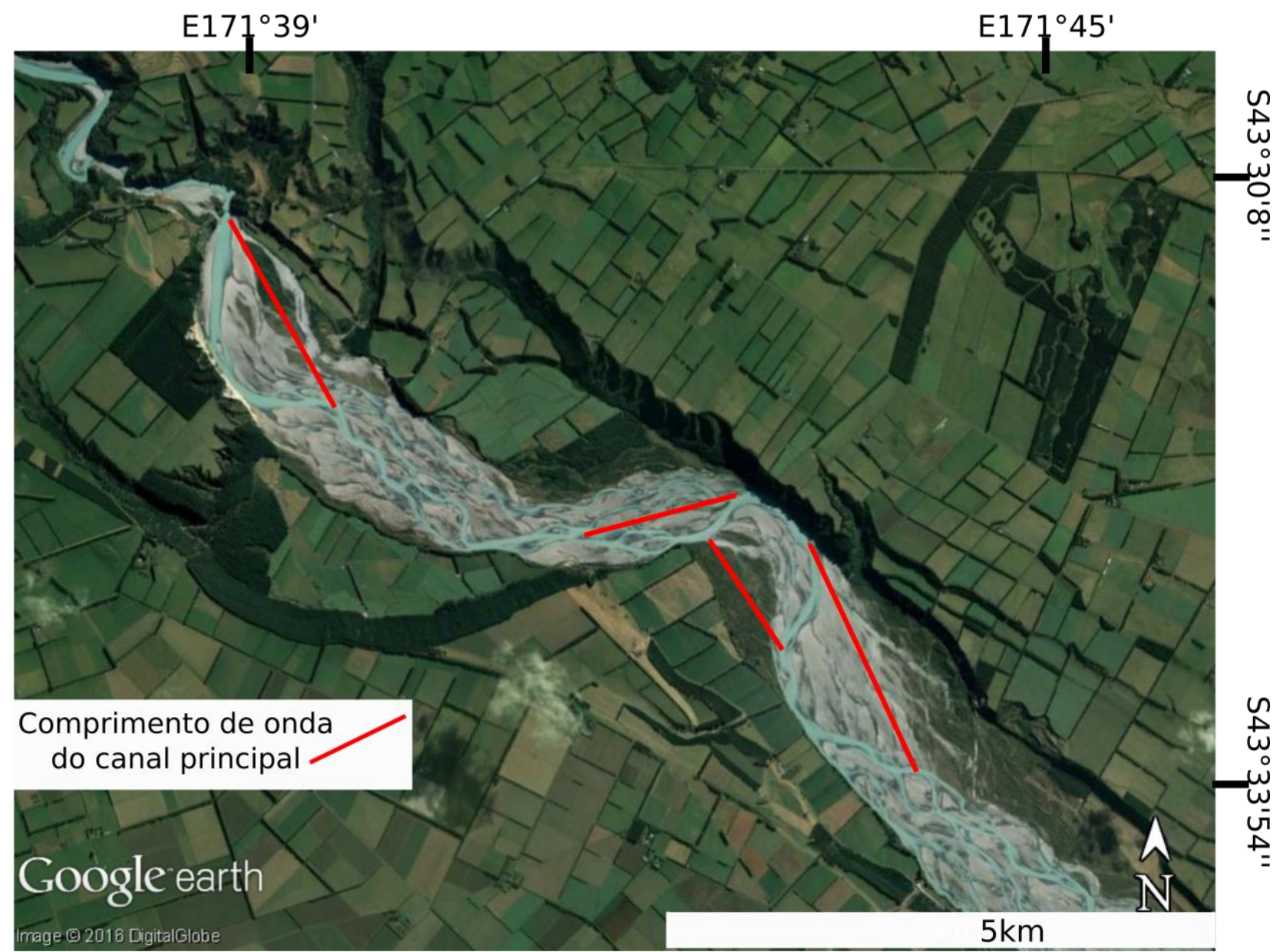

Figura 6. Rio Rakaia (Nova Zelândia) com medições do comprimento de onda da sinuosidade do canal. 


\subsection{Análise de profundidade}

\subsubsection{Paleohidráulica}

A análise de paleohidráulica consiste na quantificação dos parâmetros hidráulicos atuantes no sistema fluvial, como profundidade e largura do fluxo, além de declividade, descarga e carga sedimentar do canal (Miall, 1996). Os parâmetros que este trabalho vai desenvolver são estimativa da altura media das dunas $(\mathrm{Hm})$ e profundidade do paleocanal (D), utilizando a espessura de séries (s) como indicador direto desses parâmetros.

Apoiados no trabalho de Paola \& Borgman (1991), que propõe uma função de distribuição probabilística para estimativa da altura das dunas de múltiplas dimensões por meio das espessuras de séries preservadas em estratificações cruzadas. Este trabalho foi avaliado em experimentos de tanque (e.g. Leclair \& Bridge, 2001) que concluíram que a altura média de dunas $(\mathrm{Hm})$ equivale aproximadamente a três vezes a média de espessuras preservadas de séries com estratificações cruzadas (sm) segundo a equação:

$$
\mathrm{Hm}=2,9( \pm 0,7) \mathrm{sm}
$$

A relação com a profundidade do paleocanal (D) foi desenvolvida empiricamente por diversos autores como ( Allen, 1970; Julien \& Klaassen, 1995; Karim, 1999; Ranga Raju \& Soni, 1976; Yalin, 1964). No trabalho de Yalin (1964) foi estabelecida uma relação de seis vezes a altura máxima das dunas. Leclair \& Bridge (2001) se assume que a altura das dunas é entre 6 a 10 vezes maior do que a altura da duna.

\subsubsection{Espessura de preenchimento}

Uma forma de estimar a profundidade do canal é por meio da espessura dos depósitos de um canal em afloramento. Pela análise de fácies e elementos arquiteturais, é possível identificar elementos da base e do topo de um canal, sendo a espessura entre essas fácies um valor mínimo da lâmina d’água no local do afloramento. 


\subsection{Processamento computacional}

Os softwares utilizados neste trabalho foram: Matlab no processamento dos dados, seguindo os código de Almeida et al. (2016) e analises parâmetros estatísticos, ArcGis10.2 na realização dos mapas de paleocorrente e localização, Openstereo na representação gráfica das medidas de atitude em estereograma e rosetas, Inksape para a edição de imagens, e Gnumeric no analises estadístico e representação de diagramas Box-plot. 


\section{Capítulo 4 - Resultados}

\subsection{Arquitetura Deposicional}

Neste item são apresentadas as fácies do Membro Banzaê encontradas nos afloramentos estudados das áreas Ravina de Curralinho e Banzaê.

\subsubsection{Caracterização de Fácies}

Arenito com estratificação cruzada tabular (At)

Essa fácies é caracterizada por arenitos médios a muito grossos, com grânulos, seleção baixa a moderada, arredondados a subangulosos, sendo composta predominantemente por quartzo e feldespato e, em menor proporção, por micas. Apresenta estratificação cruzada tabular, tangencial à base, que varia desde $5 \mathrm{~cm}$ até 100 $\mathrm{cm}$ de espessura. Apresentam tonalidades laranjas, cinzas e amarelados (Figura 7A).

Interpretação

A fácies é interpretada como depósito de migração de dunas sub-aquáticas de crista retas em regime de fluxo inferior (e.g. Ashley, 1990; Harms et al., 1982).

Arenito com estratificação cruzada de baixo ângulo (Ab)

Esta fácies é caracterizada por arenito de granulação fina a média, com grãos sub arredondados e moderadamente bem selecionados. É composta predominantemente por quartzo e feldespato, com ocorrência de minerais opacos. Apresenta estratificação cruzada de baixo ângulo e estratificação plano paralela, dispostas em camadas de geometria tabular de até $20 \mathrm{~cm}$ de espessura. Apresentam tonalidades laranjas e cinzas com algumas linhas mais escuras (Figura 7B).

Interpretação

A fácies é interpretada como depósitos de forma de leito de pequena amplitude (antiduna e leito plano), formadas de regime de fluxo critico ou supercrítico (e.g. Bridge, 2003; Fielding, 2006) 


\section{Conglomerado com estratificação cruzada (Ce)}

Esta fácies é caracterizada por conglomerados polimíticos com clastos que variam de bem arredondados a angulosos, que abrangem tamanhos de 1 a $10 \mathrm{~cm}$, compostos comumente de veios de quartzo, granitos, arenitos arcosianos, e, em menor proporção, siltitos e xistos. Apresenta estratificação cruzada com séries de $20 \mathrm{~cm}$ de espessura. Localmente, gradam para arenitos conglomeráticos e apresentam tonalidades avermelhadas (Figura 7C).

Interpretação

A fácies é interpretada como depósitos de carga de fundo transportada sob regime de fluxo inferior, em correntes trativas de um sistema fluvial.

Arenito com estratificação cruzada acanalada (Aa)

Esta fácies é caracterizada por arenitos médios a grossos, com grãos de seleção baixa a moderada, arredondados a subangulosos. Localmente, possui grânulos na base das séries de estratificações cruzadas. É composta por grãos de quartzo e feldespato e apresenta séries de estratificação cruzada acanalada. A fácies ocorre em camadas tabulares ou lenticulares, de espessuras de até $30 \mathrm{~cm}$. Apresenta tonalidades laranjas, cinzas e amareladas (Figura 7D).

Interpretação

A fácies é interpretada como depósitos de migração de dunas subaquáticas de cristas sinuosas em correntes trativas de regime de fluxo inferior (e.g. Ashley, 1990; Harms et al., 1982) 

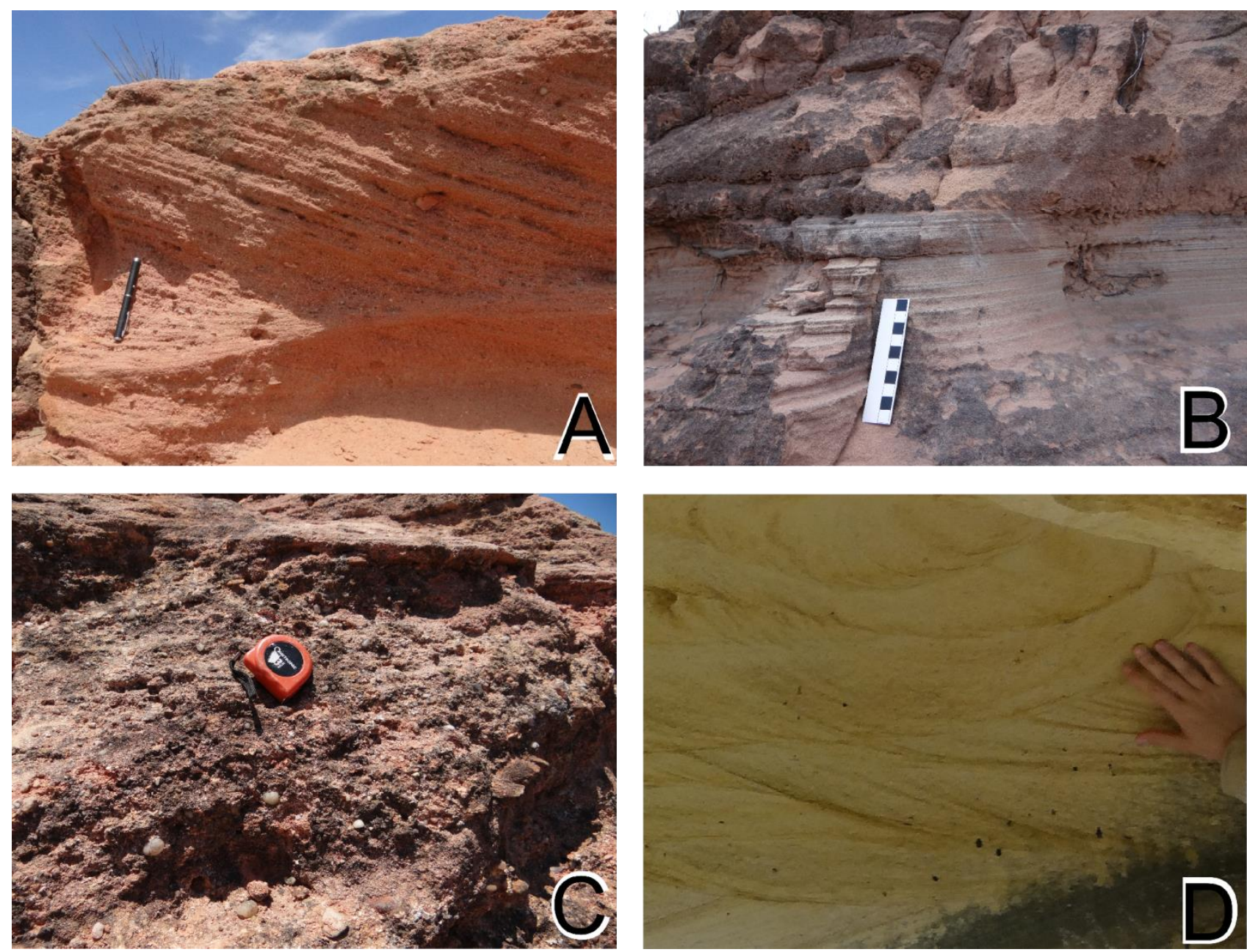

Figura 7. Fotos das fácies sedimentares presentes nos afloramentos. A. Arenito com estratificação cruzada tabular (At). B. Arenito com estratificação cruzada de baixo ângulo (Ab). C. Conglomerado com estratificação cruzada (Ce). D. Fácies dos Arenito com estratificação cruzada acanalada (Aa).

\subsubsection{Caracterização das associações de fácies e elementos arquiteturais}

\section{Depósitos de barras arenosas subaquáticas}

As fácies que compreendem este grupo são arenitos e conglomerados com estratificação cruzada tabular e arenitos com estratificação cruzada acanalada (At, Ce e Aa). Os depósitos apresentam-se com geometria tabular ou lenticular em pacotes de espessura de até vários metros, que podem chegar a ter dimensões métricas e continuidade lateral quilométrica. Os pacotes são formados por sets de aproximadamente 20-25 cm, mas podem apresentar espessuras de mais de $1 \mathrm{~m}$ como se mostra na figura 8 . Interpretam-se como barras localizadas em sistemas entrelaçados. 

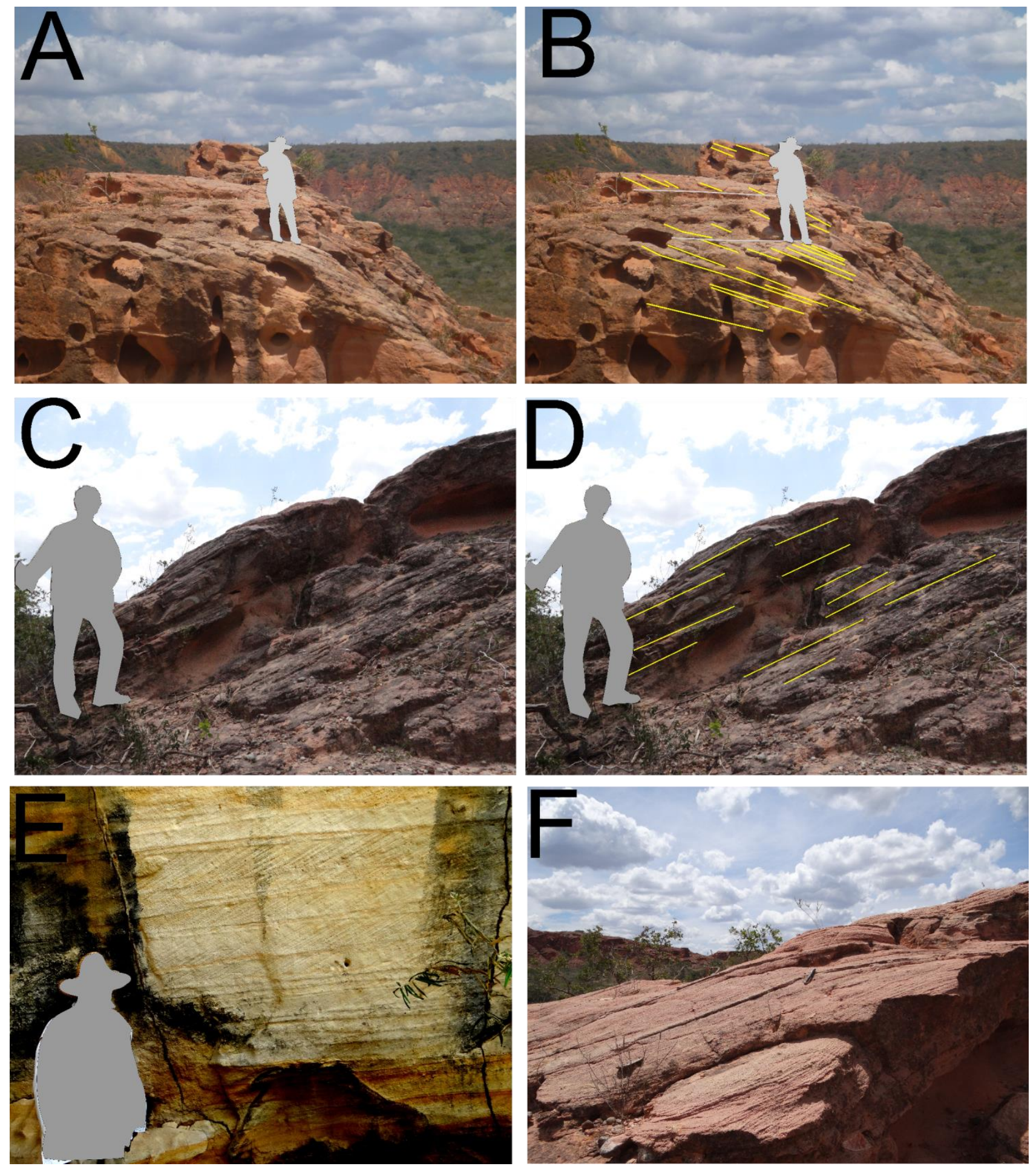

Figura 8. Fotos dos elementos arquiteturais nos afloramentos. A-D Estratificações cruzada de grande porte na Ravina de Curralinho. E. Estratificações cruzadas afloramento da área Banzaê. F. Estratificação cruzadas de médio porte na área de Banzaê. 


\subsection{Análises de Paleocorrentes}

De forma a melhor compreender os padrões de dispersão de fluxo e a paleogeografia do Membro Banzaê da Formação Marizal na Bacia do Tucano, foi realizada análise de paleocorrentes em três diferentes escalas.

Inicialmente, na área da Ravina de Curralinho, foi sistematicamente investigada uma área de exposição contínua de poucos milhares de metros quadrados, de forma a se obter um grande conjunto de dados de orientação de estratos cruzados e superfícies limitantes, formados sob uma mesma direção de fluxo, permitindo a caracterização da dispersão das medidas e estimativas do erro associado a amostras menores.

Uma segunda escala de análise foi abordada na região principal de exposição do Membro Banzaê, na área tipo da unidade. Nessa região, diversas estações de medidas foram obtidas em uma área de centenas de quilômetros quadrados, de forma a se avaliar as dimensões da sinuosidade (rank 3 de Miall, 1974) desse sistema.

Uma terceira escala foi abordada pela compilação dos dados obtidos pelo grupo de pesquisa em trabalhos anteriores em diversas áreas da Bacia do Tucano, integrados aos dados obtidos neste trabalho para a reconstituição da paleogeografia e contextualização dos dados deste trabalho no sistema de tributários e rio tronco na escala da bacia.

\subsubsection{Escala hectométrica - Área Ravina de Curralinho}

A área de Ravina de Curralinho é um afloramento de centenas de milhares de metros quadrados composto por um conjunto de morros não vegetados, que atingem até $20 \mathrm{~m}$ de espessura de rocha bem exposta (Figura 9A). O local é caracterizado por sucessões de arenitos com estratificação cruzada tabular e, em menor proporção, com estratificação cruzada acanalada ou de baixo ângulo. Nos últimos 3 metros da sucessão ocorrem conglomerados estratificados relacionando a uma superfície erosiva presente em todo o afloramento.

Para as análises na área da Ravina de Curralinho, foram adquiridas 1468 medidas de superfícies (781 de estratificações cruzadas tabulares e 687 de limites de série), em um total de 15 colunas estratigráficas levantadas. As medidas de paleocorrente das colunas estratigráficas foram agrupadas em 4 conjuntos maiores, de acordo com a proximidade geográfica entre as mesmas. Na figura 9B é possível ilustrar a quarta seção e a agrupação das medidas nos grupos 2, 3 e 4. A partir dos dados pareados das medidas de 
estratificação cruzada e do respectivo limite de série, foram reconstruídas as superfícies das formas de leito, para identificar a direção de acréscimo das formas de leito (Almeida et al., 2016), conforme exposto no capítulo de metodologia (Capítulo 3.2.1). Nos mapas, as setas pretas representam os valores médios de paleocorrente, enquanto as setas vermelhas, as superfícies reconstruídas da barra sobre a qual migravam as formas de leito. Uma variação entre o vetor médio da paleocorrente e da superfície reconstruída de 0 a $30^{\circ}$ indica acréscimo a jusante, de 30 a $60^{\circ}$, oblíqua e de 60 a $90^{\circ}$, lateral (Miall, 2016).

O afloramento foi subdividido verticalmente em quatro seções de acordo com os seguintes critérios: variação abrupta da granulação, da espessura das séries e da inclinação dos limites de séries. No geral, todos os níveis apresentam uma tendência de fluxo para SSO e 92\% dos dados de paleocorrente mostram um alto fator de consistência, sendo maior a 0.70 , com desvio padrão das médias de paleocorrente de $21.08^{\circ}$. A figura 10 mostra um mapa com os quatro agrupamentos de medidas de paleocorrente e os quatro níveis estratigráficos.

- Seção 1: Seção basal com aproximadamente $5 \mathrm{~m}$ de espessura. Como se observa na figura 10, os diagramas de rosetas e os vetores médios apresentam uma distribuição unimodal, com paleofluxo no quadrante SSO. Em relação ao tipo de acréscimo, a seção mostra uma direção nitidamente a jusante.

- Seção 2: Seção intermediária com aproximadamente 6 m de espessura. Também apresenta paleofluxo para o quadrante SSO. Em relação ao tipo de acréscimo, a seção mostra uma direção a jusante com componente de acréscimo a oeste nas partes central e sul do mapa.

- Seção 3: Seção intermediária com aproximadamente $6 \mathrm{~m}$ de espessura. As rosetas desse nível estratigráfico mostram distribuições unimodais e paleofluxo para SSO na região norte e para SSE na região sul. Em relação ao tipo de acréscimo, a zona sul volta a jusante na parte sul.

- Seção 4: Está localizada no topo do afloramento e tem aproximadamente $3 \mathrm{~m}$ de espessura. Apresenta paleofluxo para SSO e OSO na região norte e para SSE na região sul. Em relação ao tipo de acréscimo, a seção mostra um acréscimo a jusante com componente leste na parte sul. 

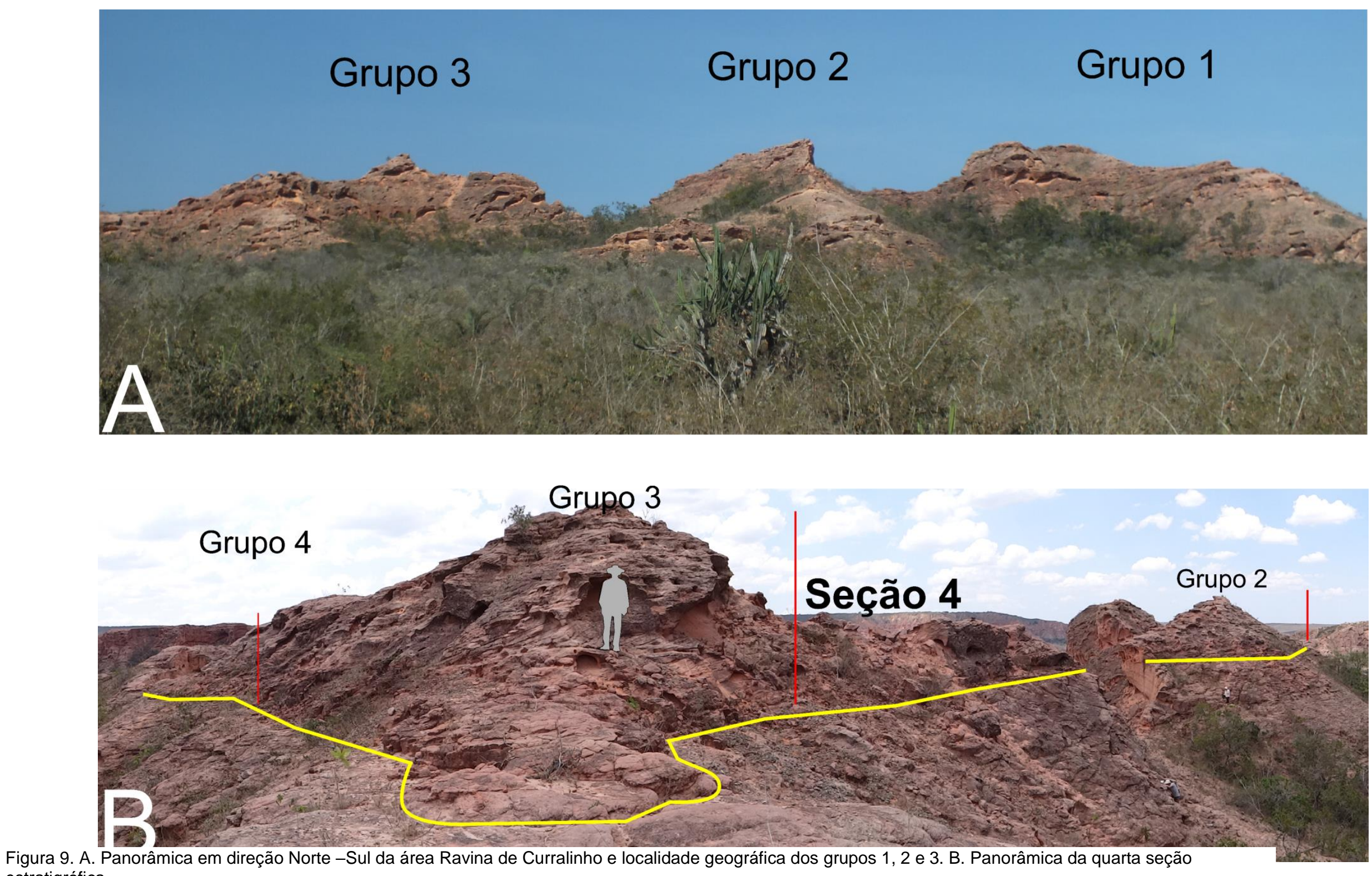
estratigráfica. 


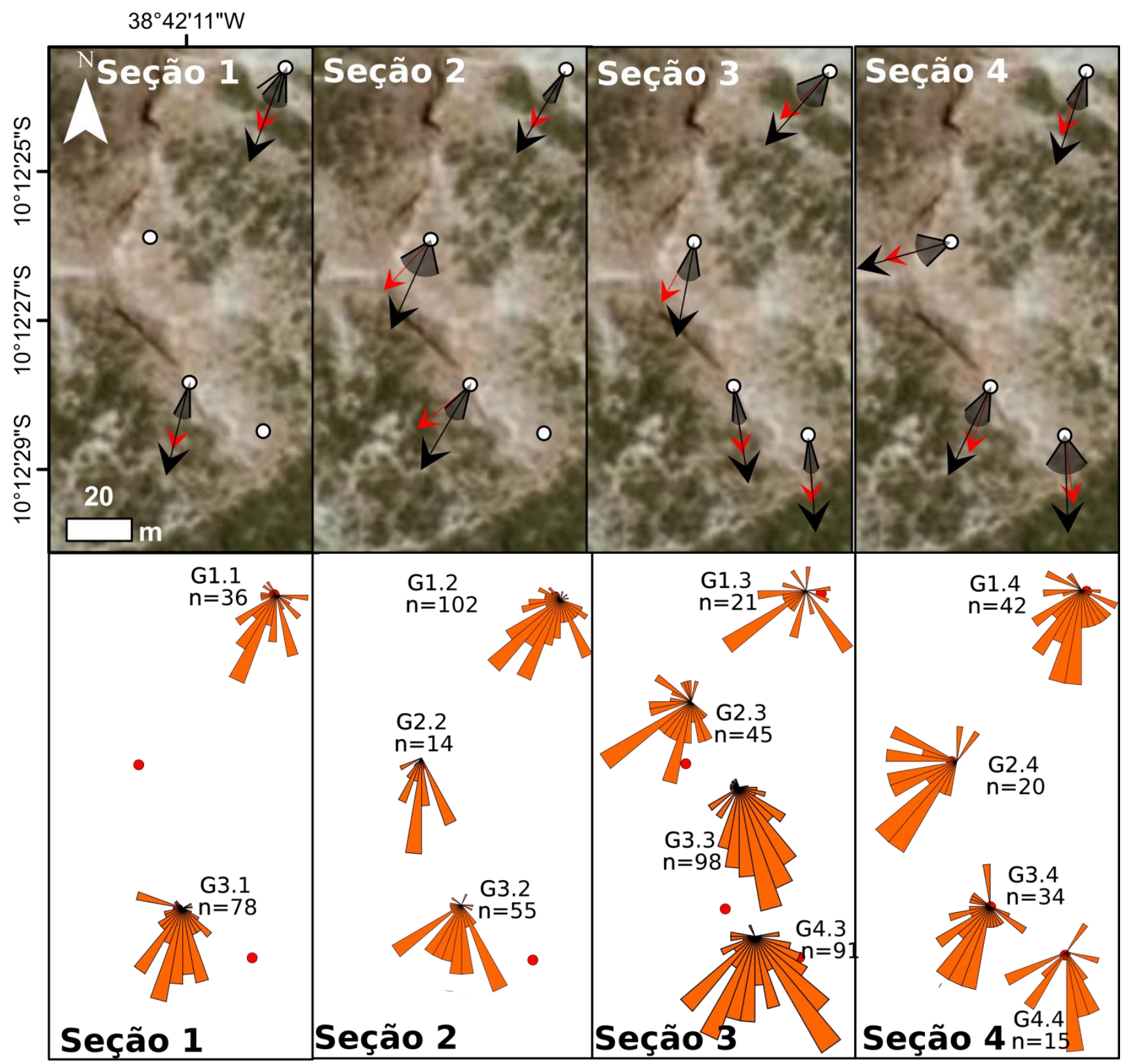

\begin{tabular}{|c|c|c|}
\hline Paleocorrentes & Erros & $\checkmark \begin{array}{l}\text { Superfície } \\
\text { reconstruída }\end{array}$ \\
\hline Rosetas & $\begin{array}{l}\text { O Afloramentos } \\
\text { G3.4 estudados }\end{array}$ & $\begin{array}{c}\mathrm{n}=34 \text { Número de } \\
\text { medidas }\end{array}$ \\
\hline
\end{tabular}

Figura 10. Parte superior, mapa com o vetor médio das paleocorrentes e reconstruções de superfícies nas seções estratigráficas da Ravina de Curralinho. Parte inferior, mapa com as distribuições das paleocorrente em rosetas de cada seção. 
O anexo 1 mostra o resultado gráfico das análises de reconstrução de superfícies barra (Almeida et al. 2016). Como avanço da metodologia de análises de paleocorrente o presente trabalho apresenta o intervalo de erro associado em cada paleocorrente local (ver Capítulo 3.2.1).

De forma geral, a análise de paleocorrentes revela que não há variação significativa na direção de fluxo na escala do afloramento, dado que todas as estações de medida, com exceção de uma, apresentam vetor médio dentro de um range de menos de $45^{\circ}$ (Figura 10) e mesmo a estação mais discrepante (seção 4, Figura 10) não diverge mais de $90^{\circ}$ das demais. Desta forma, pode-se considerar que todo o afloramento representa uma mesma área do sistema fluvial que é menor que a sinuosidade do sistema, podendo todas as medidas serem consideradas como uma amostra pontual da dispersão de estratos cruzados gerados em uma mesma direção de fluxo na escala do sistema. Por este motivo, a localidade foi utilizada para como amostra de referência para a determinação do erro associado a medidas de paleocorrentes com amostras menores em outras localidades de exposição da mesma unidade estratigráfica (Membro Banzaê da Formação Marizal).

Com relação às reconstituições de superfícies das barras sobre as quais migravam as formas de leito (Figura 10 setas vermelhas), o padrão homogêneo de acréscimo para a jusante indica geometria simples e amplo predomínio de deposição na zona jusante de barras, onde velocidades de fluxo menores são resultantes da expansão do fluxo.

\subsubsection{Escala quilométrica - Área de Banzaê}

A região do Município de Banzaê tem inúmeros afloramentos de fácil acesso, excelente qualidade e continuidade lateral quilométrica, como se mostra nas figuras $11 \mathrm{e}$ 12. A região permitiu a aquisição de 2129 medições, incluindo estratos cruzados e limites de séries em 41 afloramentos. O membro Banzaê nessa região, como o descreve Freitas (2014), apresenta dois limites erosivos contínuos, que permitiram uma clara correlação entre as seções estratigráficas na área. No presente trabalho, os limites serviram para subdividir o membro e elaborar 3 mapas da região dos níveis estratigráficos A (basal), B (intermediário) e C (superior). O afloramento 41 coresponde aos dados da Fazenda Retiro obtidos por Freitas (2014).

Todos os afloramentos apresentaram uma distribuição unimodal da direção de paleocorrentes, como se observa nas rosetas das figuras $13 \mathrm{~B}, 14 \mathrm{~B}$, e $15 \mathrm{~B}$. No geral, as paleocorrentes mostram um sistema fluvial fluía consistentemente para sul, com medidas 
dos vetores médios variando de OSO a ESE. Para os níveis estratigráficos $A, B$ e C, o desvio padrão calculado em relação à média foi de 31.7, 32.5 e 47.6, respectivamente e $88 \%$ dos afloramentos apresentam um fator de consistência maior do que 0.7.

A partir dos dados pareados das medidas de estratificação cruzada e do respectivo limite de série, foram reconstruídas as superfícies das formas de leito, para identificar a direção de acréscimo das formas de leito, conforme exposto no capítulo de metodologia (Capítulo 3.2). Nos mapas, as setas pretas representam os valores médios de paleocorrente, enquanto as setas vermelhas, as superfícies reconstruídas da forma de leito. Uma variação entre o vetor médio da paleocorrente e da superfície reconstruída de 0 a $30^{\circ}$ indica acréscimo a jusante, de 30 a 60, oblíqua e de 60 a 90, lateral (Miall, 2015). Os anexos 2, 3, 4 mostram o resultado gráfico das análises de reconstrução de superfícies barra (Almeida et al., 2016).

Para a descrição dos mapas, a zona norte faz referência até a latitude $10^{\circ} 30^{\prime} 0^{\prime \prime S}$, a zona centro entre as latitudes $10^{\circ} 30^{\prime} 0^{\prime \prime} S$ e $10^{\circ} 33^{\prime} 0^{\prime \prime} S$ e a zona sul desde a latitude $10^{\circ} 33^{\prime} 0^{\prime \prime} \mathrm{S}$.
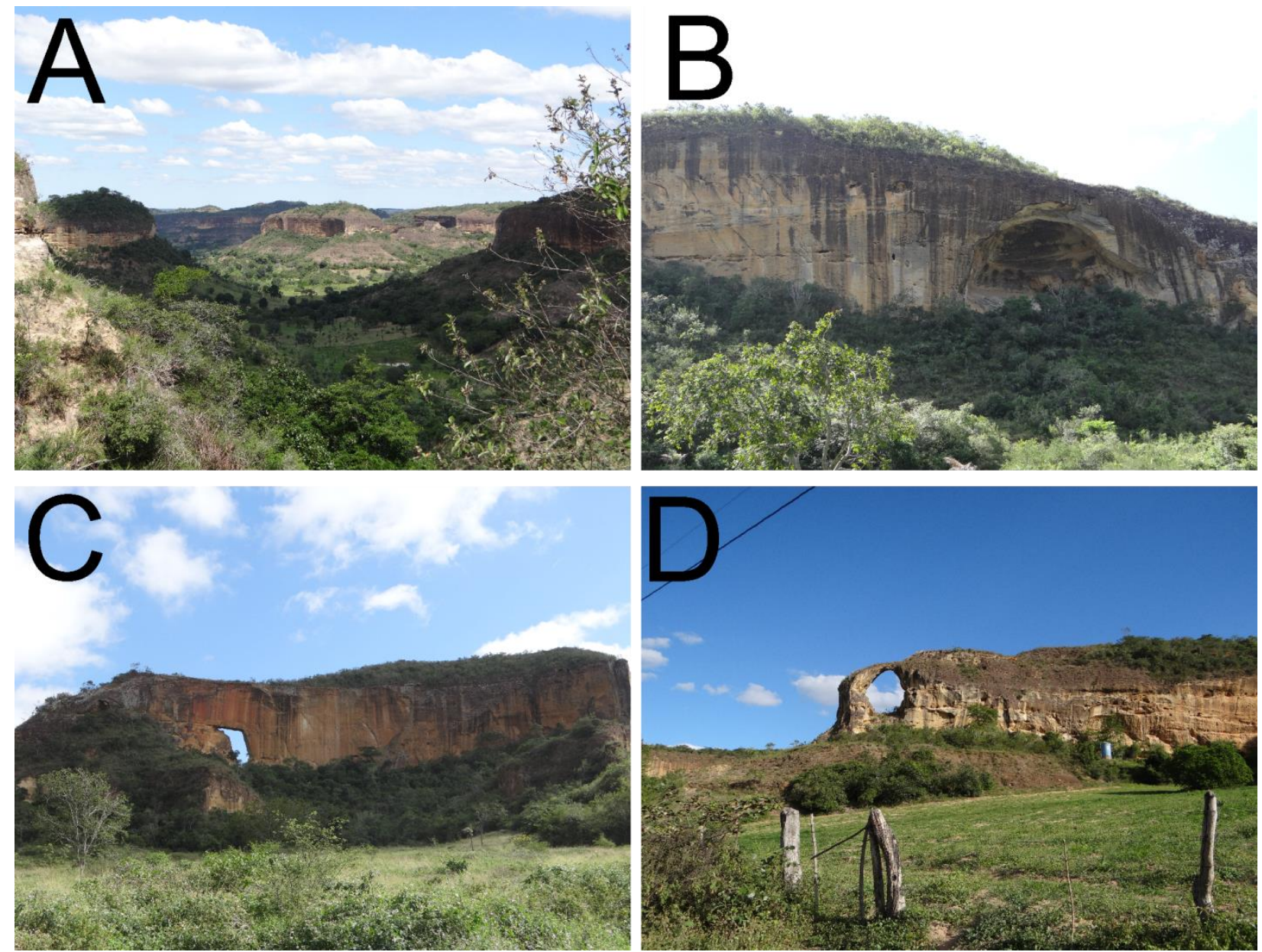

Figura 11. Expressões geomorfológicas dos afloramentos da área de Banzaê. 

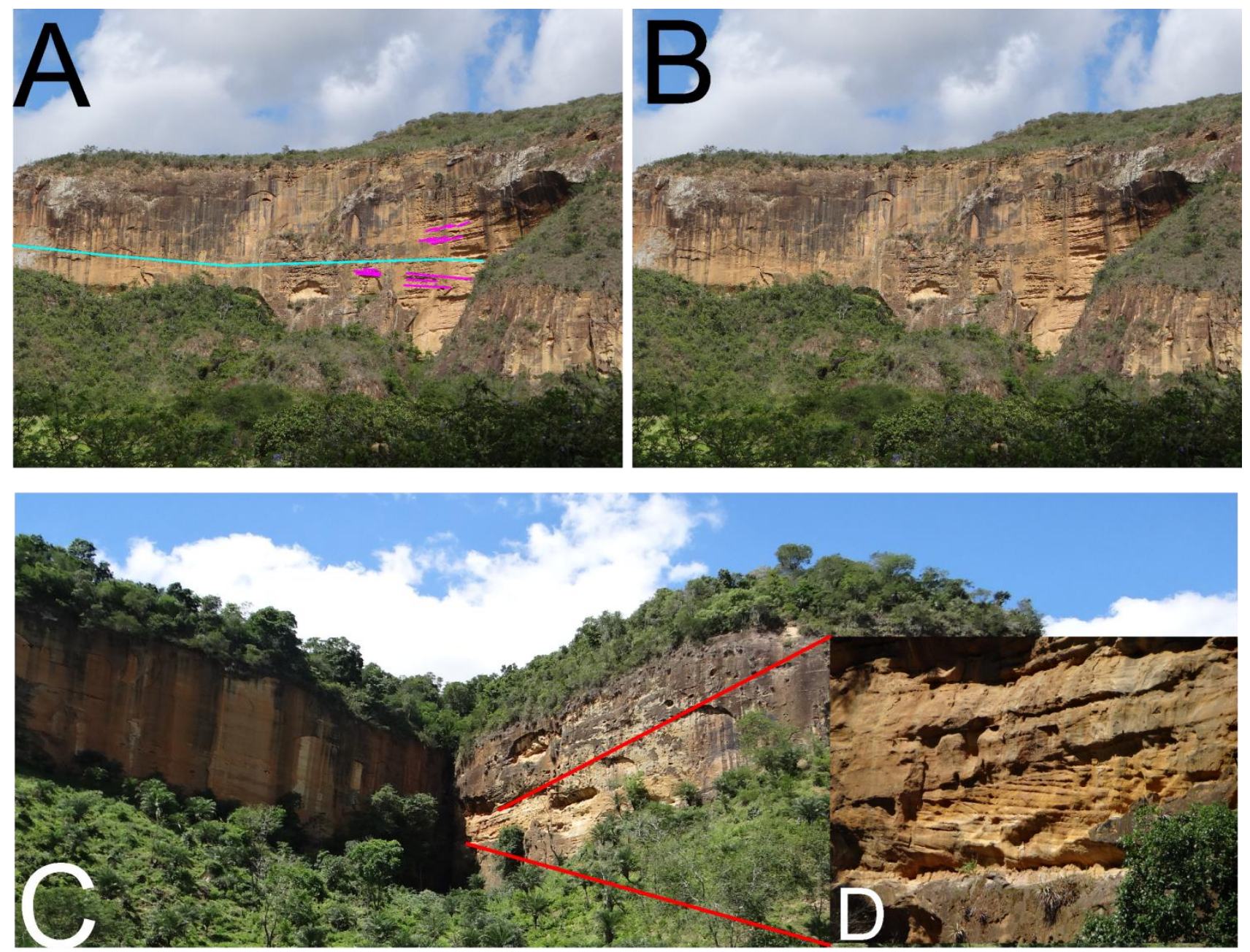

Figura 12. Expressões geomorfológicas e fácies dos afloramentos da área de Banzaê. A e B. Fotografia resaltando a direção entre as seções estratigráficas intermédiaria B e superior C (linha azul) e estratificações cruzada (linhas roxas). D Fotografia que detalhada de estratificação cruzada tabular.

\section{Mapa A. Seção basal}

Para as análises do mapa A foram adquiridas 469 medidas de superfícies (333 de estratificações cruzadas tabulares e 136 limites de séries) em 14 afloramentos.

Conforme mostrado na figura 13A, na zona norte, as medidas apresentam variações nas direções leste, no quadrante SSE (ponto 23) e oeste, nos quadrantes OSO (24) e SSO (10). Na zona central, apresentam uma tendência em direção a oeste, nos quadrantes SSO $(5,13)$ e OSO $(40)$, com algumas contribuições para SSE $(6,36)$. Na zona sul do mapa, continua apresentando tendência com valores mais próximos de oeste, principalmente no quadrante SSO $(15,17,18,19)$, e com algumas contribuições no quadrante SSE $(14,34)$.

Em relação ao tipo de acréscimo das formas de leito, as zonas norte, central e sul mostram uma direção de acréscimo a jusante. 


\section{Mapa B. Seção intermediária}

Para as análises do mapa B foram adquiridas 1459 medidas de superfícies (999 de estratificações cruzadas tabulares e 460 limites de séries), por meio de levantamentos em 33 afloramentos.

Conforme mostrado na figura 14A, na zona norte, há uma tendência em direção SSE $(10,25,26)$. Enquanto na zona central, muda paulatinamente para oeste, nos quadrantes SSO $(4,5,12,31,32,36,41)$ e OSO $(7,13,40)$, com algumas contribuições em direção SSE $(9,11,38)$. A zona sul do mapa continua com uma tendência para oeste, principalmente nos quadrantes SSO (2, 3, 20, 22, 29, 30, 34, 35, 37, 39) e OSO (33), com algumas contribuições para o leste, nos quadrantes SSE $(1,8,16,17,28)$ e ESE $(27)$.

Em relação ao tipo de acréscimo das formas de leito, a zona norte mostra uma direção de acréscimo a jusante; a zona central e sul, mostra acréscimo predominantemente a jusante, e se apresenta um afloramento com direção de acréscimo obliqua para o oeste $(36,30)$.

\section{Mapa C. Seção superior}

Para as análises do mapa C foram adquiridas 201 medidas de superfícies (138 de estratificações cruzadas tabulares e 63 limites de séries), por meio de levantamentos em 6 afloramentos.

$\mathrm{Na}$ figura 15A, observa-se que os vetores médios apresentam direção geral para sul nas regiões aflorantes. Na zona central, apresentam forte tendência para oeste, nos quadrantes OSO $(31,32,41)$ e SSO (4). A tendência dos vetores na zona sul muda para leste, com medidas nos quadrantes SSE (21) e ESE (30).

Em relação ao tipo de acréscimo das formas de leito, tanto a zona central como a sul apresentam acréscimo a jusante. 


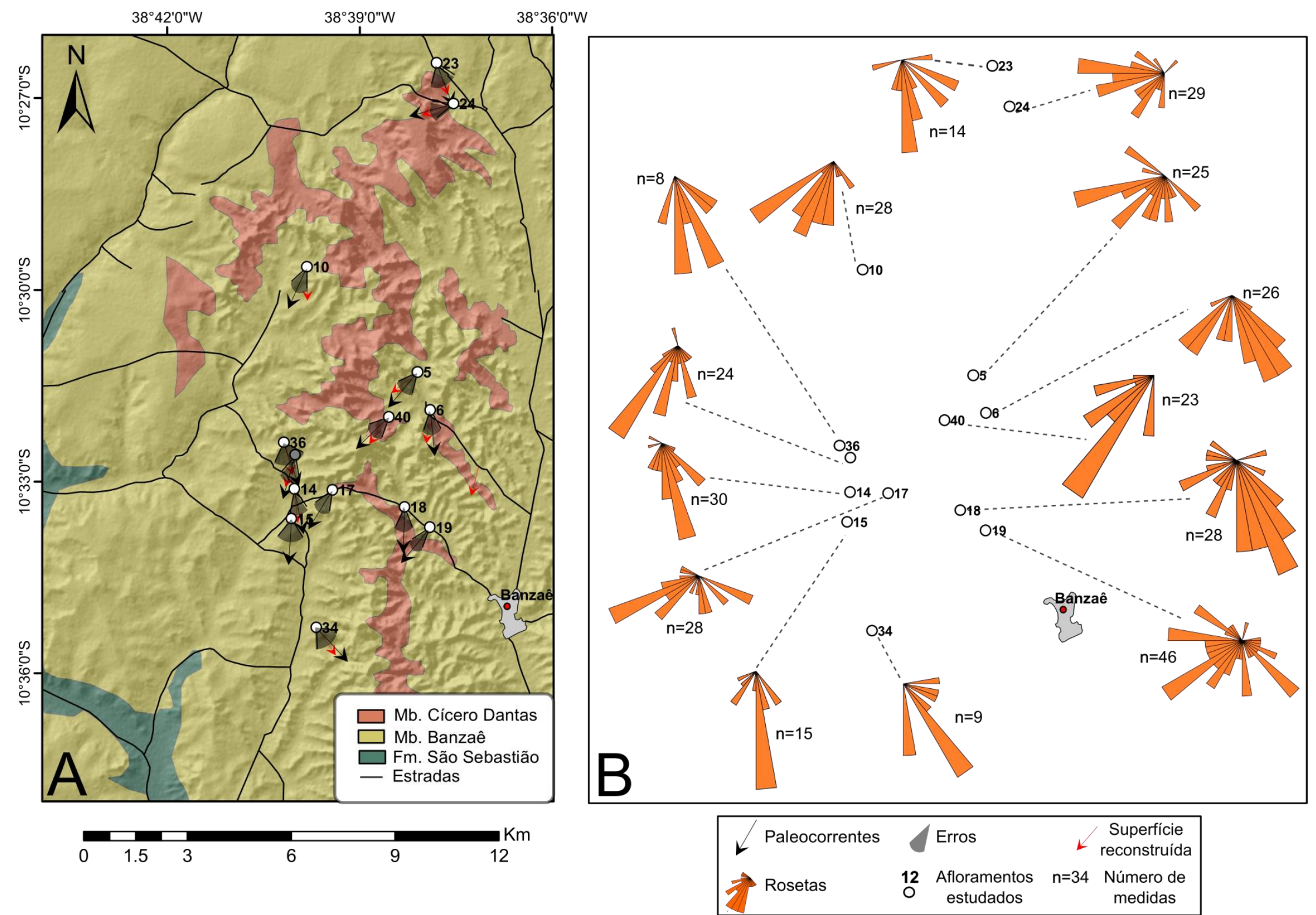

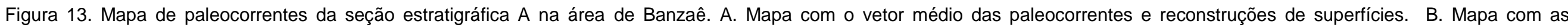
distribuições das paleocorrente em gráficas de rosetas. 


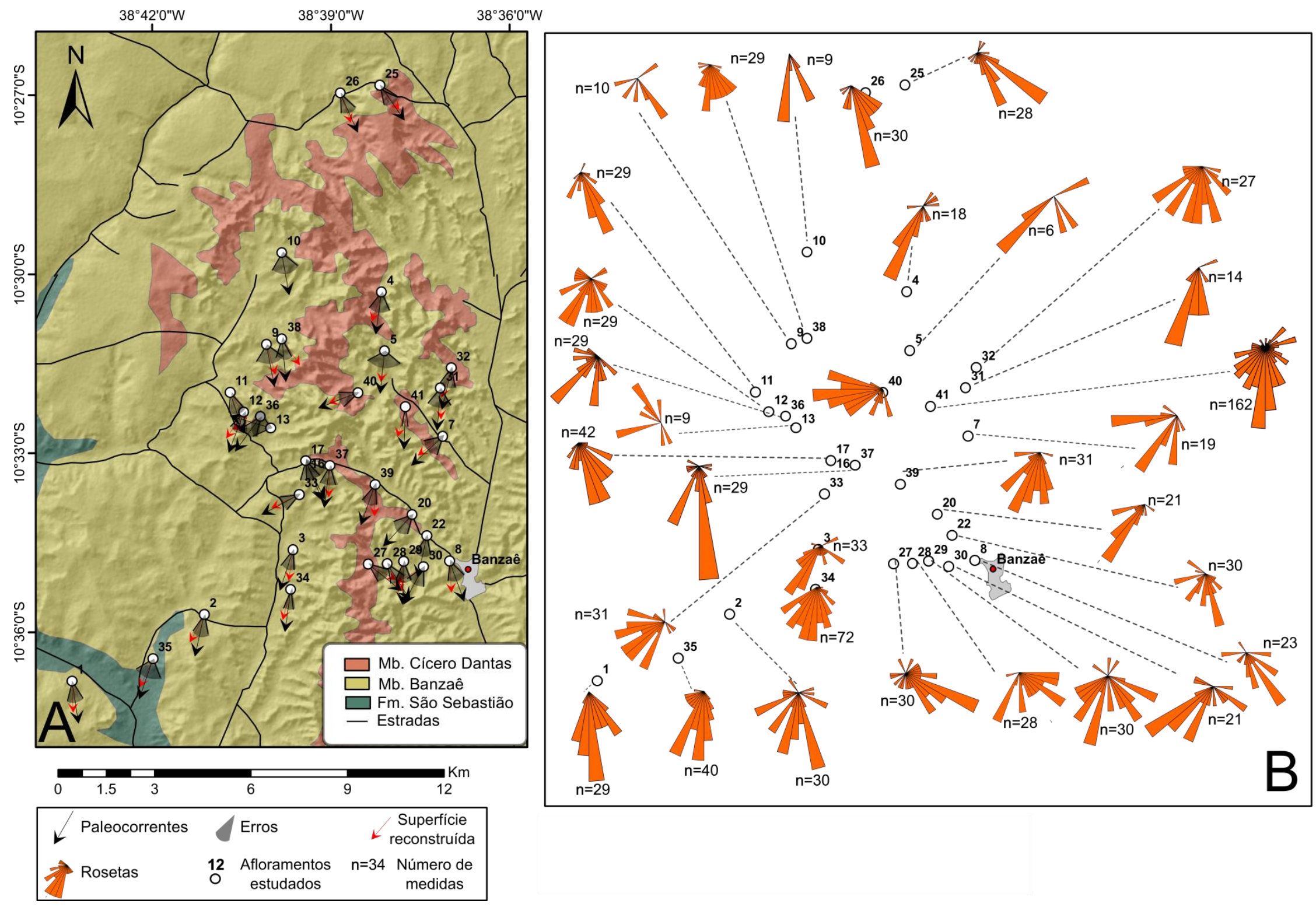

Figura 14. Mapa de paleocorrentes da seção estratigráfica B na área de Banzaê. A. Mapa com o vetor médio das paleocorrentes e reconstruções de superfícies. B. Mapa com as distribuições das paleocorrente em gráficas de rosetas. 


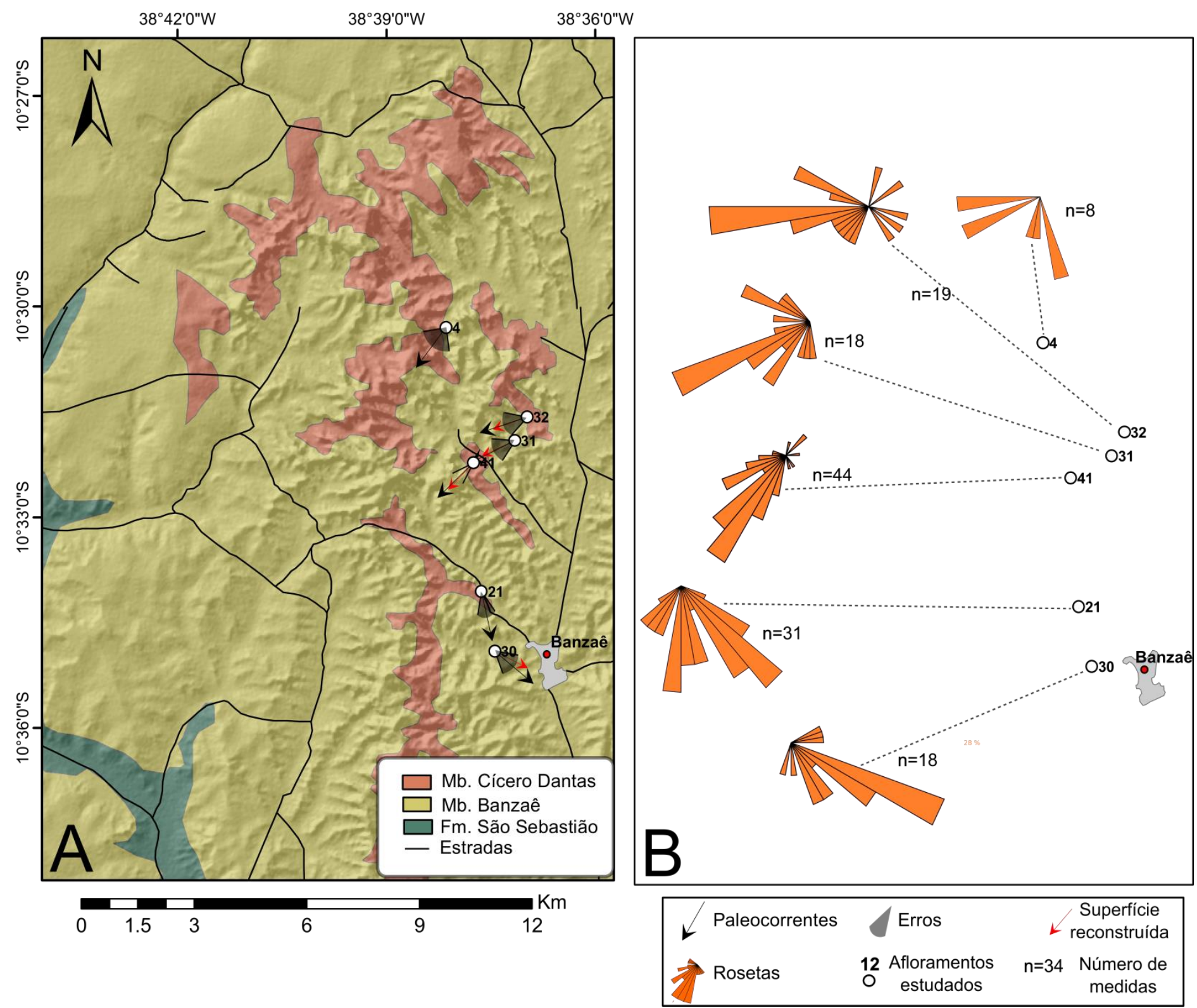

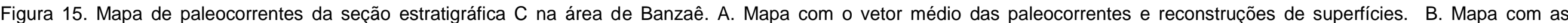
distribuições das paleocorrente em gráficas de rosetas. 


\subsubsection{Escala da sinuosidade}

Considerando-se os três níveis estratigráficos analisados na região de Banzaê, nota-se uma variação no sentido de paleocorrente em diferentes áreas (Figura 16), mesmo considerando-se o erro individual de cada estação de medidas. Essa variação em área é compatível com a presença de sinuosidade do canal principal em escala maior que barras individuais (rank 3 de Miall 1974). Assim, os dados permitem interpretar a presença de curvas no canal principal com comprimento de onda próximo a $9 \mathrm{~km}$, com implicações para a interpretação da escala do sistema fluvial (ver item 5.1.2 Discussão).

\subsubsection{Escala da Bacia do Tucano}

Os dados aqui apresentados inserem-se em um contexto de um sistema de drenagem em escala bacinal reconstituído por Freitas (2014), Abdala (2014) e Carrera (2015), que claramente apresenta uma área de orientação Norte-Sul na metade oeste da bacia em que predominam canais axiais e, ao menos no lesta da sub-bacia do Tucano Central, um sistema de rios tributários mais rasos e de granulação mais grossa. Assim, os dados preexistentes apontam para paleofluxo para Oeste-Sudoeste neste sistema tributário e, fluxo para Sul-Sudeste no sistema axial nas sub-bacias Tucano Central e Norte e Sul-Sudoeste na sub-bacia Tucano Sul, apesar da orientação Norte-Sul da bacia (Figura 17).

Os dados aqui coletados mostram que de fato o aparente paleofluxo médio para sudeste ou sudoeste em diferentes sub-bacias é um artefato da baixa amostragem espacial prévia. A malha de dados da região de Banzaê mostra claramente média para sul e dispersão resultante de sinuosidade em escala quilométrica, concordando com a interpretação de um sistema verdadeiramente axial para esses depósitos. 

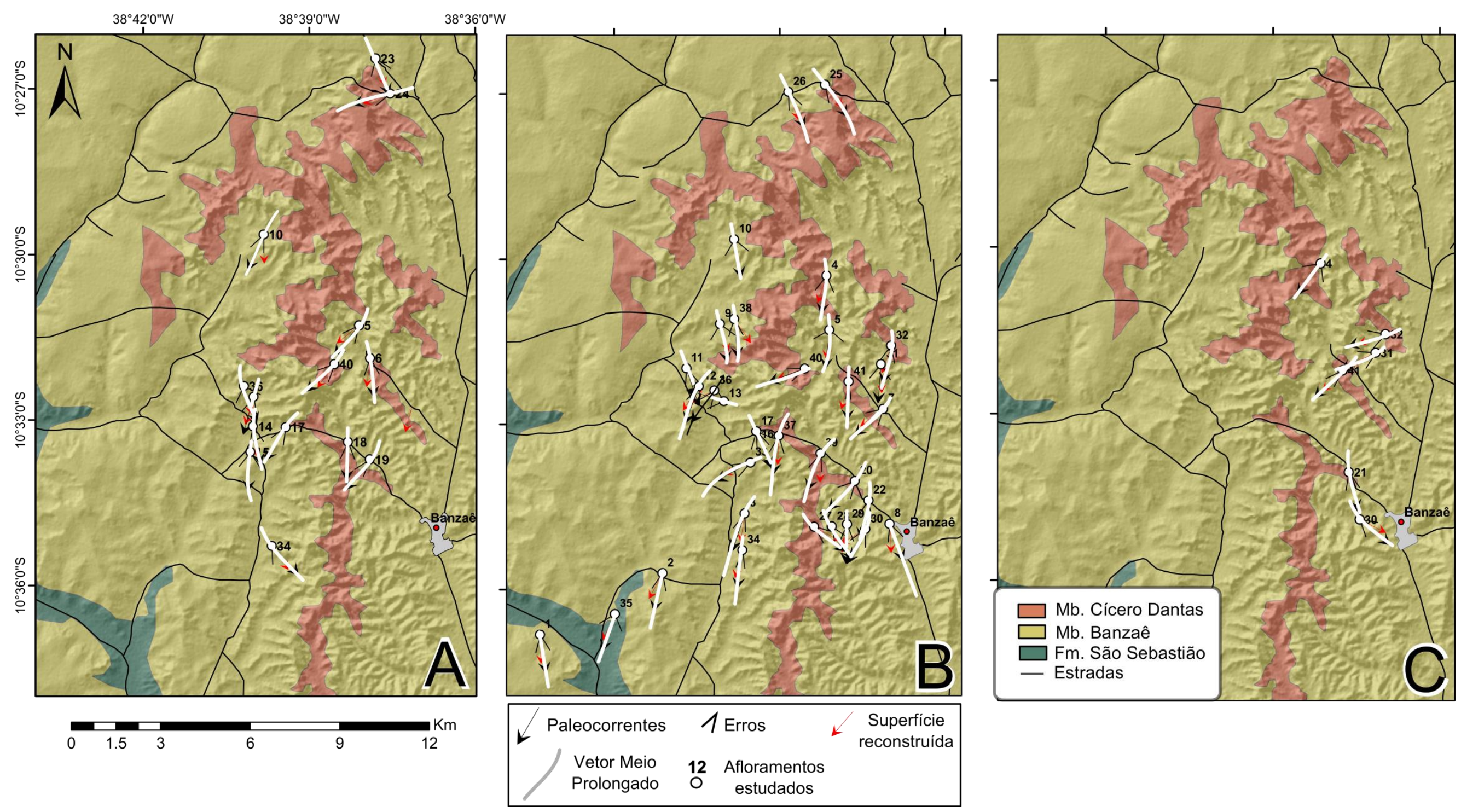

Figura 16. Mapas de paleocorrentes dos três níveis estratigráficos na área de Banzaê. 


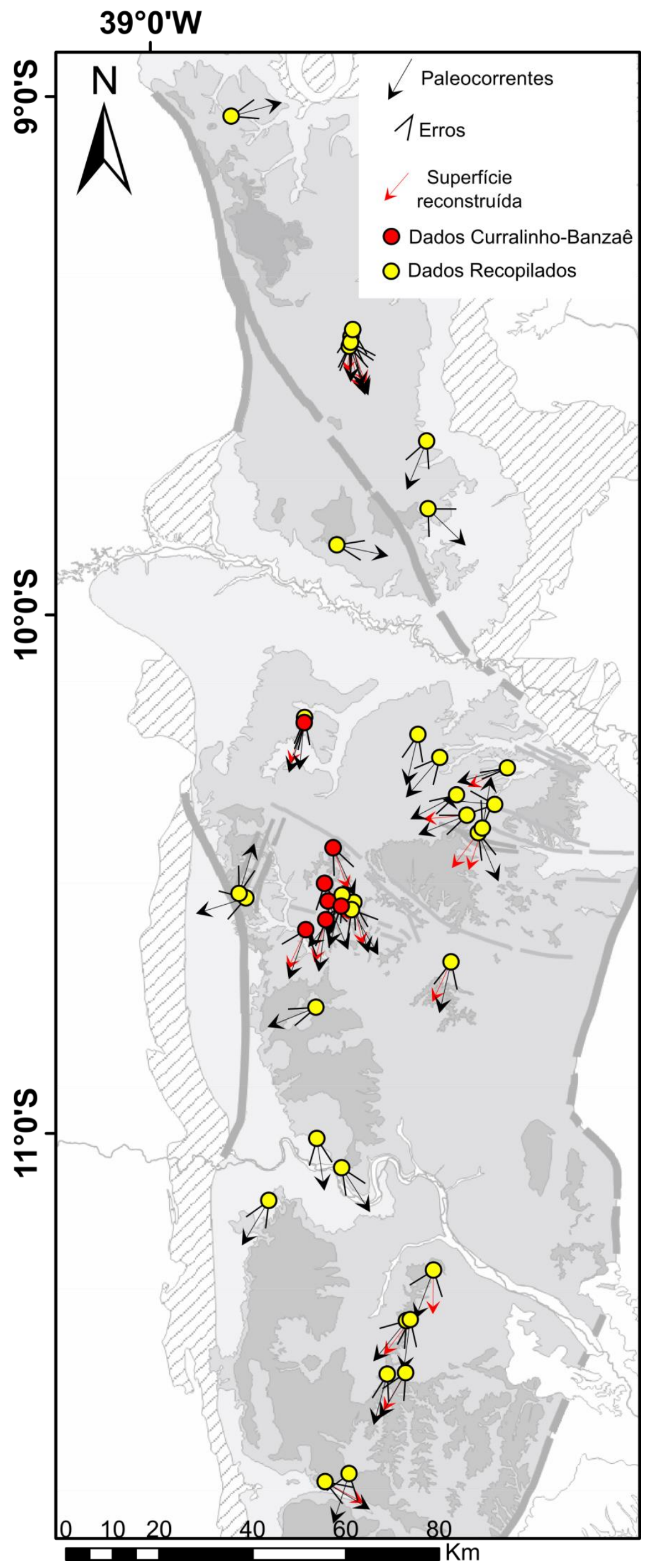

Figura 17. Mapa de paleocorrentes do Membro Banzaê. (Modificado de Abdala, 2014 e Freitas, 2014). 


\subsection{Análises de Paleohidráulica}

Com o objetivo de avaliar a escala do sistema investigado com dados independentes da análise de escala da sinuosidade apresentada acima, foi aplicada abordagem tradicional de estimativa da profundidade dos canais com base nas espessuras preservadas de séries de estratos cruzados. Assim, a partir dos dados da medição sistemática das espessuras de série, foram elaborados diagramas caixas para apresentar os dados estatísticos. A partir desses dados, foram inferidos o tamanho original da forma de leito que ficou preservada e a profundidade do canal onde a forma de leito foi formada, conforme descrito no capítulo da metodologia (Capítulo 3.3)

\subsection{1 Área Ravina de Curralinho}

Para a área da Ravina do Curralinho, foram coletadas 1370 medidas de espessura de série. Assim como no caso das medidas de paleocorrente, descritas no item anterior 4.1.1, as medidas nesse afloramento foram subdivididos em quatro níveis estratigráficos, chamados, da base pro topo, de Seções 1 a 4. Além disso, as medidas foram agrupadas nos Grupos 1 a 4, aproximadamente de norte para sul, de acordo com proximidade geográfica entre as medidas.

A figura 18 ilustra a distribuição de espessuras em cada seção estratigráfica nessa área. Observa-se que há uma similaridade nas distribuições dos dados nas quatro seções estratigráficas, as quais apresentam uma assimetria positiva: $75 \%$ dos dados estão concentrados na parte inferior da distribuição, com valores menores do que $25 \mathrm{~cm}$, e 0 restante dos dados se estendem para espessuras maiores. Todas as seções exibem valores atípicos só na parte direita da distribuição (valores maiores), apresentando valores de 50 a $200 \mathrm{~cm}$. Cabe ressaltar que a seção 2 apresenta a menor dispersão e a maior simetria dos dados de espessura do afloramento. A tabela 1 mostra medidas de estatística descritiva, evidenciando as semelhanças dos valores médios nas seções, que variam de 19.08 a $24.91 \mathrm{~cm}$. 


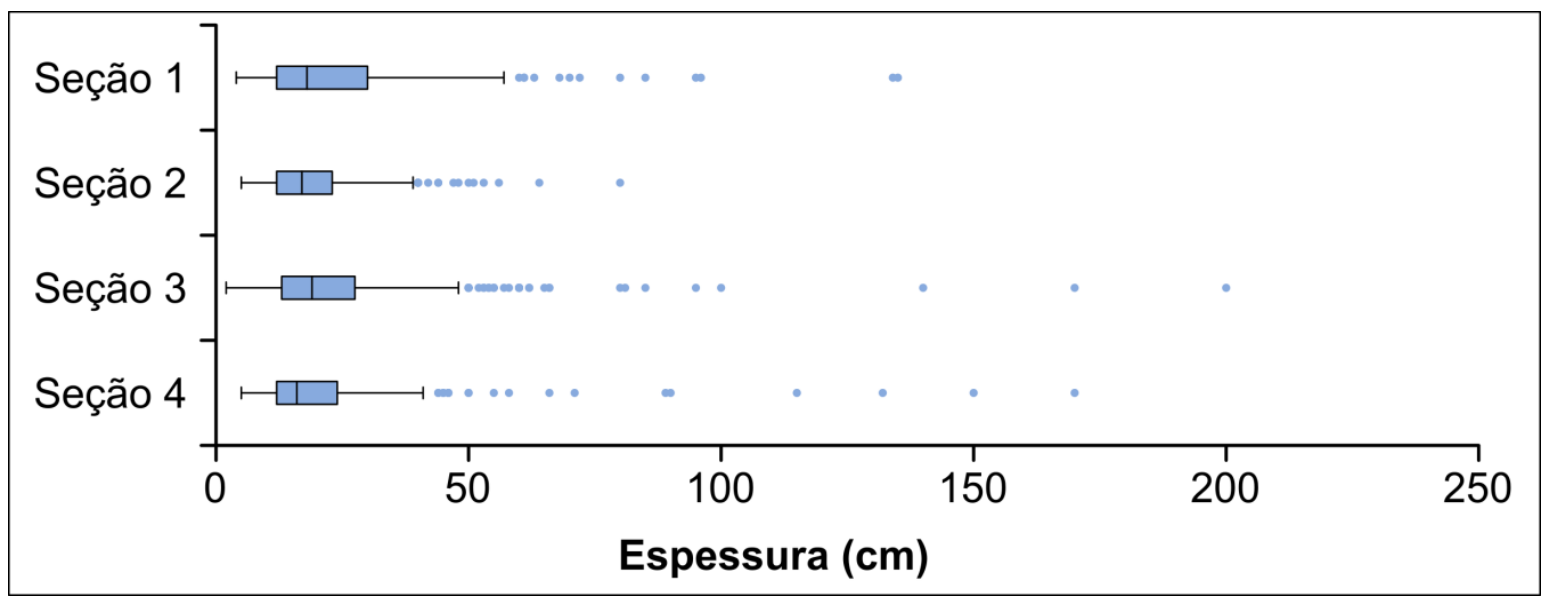

Figura 18. Diagramas de caixas das espessuras de séries das seções estratigráficas da Ravina de Curralinho.

$\begin{array}{ccccc} & \text { Seção 1 } & \text { Seção 2 } & \text { Seção 3 } & \text { Seção 4 } \\ \text { Média } & 24.91 & 19.08 & 24.07 & 21.26 \\ \text { Error Estandar } & 1.24 & 0.56 & 0.92 & 1.14 \\ \text { Mediana } & 18 & 17 & 19 & 16 \\ \text { Moda } & 10 & 10 & 20 & 10 \\ \text { Minimo } & 4 & 5 & 2 & 5 \\ \text { Máximo } & 135 & 80 & 200 & 170 \\ \text { Numero de dados } & 243 & 327 & 519 & 281\end{array}$

Tabela 2. Compilação das medidas de estadística descritiva da Ravina de Curralinho.

A figura 19 ilustra a distribuição detalhada espessuras de cada seção estratigráfica, separando os dados por localidades e organizando de Norte a Sul.

- Seção 1: Como se observa na figura 19 e na tabela 2, as espessuras estão concentradas na área do gráfico com valores menores a $25 \mathrm{~cm}$. A média de espessura dos sets diminui para norte e os valores máximos atípicos estão ao redor de $130 \mathrm{~cm}$.

- Seção 2: As espessuras também estão concentradas nas áreas de valores menores a $25 \mathrm{~cm}$. Observa-se diminuição de espessura dos sets do sul para o centro do mapa; e um sucessivo aumento, do centro para o norte. Os valores máximos atípicos são menores de $1 \mathrm{~m}$.

- Seção 3: Tem uma distribuição dos dados com assimetria positiva com concentração de espessuras em valores menores a $25 \mathrm{~cm}$. Observa-se diminuição dos valores máximos atípicos do sul para o centro do mapa (200 para $60 \mathrm{~cm}$ ); e um sucessivo aumento do centro para o norte (60 para $140 \mathrm{~cm})$.

- Seção 4: Tem uma distribuição dos dados com assimetria positiva com concentração de espessuras menores a $25 \mathrm{~cm}$. Observa-se diminuição dos valores 
dos pontos máximos atípicos do sul para o centro do mapa (175 para $45 \mathrm{~cm}$ ); e sucessivo aumento do centro para no norte (45 para $130 \mathrm{~cm}$ ). Os valores das médias apresentam a mesma tendência.
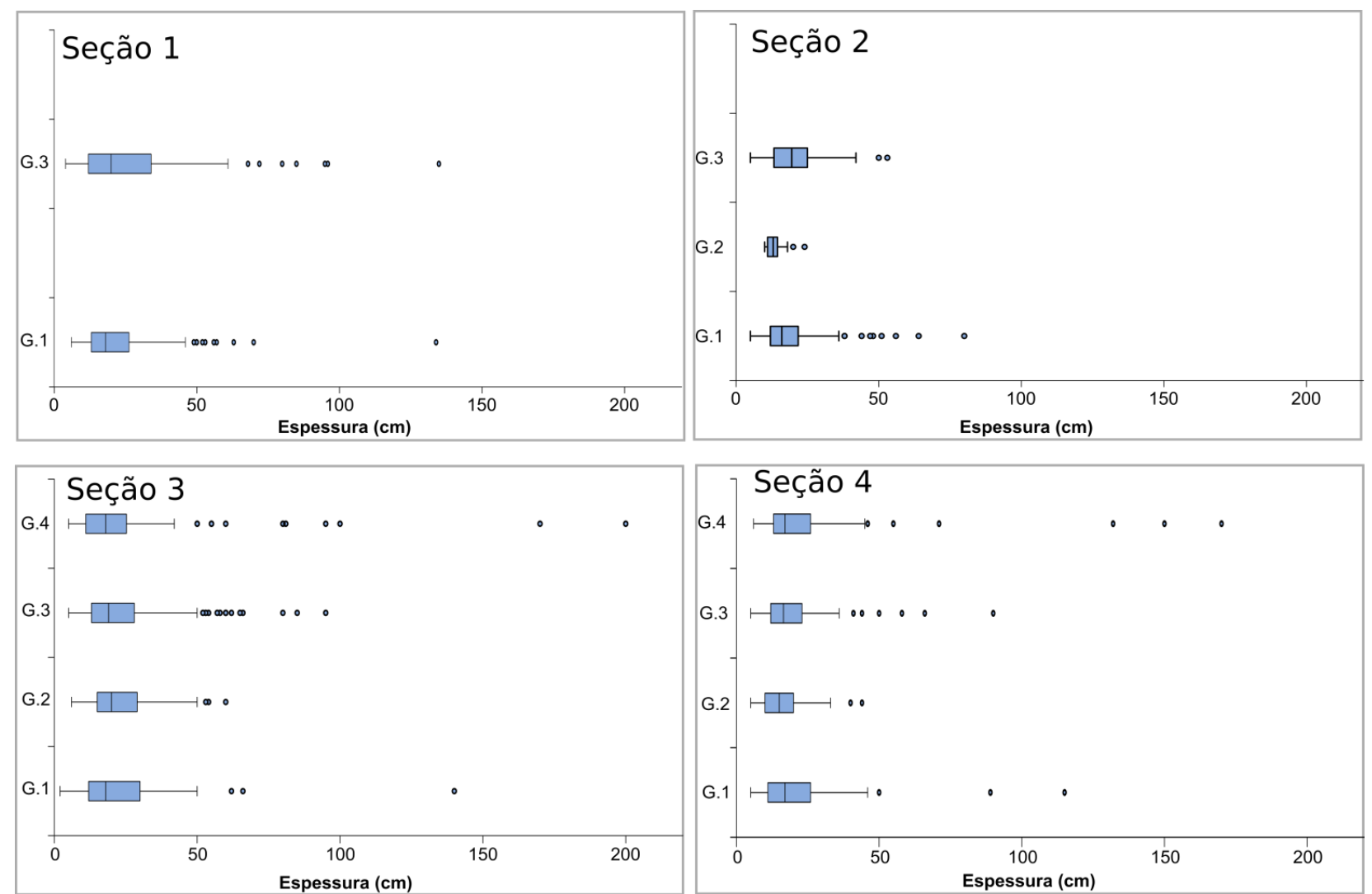

Figura 19. Diagramas de caixas da espessura de séries nas seções estratigráficas divididas e organizadas de Norte a Sul em cada localidade da Ravina de Curralinho.

$\begin{array}{lllll} & \text { Seção 1 } & \text { Seção 2 } & \text { Seção 3 } & \text { Seção 4 } \\ \text { Gr. 1 } & 23.58 & 18.61 & 24.14 & 20.75 \\ \text { Gr. 2 } & & 13.87 & 23.48 & 16.41 \\ \text { Gr. 3 } & 26.04 & 20.74 & 23.52 & 20.29\end{array}$

Tabela 3. Compilações das médias de cada grupo em cada seção estratigráfica da Ravina de Curralinho

Conforme exposto no capítulo de metodologia (Capítulo. 3.3), considerou-se que a altura das dunas equivale aproximadamente a três vezes o valor da média da espessura de série. A média de todo o afloramento é de $22.8 \mathrm{~cm}$, o que representaria formas de leito precursoras com tamanho médio de aproximadamente $68.5 \mathrm{~cm}$ de altura. Assumindo que a profundidade do canal é de 6 a 10 vezes a altura da duna (Leclair \& Bridge, 2001), a profundidade estimada para a área de Curralinho estaria em torno de 4.1 a $6.9 \mathrm{~m}$. A tabela 3 apresenta as medidas estimadas de altura de duna $(H)$ e profundidade do canal (D). 


$\begin{array}{lllll} & \text { Sm (cm) } & \text { H }(\mathbf{c m}) & \text { D1 (m) } & \text { D2 (m) } \\ \text { Seção 1 } & 24.9 & 72.2 & 4.3 & 7.2 \\ \text { Seção 2 } & 19.1 & 55.3 & 3.3 & 5.5 \\ \text { Seção 3 } & 24.1 & 69.8 & 4.2 & 7.0 \\ \text { Seção 4 } & 21.3 & 61.6 & 3.7 & 6.2\end{array}$

Tabela 4. Estimativas de profundidade das seções estratigráficas da Ravina de Curralinho. Sm (Média da espessura da série), H (altura da duna), D1 (profundidade do canal seis vezes maior a H) e D2 (profundidade do canal dez vezes maior a H).

\subsection{2 Área de Banzaê}

Para a área da Banzaê, foram coletadas 681 medidas de espessura de série. Assim como no caso das medidas de paleocorrente, descritas no item anterior 4.1.2, as medidas nesse afloramento foram subdivididos em quatro três estratigráficos, chamados, da base pro topo, de Seções A, B e C.

A Figura 20 ilustra a distribuição de espessuras encontrada nessa área, considerando todas as medidas de cada um dos três níveis estratigráficos descritos. Observa-se que as distribuições das seções apresentam uma assimetria positiva: 0 percentil três em A corresponde ao valor de $26 \mathrm{~cm}$, em B, de $24 \mathrm{~cm}$ e em C, de $30 \mathrm{~cm}$. As três distribuições concentram os dados nos valores menores. Todas as seções apresentam valores atípicos na parte direita do gráfico. O valor máximo é $140 \mathrm{~cm}$. A tabela 4 mostra a estatística descritiva.

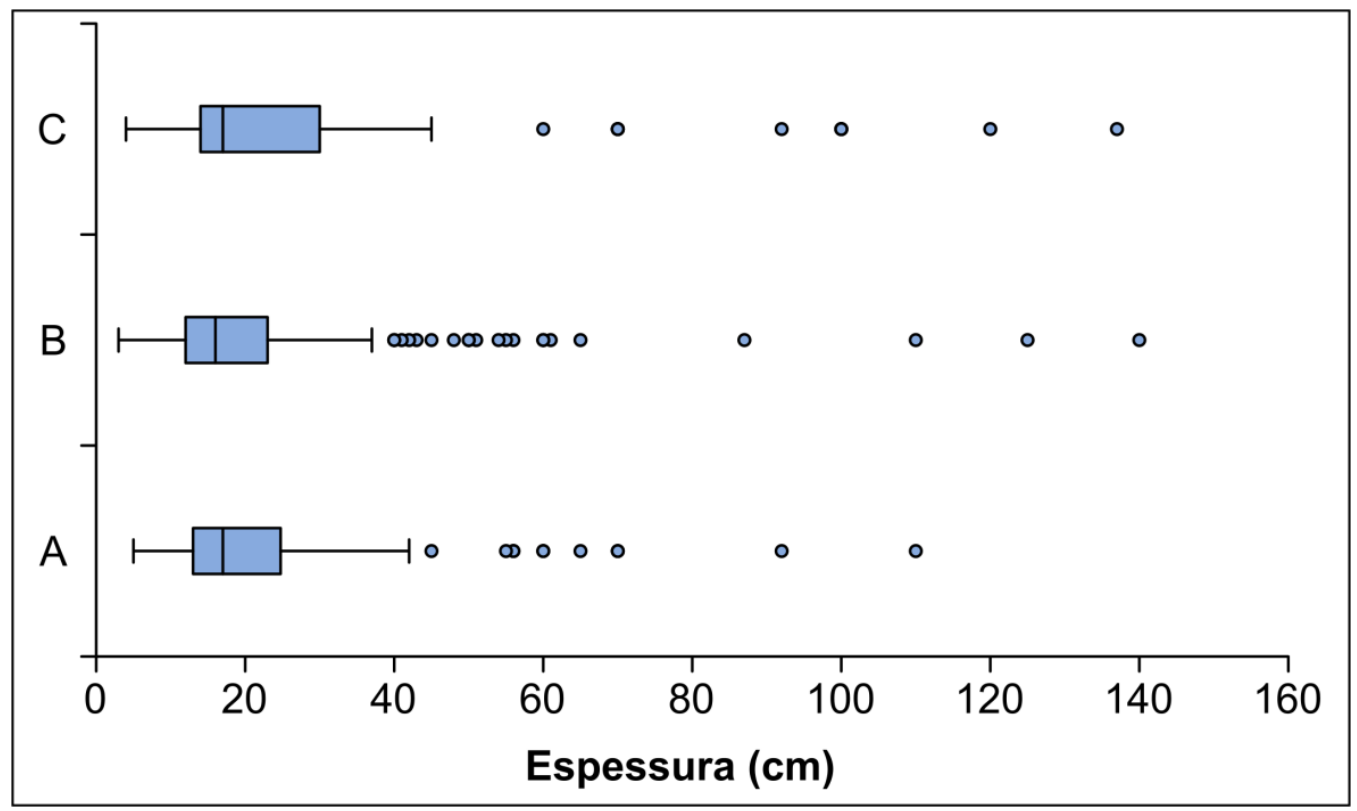

Figura 20. Diagramas de caixas das espessuras de séries das seções estratigráficas da área de Banzaê. 


$\begin{array}{cccc} & \text { A } & \text { B } & \text { C } \\ \text { Média } & 20.95 & 19.67 & 31.36 \\ \text { Desvio Padrão } & 0.88 & 0.72 & 4.41 \\ \text { Mediana } & 17.00 & 16.00 & 17.00 \\ \text { Moda } & 15.00 & 15.00 & 15.00 \\ \text { Mínimo } & 5.00 & 3.00 & 4.00 \\ \text { Máximo } & 110.00 & 140.00 & 137.00 \\ \text { Número de dados } & 238.00 & 390.00 & 53.00\end{array}$

Tabela 5. Recopilação das medidas de estadística descritiva das seções estratigráficas da área de Banzaê.

A figura 21 mostra três mapas com a relação da média da espessura das séries em cada afloramento na área de Banzaê para cada seção. No geral, as três seções são bastante homogêneas, não havendo grandes variações das espessuras médias de série nas áreas estudadas. A Seção A apresenta pouca variação de espessura ao longo da área, com uma possível tendência de diminuição para o sul. $A$ Seção $B$ engloba uma área bem extensa e os valores de espessura média não apresentam nenhuma tendência. $A$ Seção C está restrita a uma região lateral e mostra uma tendência de aumento de espessura para sul. A figura 22 mostra os três mapas com as medidas máximas da espessura de série em cada afloramento. A Seção A não apresenta direções de tendência claras. A Seção $B$ os maiores valores de espessura máxima estão concentrados no centro do mapa. A Seção $C$ mostra uma tendência de aumento de espessura para sul.

Conforme exposto no capítulo de metodologia (Capítulo 3.3), considerou-se que a altura das dunas equivale aproximadamente a três vezes 0 valor da média da espessura de série. A média da seção A, B e C é de 20.95, 19.67 e $31.36 \mathrm{~cm}$, respectivamente. Assim, a média das alturas estimadas das dunas precursoras para cada seção seria de 62.9, 59.0 e $94.1 \mathrm{~cm}$. De acordo com esse cálculo, a profundidade do canal estimado para as três seções seria de 3.8 a 6.3 m, na Seção A; 3.5 a 5.9 m, na Seção B e 5.6 a 9.4 m, na Seção C. 

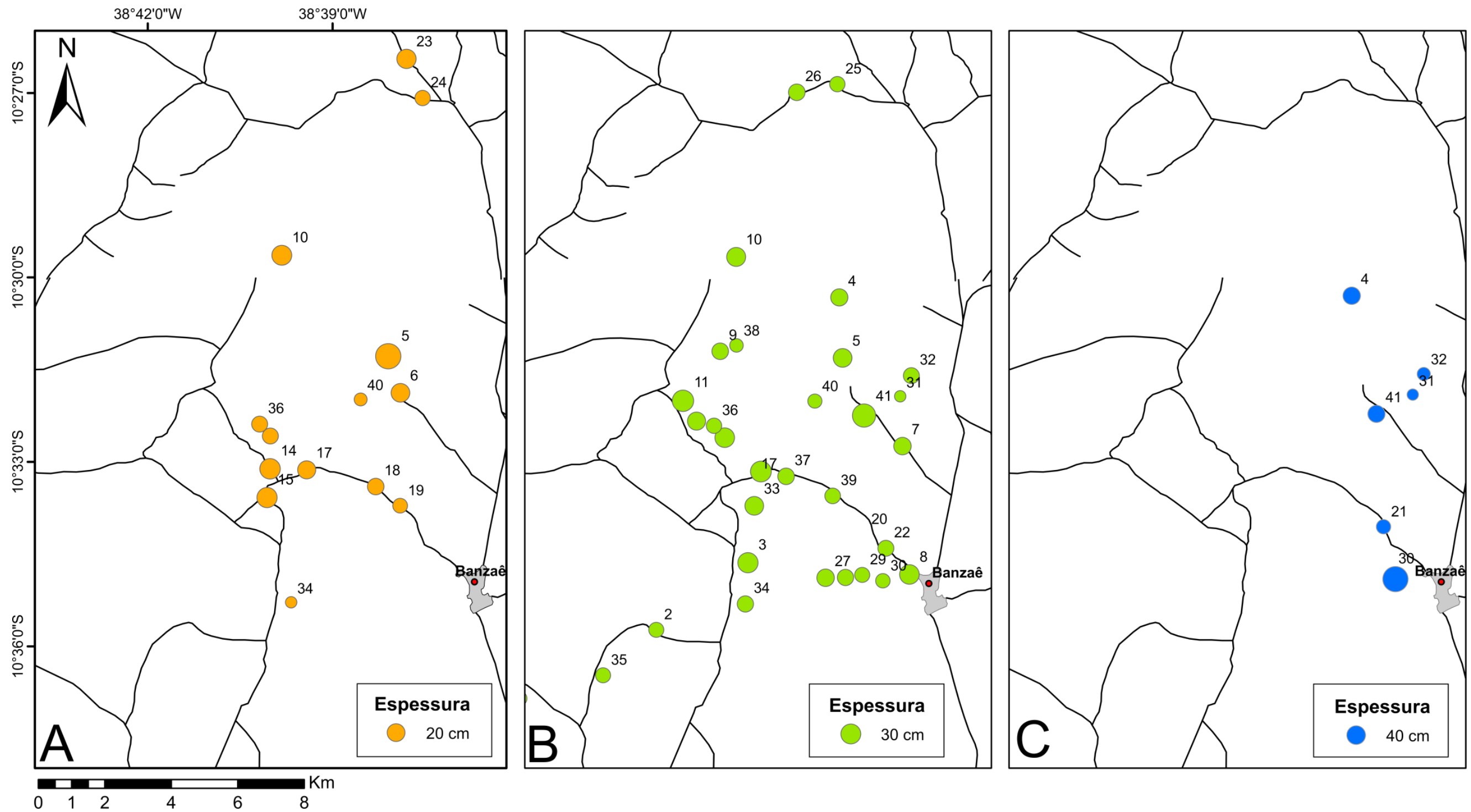

Figura 21. Mapa de distribuição da média das espessuras de serie nas três seções estratigráficas da área de Banzaê. 

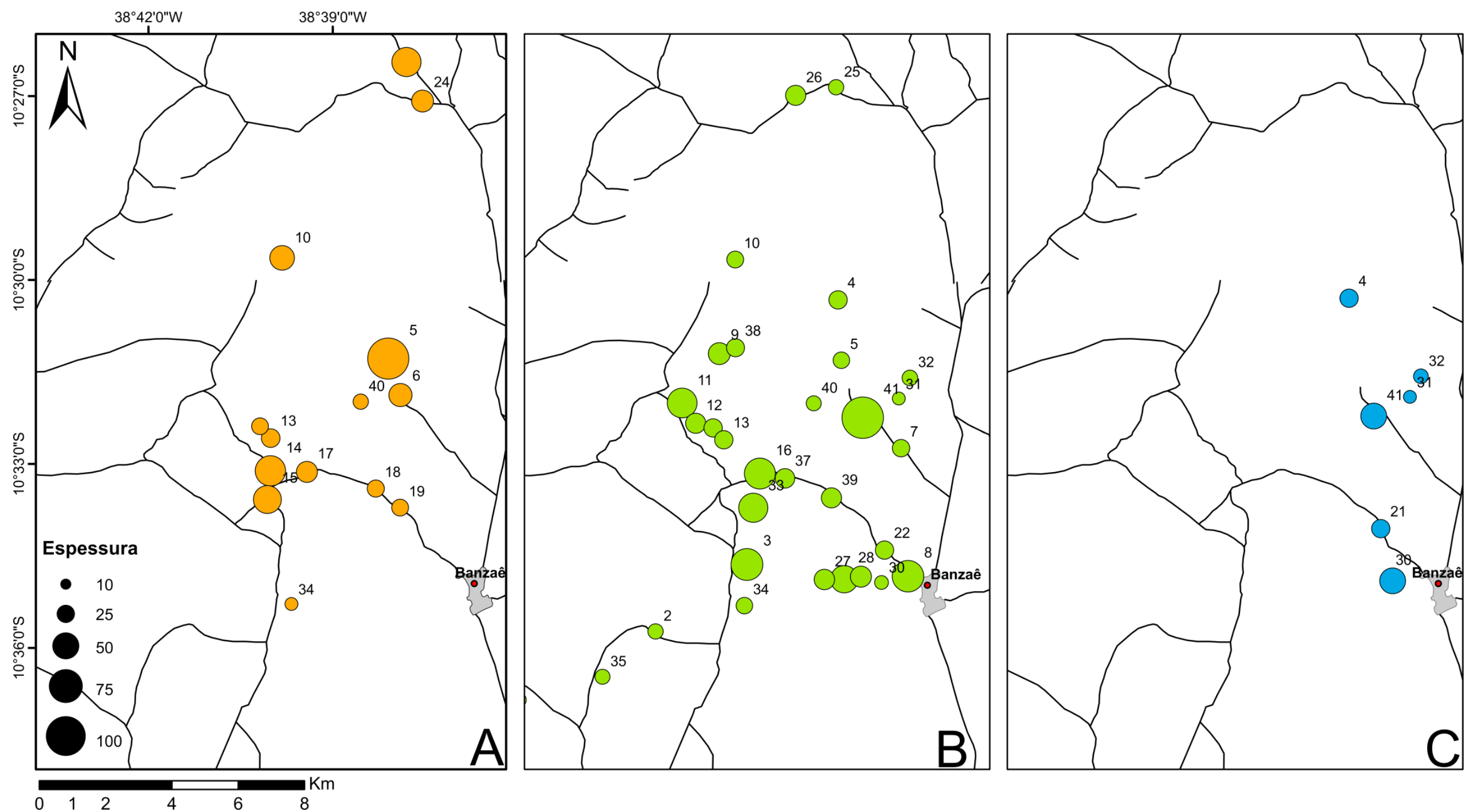

Figura 22. Mapa de distribuição das espessuras de séries máximas nas três seções estratigráficas da área de Banzaê. 


\subsubsection{Comparação com dados anteriores Bacia do Tucano}

Os resultados da medição sistemática de espessura de séries realizados neste trabalho estão de acordo com dados anteriormente analisados por Abdala (2014) e Freitas (2014), com pequena variação nas médias encontradas. Assim, Freitas (2014) distingue depósitos de preenchimento de canal de depósitos de barras ativas em canais principais, obtendo valores médios de espessura de estratos cruzados de $17 \mathrm{~cm}$ para os primeiros e $41 \mathrm{~cm}$ para as segundas. Essa variação é semelhante à encontrada no presente trabalho e sugere canais de dimensão compatível. Em escala regional, Abdala (2014) compilou dados e obteve medidas de estratos cruzados para diversas áreas da Bacia do Tucano obtendo valores maiores para o sistema de rios axiais, média de cruzadas de $23 \mathrm{~cm}$. Os dados aqui apresentados relacionam-se ao sistema de rios axiais, e são semelhantes aos apresentados por Abdala (2015).

Para a região de Banzaê, mais especificamente na localidade da Fazenda Retiro, a profundidade do canal foi estimada a partir do levantamento estratigráfico detalhado do trabalho de Freitas (2014), o qual estima uma espessura de $17 \mathrm{~m}$ aproximadamente entre as duas superfícies erosivas, que englobam o que se interpreta como uma sequência deposicional completas que englobam depósitos tanto da base como do topo do canal (representados pelos intraclastos de argila) pelo qual se estima esta espessura como a profundidade mínima da coluna dá agua.

\subsection{Comparações entre os dados de paleocorrente e paleohidráulica}

Na Figura 23 se mostra a relação entre a paleosinuosidade e profundidade do canal com as espessuras máximas das seções estratigráficas $A, B$ e $C$ da região de Banzaê. Os mapas A e C não apresenta uma relação clara. No entanto o mapa B mostra uma relação no centro do mapa, os valores mais profundos $(3,16,33,27,41)$ se encontram encaixados por valores menores no ao leste $(7,32,37,41)$ e ao oeste $(4,5,40,13)$. Coincidindo com a mudança de direção das paleocorrentes. Interpreta se uma mudança do canal com profundidades maiores no centro. 

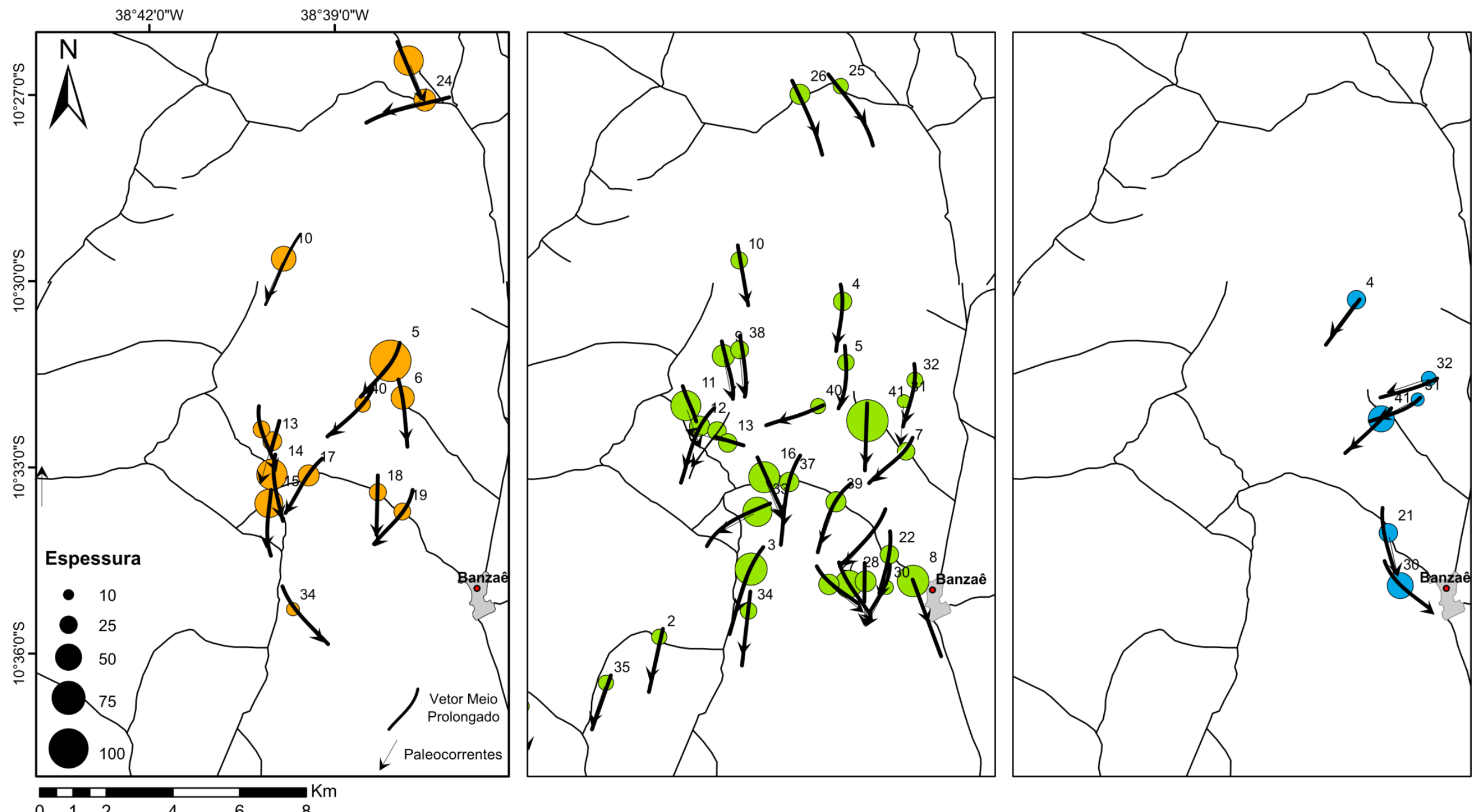

Figura 23. Mapa da relação de paleocorrente e espessuras de séries máximas nas três seções estratigráficas da área de Banzaê. 


\section{Capítulo 5 - Discussão}

\subsection{Sinuosidade}

Os resultados de paleocorrente apresentam pouca variação nos níveis estratigráficos na escala hectométrica na Ravina de Curralinho e já na escala quilométrica se apresenta uma clara variação dos vetores médios correspondentes à região de Banzaê.

\subsubsection{Sinuosidade do canal em escala quilométrica na região de Banzaê}

A fim de estimar a escala do rio que corria na época da deposição de Membro Banzaê a partir da sinuosidade do canal, foram comparadas as medidas de comprimento de onda computadas para a região de Banzaê com o comprimento de onda de uma seleção de rios entrelaçados ativos no mundo. O comprimento de onda foi calculado conforme descrito na metodologia do capítulo 3.2. As medidas de comprimento de onda dos canais atuais foram coletadas na escala do rank 3 de Miall (1974).

$\mathrm{Na}$ figura 24 estão representados os níveis estratigráficos $\mathrm{A}, \mathrm{B}$ e $\mathrm{C}$ da região de Banzaê, com as respectivas interpretações extraídas dos dados de paleocorrente. As direções de paleocorrente observadas em planta foram extrapoladas, resultando em mapas paleogeográficos que mostram a possível orientação de canais durante os três intervalos estratigráficos. A varação da direção é interpretada como a reconstrução do comprimento de onda relacionado à sinuosidade do canal.

A extensão das paleocorrentes no mapa A permite interpretar curvas do canal nas metades superior e inferior do mapa. Na metade superior, as paleocorrentes mudam de direção OSO (24), ao norte, para SSE (14), ao centro. Na metade inferior, as paleocorrentes variam de direção SSO (5), ao centro, para SSE (34), ao sul. Na região central, ocorre uma variação de direção de SSE (6) para SSO (19). As três curvas do rio traçadas no mapa apresentam comprimento de onda mínimo de 11,10 e $5 \mathrm{~km}$, respectivamente.

No mapa B, foram observadas duas curvas do canal, englobando o mapa inteiro. A primeira curva ocorre na região norte, onde o canal começa com direção SSE $(25,26)$ que muda para OSO $(7,33,40)$ no centro. A seguir, observa-se nova mudança de paleocorrente para SSO, na porção inferior do mapa, marcando a curva seguinte do canal. 
As curvas do canal apresentam comprimento de onda de 10 e $7 \mathrm{~km}$ respectivamente. Cabe ressaltar que a variação de direção do canal na zona norte no mapa A vai de OSO a SSE e no mapa B de SSE a OSO.

O mapa $\mathrm{C}$ apresenta uma única curva do canal, em sua região central, na qual as paleocorrentes variam de uma direção $\operatorname{OSO}(31,32,41)$ para sul a SSE $(21,30)$. A curva formada pelo canal apresenta comprimento de onda mínimo de $7 \mathrm{~km}$.

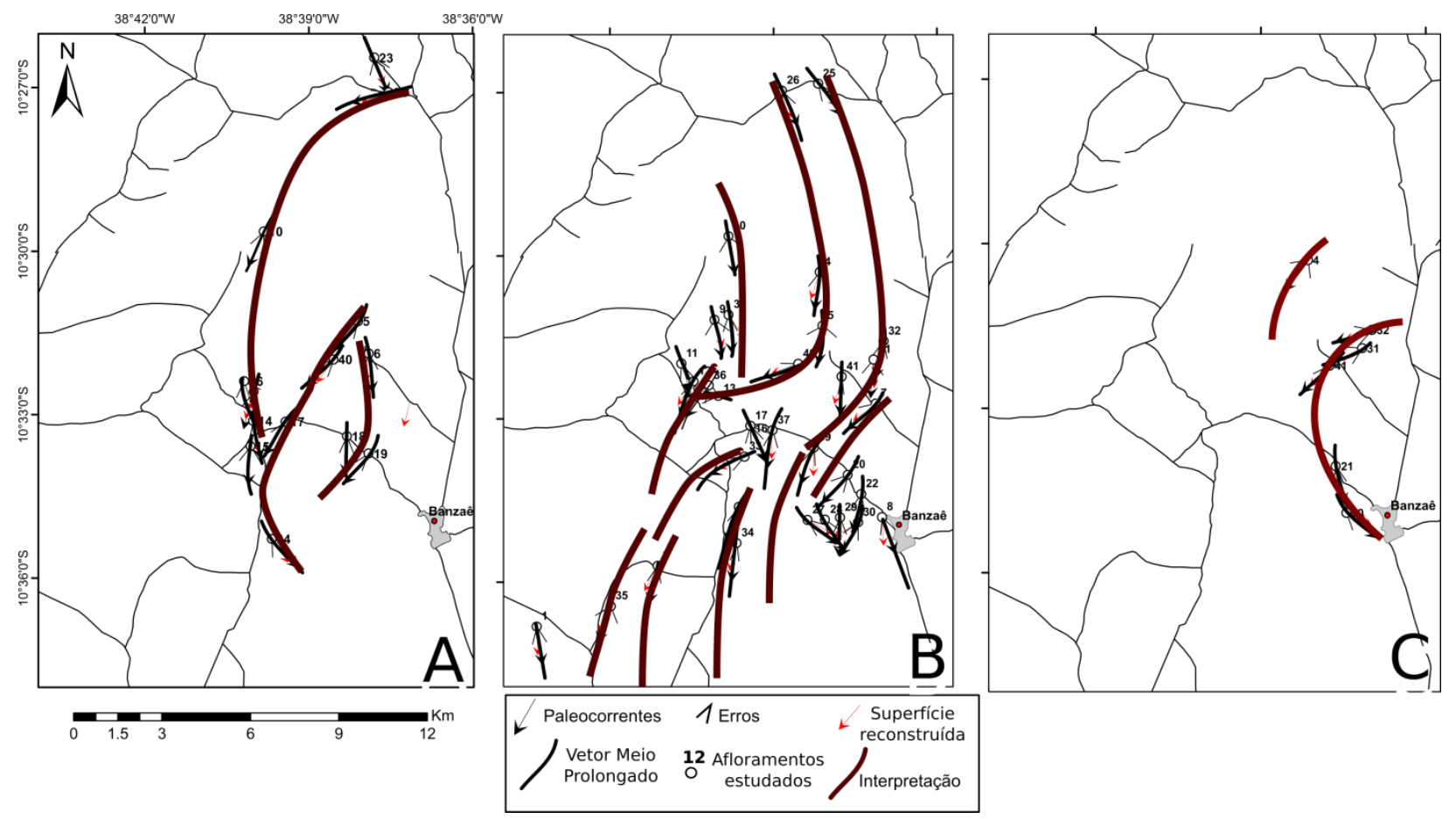

Figura 24. Mapa das interpretações da sinuosidade nas três seções da área Banzaê.

\subsubsection{Comparação com sistemas ativos}

A figura 25 e 26 apresenta sete sistemas fluviais ativos de rios entrelaçados de diversas dimensões e vazão. Pelos dados da figura 25, pode-se observar que 0 comprimento de onda da sinuosidade dos rios está diretamente relacionado com a vazão, dado que os rios de maior vazão apresentam comprimentos de ondas significativamente maiores do que os rios de menor vazão; apresentando uma línea de tendência positiva uma alta correlação entre as variáveis mostrando um $\mathrm{r}^{2}$ de 0.92 .

Associados a cada rio, estão histogramas que detalham a sinuosidade destes. $\mathrm{Na}$ figura, está representado o rio Brahmaputra, da Índia e Bangladesh, os rios Ghaghara e Kosi, da India, o rio Irrawaddy, de Mianmar, os rios Waitaki e Rakaia, da Nova Zelândia, e o rio Karakash, da China. Para cada caso, é mostrado um histograma com as medidas 
obtidas dos comprimentos de onda dos respectivos canais, com a finalidade de comparar esses dados com os dados obtidos para a região de Banzaê.

Os rios Brahmaputra e Irrawaddy, com vazão maior que $10^{3} \mathrm{~m}^{3} / \mathrm{s}$, apresentam histogramas com uma distribuição normal e simétrica, moda de $8 \mathrm{~km}$ e valores máximos de $16 \mathrm{~km}$. Os dados nos histogramas dos rios Ghaghara e Kosi, que apresentam vazão de $10^{2} \mathrm{~m} 3 / \mathrm{s}$, estão concentrados entre 1 e $7 \mathrm{~km}$. E os dados nos histogramas dos rios Waitaki, Rakaia e Karakash, com vazão de $10^{1} \mathrm{~m}^{3} / \mathrm{s}$, estão concentrados no menor intervalo, até 3 $\mathrm{km}$.

No geral, o valor médio estimado de comprimento de onda da região de Banzaê foi $9 \mathrm{~km}$. Comprando esse valor obtido com os comprimentos de onda dos rios atuais, Banzaê poderia ser correlacionado com um rio de grande porte, com uma vazão de $10^{3} \mathrm{~m}^{3} / \mathrm{s}$, conforme mostrado no gráfico da figura 25. Assim, a estimativa do porte do rio da época de deposição da Formação Marizal - Membro Banzaê a partir dos dados de sinuosidade aponta se tratar de um rio de grande ponte.

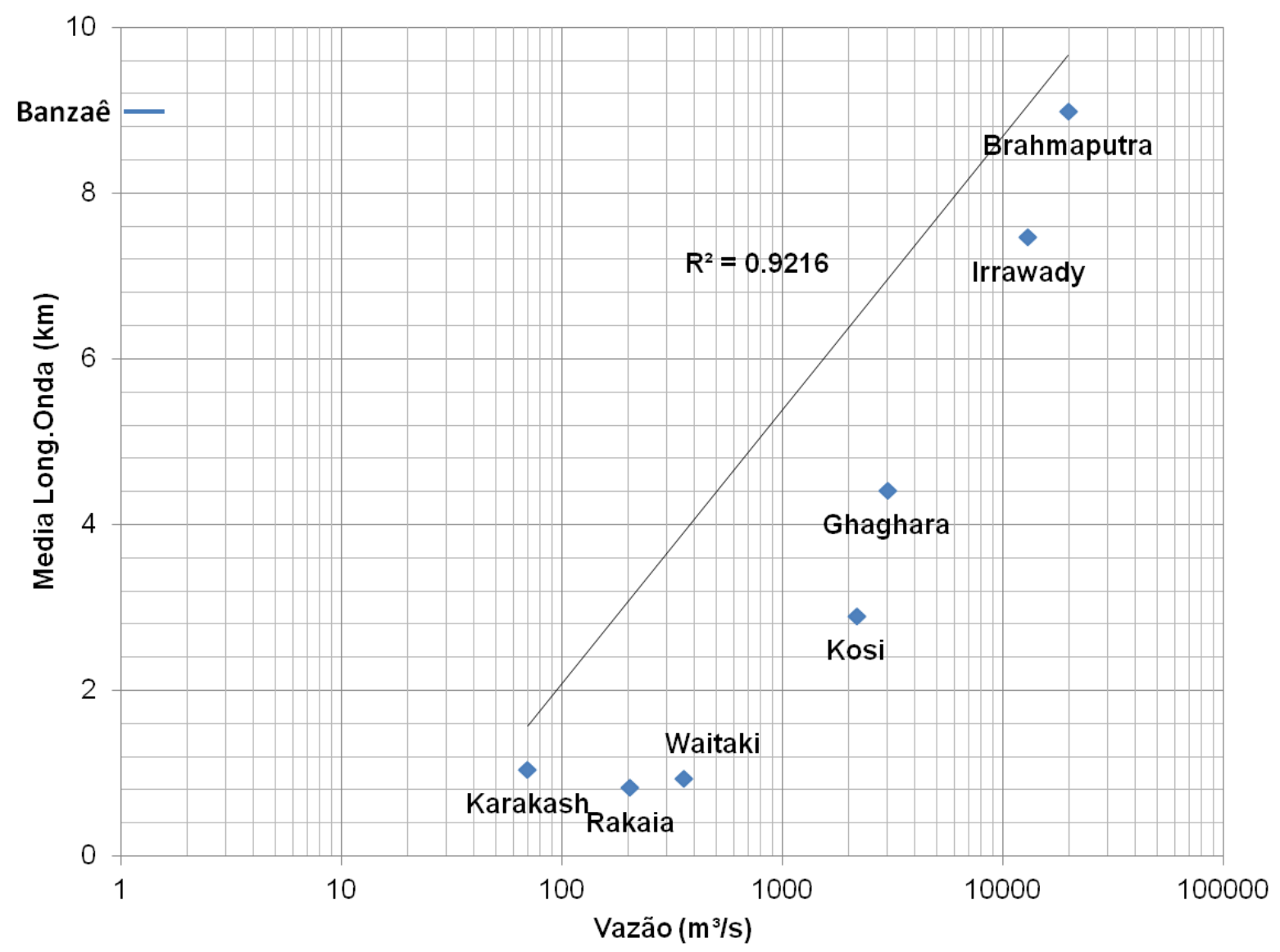

Figura 25. Gráfico da relação do comprimento de onda da sinuosidade com a vazão de sete rios atuais. 

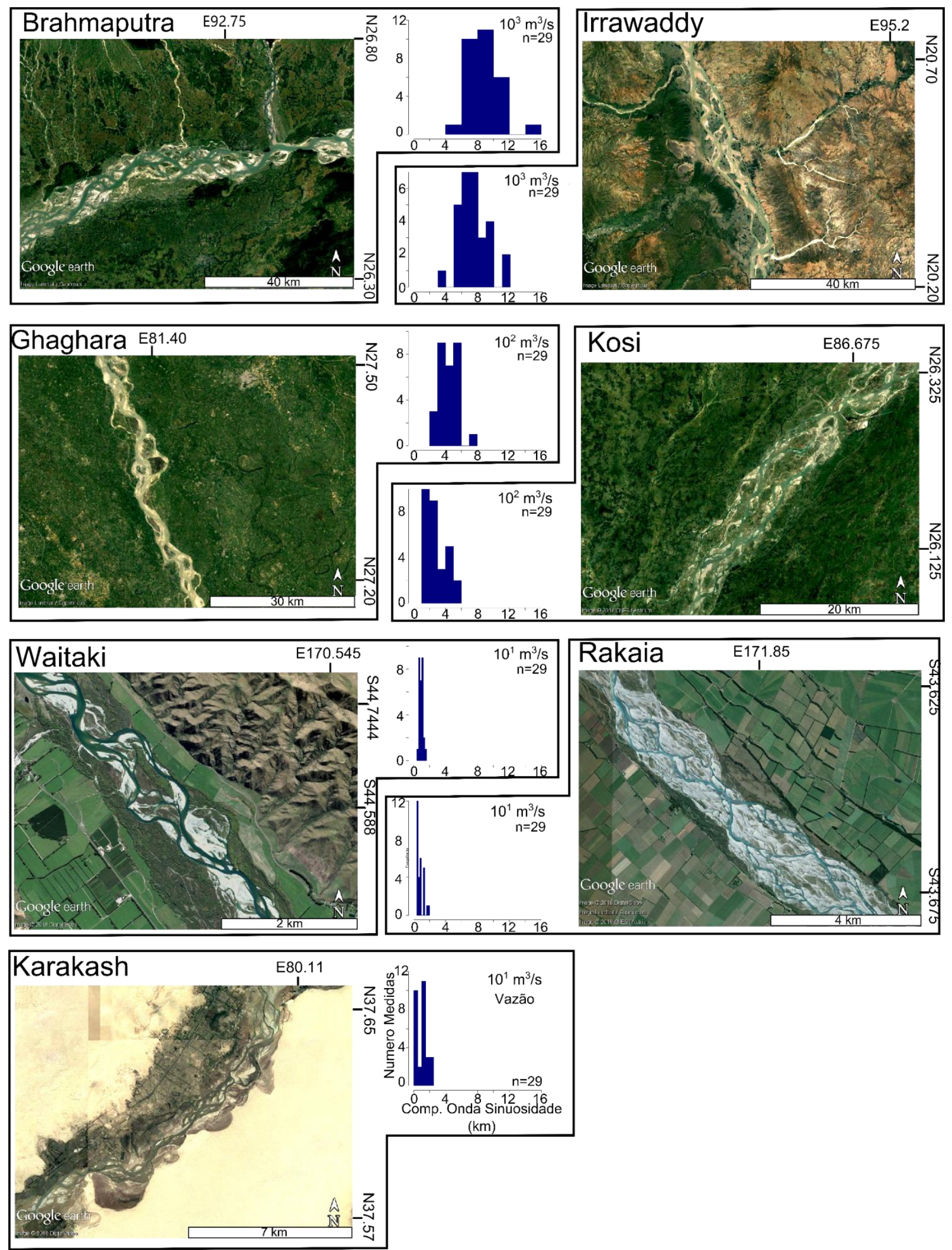

Figura 26. Imagens satélites do Brahmaputra, Ghaghara, Kosi, Irrawaddy, Waitaki, Rakaia e Karakash, associadas a histogramas com o comprimento de onda da sinuosidade do canal. 


\subsection{Profundidade}

A estimativa da profundidade do rio que gerou os depósitos fluviais do Membro Banzaê foi acessada de duas formas. (1) Seguiram-se os trabalhos de Paola \& Borgman, (1991) e Leclair \& Bridge, (2001), que calculam a espessura da coluna de água por meio da reconstrução da a altura original da duna, a partir dos dados de espessura das séries de estratificação cruzada. (2) A partir da espessura das seções estratigráficas A, B e C da região de Banzaê, que representam uma porção substancial do canal na direção vertical.

\subsubsection{Paleohidráulica: espessuras de série}

A figura 27 e tabela 5 apresentam os dados de espessura de série e as profundidades estimadas dos canais obtidas nesse trabalho, além de incluir esses mesmos dados para outras áreas da Bacia do Tucano, sempre referentes ao Membro Banzaê, compilados por outros pesquisadores do mesmo grupo de pesquisa.

Nos trabalhos onde se apresenta uma distribuição de dados ao longo de toda a Bacia de Tucano foram estimavas profundidades entre 3.9 e 5.2 metros Abdala (2014) e mais de 10 metros para canais ativos a partir dos depósitos de barras Freitas (2014).

Conforme apresentado no capítulo de resultados, a área da Ravina de Curralinho apresenta estimativas de profundidade que variam de 4.1 a $6.9 \mathrm{~m}$ - usando a média dos valores de espessura e usando os valores máximos a profundidade varia de 36 a $60 \mathrm{~m}$. As seções estratigráficas de Banzaê apresentam intervalos de profundidade similares, variando de 3.8 a $6.5 \mathrm{~m}$ com os valores médios e de 25.2 a $42.0 \mathrm{~m}$ com os valores máximos.

Nota-se assim que há uma relação coerente da profundidade entre todas as medidas da Bacia do Tucano. É possível fazer estimações acerca da profundidade dos canais do sistema fluvial na escala da bacia.

\subsubsection{Comparação com sistemas fluviais ativos}

Para comparar os dados de profundidade estimados para o Membro Banzaê com os rios atuais, foram coletadas, profundidades médias e máximas de rios atuais, de grande e 
de menor porte. Dados de profundidade de rios ativos são raros e de difícil acesso e, portanto, a compilação não ficou restrita a rios entrelaçados.

Rios de grande porte apresentam valores de profundidade de várias dezenas a centenas de metros: o rio Brahmaputra apresenta varias estimações de profundidade no tramo Jamuna, Coleman (1968) estima 46 metros de profundidade máxima na confluência com o rio Ganges e uma média de 28 metros, Roden (1998) estima uma média de 13 metros de profundidade, Best et al. (2007) estima uma média de 5 metros e Sarker et al. (2014) estima 8 metros de profundidade; o rio Mississippi tem uma profundidade média de 40 m e máxima de 52 m (Knox \& Latrubesse, 2016); rio Yangtze tem uma média de aproximadamente $20 \mathrm{~m}$ (Chen et al., 2012); o rio Amazonas tem, em seu terço final, média de $56 \mathrm{~m}$, podendo chegar a mais de $100 \mathrm{~m}$ de profundidade, (medido a partir de perfil apresentado em Kosuth et al., 2009); enquanto o rio Congo chega a impressionantes 220 metros (Oberg et al., 2009).

Rios de menor porte apresentam valores menores, inferiores a 10 metros de profundidade: o rio South Saskatchewan tem uma média de 3-5 m (Cant \& Walker, 1978); o rio Waal tem uma média de 5 m (Wilbers \& Ten Brinke, 2003); enquanto o rio Reno tem uma média de 3-4 m de profundidade (Carling et al., 2000)

Para o Membro Banzaê, foram obtidas diversas estimativas de profundidade do canal. A profundidade do canal na seção B é aproximadamente $17 \mathrm{~m}$, medição da figura 5.06 de Freitas (2014), estimada a partir da espessura do preenchimento, deve ser considerada a espessura mínima da lamina d’água. Por se tratar de um depósito de barra, observa-se na seção a espessura presente do fundo do canal até o que foi preservado do topo da barra. É interessante notar que mesmo os maiores valores de profundidade obtida a partir de média das espessuras de série, que correspondem a 4 a $6 \mathrm{~m}$, estão abaixo da espessura mínima necessária para a formação dos depósitos de barra presentes em Banzaê, sendo, portanto, subestimados. Os valores mínimos do intervalo de profundidades possíveis obtidos a partir do cálculo que utilizou os valores de espessura máxima parecem ser mais coerentes com a situação descrita.

De acordo com os dados de profundidade obtidos nas áreas estudadas no presente trabalho, correspondentes a Rabina de Curralinho e Banzaê, mais os dados recopilados dos trabalhos e Abdala (2014) e Freitas (2014), a profundidade do rio que depositou 0 Membro Banzaê estaria no limite entre um rio de maior ou menor porte. Já a espessura de preenchimento e os valores estimados da profundidade a partir das espessuras máximas indicam que o canal atingiu a ordem de algumas dezenas de metros. Comparando esses 
valores de profundidade do canal dos rios atuais poderia ser correlacionado como um rio de grande porte, confirmado as estimativas de Freitas (2014).

\begin{tabular}{|c|c|c|c|c|c|c|c|c|}
\hline & \multicolumn{4}{|c|}{ Médias } & \multicolumn{4}{|c|}{ Máximos } \\
\hline & Sm & $\mathrm{Hm}(\mathrm{cm})$ & $\mathrm{D} 1(\mathrm{~m})$ & $\mathrm{D} 2(\mathrm{~m})$ & SM & $\mathrm{H}(\mathrm{cm})$ & $\mathrm{D} 1(\mathrm{~m})$ & $\mathrm{D} 2(\mathrm{~m})$ \\
\hline Curralinho & 22.8 & 68.5 & 4.1 & 6.9 & 200.0 & 600.0 & 36.0 & 60.0 \\
\hline Seção 1 & 24.9 & 72.2 & 4.3 & 7.2 & 135.0 & 405.0 & 24.3 & 40.5 \\
\hline Seção 2 & 19.1 & 55.3 & 3.3 & 5.5 & 80.0 & 240.0 & 14.4 & 24.0 \\
\hline Seção 3 & 24.1 & 69.8 & 4.2 & 7.0 & 200.0 & 600.0 & 36.0 & 60.0 \\
\hline \multirow[t]{3}{*}{ Seção 4} & 21.3 & 61.6 & 3.7 & 6.2 & 170.0 & 510.0 & 30.6 & 51.0 \\
\hline & \multicolumn{4}{|c|}{ Médias } & \multicolumn{4}{|c|}{ Máximos } \\
\hline & $\mathrm{Sm}$ & $\mathrm{Hm}(\mathrm{cm})$ & $\mathrm{D} 1(\mathrm{~m})$ & $\mathrm{D} 2(\mathrm{~m})$ & SM & $\mathrm{H}(\mathrm{cm})$ & $\mathrm{D} 1(\mathrm{~m})$ & D2 (m) \\
\hline Banzaê & 21.0 & 63.0 & 3.8 & 6.3 & 140.0 & 420.0 & 25.2 & 42.0 \\
\hline A & 20.9 & 62.7 & 3.8 & 6.3 & 110.0 & 330.0 & 19.8 & 33.0 \\
\hline $\mathrm{B}$ & 19.7 & 59.1 & 3.5 & 5.9 & 140.0 & 420.0 & 25.2 & 42.0 \\
\hline \multirow[t]{3}{*}{ C } & 31.4 & 94.2 & 5.7 & 9.4 & 137.0 & 411.0 & 24.7 & 41.1 \\
\hline & \multicolumn{4}{|c|}{ Médias } & \multicolumn{4}{|c|}{ Máximos } \\
\hline & Sm & $\mathrm{Hm}(\mathrm{cm})$ & $\mathrm{D} 1(\mathrm{~m})$ & D2 (m) & SM & $\mathrm{H}(\mathrm{cm})$ & $\mathrm{D} 1(\mathrm{~m})$ & $\mathrm{D} 2(\mathrm{~m})$ \\
\hline Tucano* & 22.5 & 65.3 & 3.9 & 6.5 & 180.0 & 540.0 & 32.4 & 54.0 \\
\hline
\end{tabular}

Tabela 6. Recopilação das estimações de profundidade das seções estratigráficas da Ravina de Curralinho, Banzaê e Membro Banzaê (Abdala, 2014). Sm (Média da espessura da série), SM (Máximo da espessura de serie), $\mathrm{H}$ (altura da duna), D1 (profundidade do canal seis vezes maior a H) e D2 (profundidade do canal dez vezes maior a H).

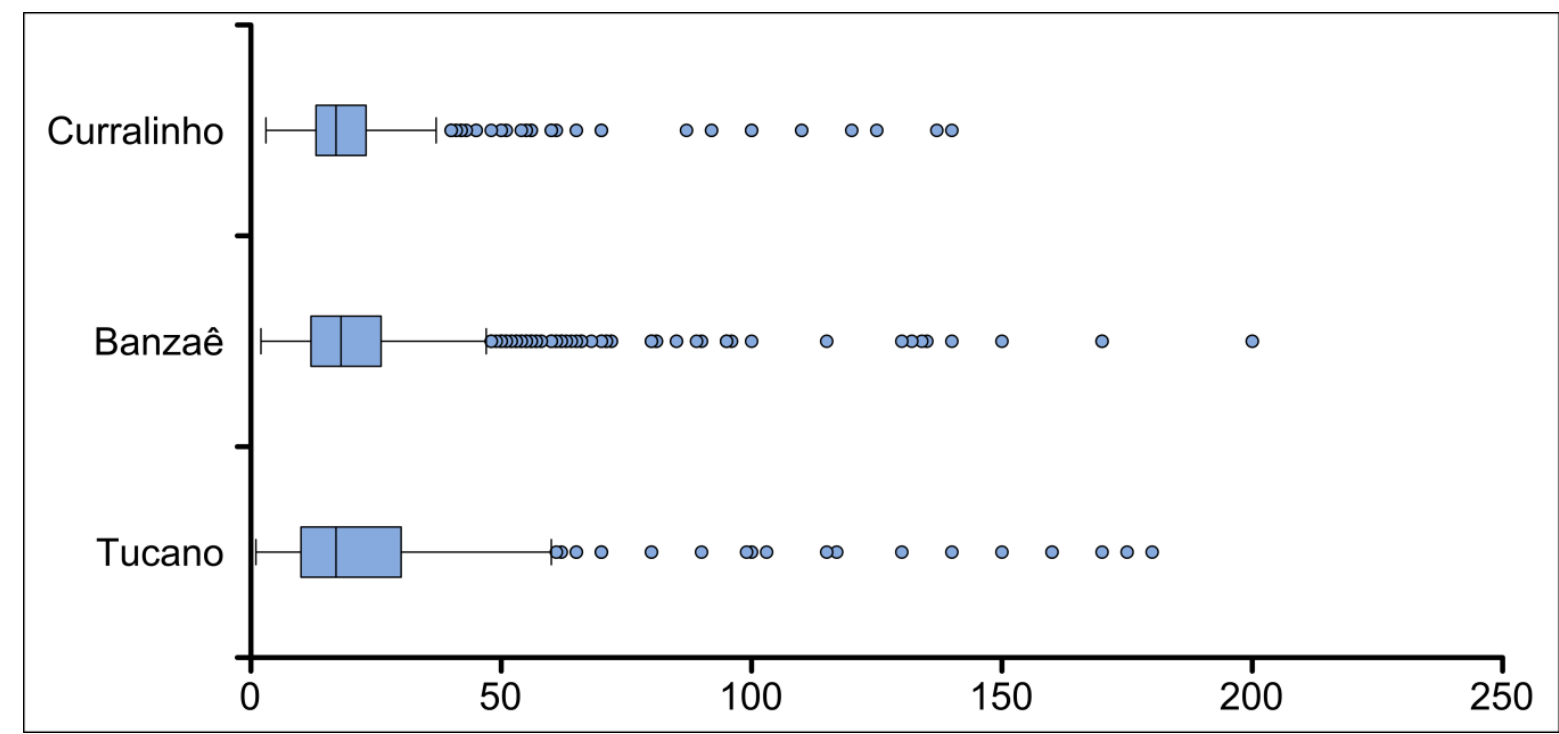

Figura 27. Diagramas de caixas das espessuras de séries da Rabina de Curralinho e Banzaê (dados do presente trabalho) e o Membro Banzaê (compilados de Abdala, 2014). 
Os resultados das análises de paleosinuosidade apresentam valores do comprimento de onda entorno a dezenas de $\mathrm{km}$ comparando com os rios atuais o paleorio se encontra no rango dos rios de grande porte, com vazões maiores a $10^{2} \mathrm{~m} / \mathrm{s}$, sendo um menor ao o rio Brahmaputra.

As estimavas da profundidade do canal com as médias das espessuras se encontram com os valores 4-7 metros, concordante com os dados de profundidade média da literatura do Brahmaputra de Best et al. (2008) e Sarker et al. (2014). Não entanto esta profundidade não explicaria a espessura total do preenchimento e estaria mais relacionada com a profundidade máxima (25-42 m) e os perfis de Roden (1998) com uma média de 13 metros.

Comparando os parâmetros paleosinuosidade e paleohidráulico da Formação Marizal e com rio Brahmaputra, o rio atual apresenta ordens de grandeza parecidas aos encontrados no presente trabalho. 


\section{Capítulo 6 - Conclusões}

Integrando as análises de fácies, paleocorrentes, reconstrução de superfícies de barras, paleohidráhulica e distribuição espacial de espessuras de séries de estratos cruzados, foi possível interpretar uma evolução espaço - temporal e paleo dinâmica dos depósitos do Membro Banzaê na Bacia do Tucano. O predomínio de elementos de acréscimo frontal em barras arenosas, como demonstrado pela reconstituição pelo método de Almeida et al. (2016) para 40 afloramentos, em um total de 1184 medidas pareadas de estrato cruzado e limite de série, é compatível com a interpretação de um sistema de rios entrelaçados dominados por carga de fundo, corroborando interpretações anteriores na mesma região (e.g. Freitas, 2014).

Obtiveram-se três mapas de paleocorrentes de diferentes níveis estratigráficos: A (basal), B (intermediário) e C (superior) em uma área de $250 \mathrm{Km}^{2}$ nas proximidades do município de Banzaê, a partir de 1264 medidas estratificação cruzada. A variação no sentido da palecorrentes mostra padrões de sinuosidade do canal principal, apresentando duas geometrias: uma côncava a oeste pela mudança de paleocorrente do SSE para o OSO e a segunda côncava a leste coma mudança de OSO ate SSE.

A partir de 2051 medidas de espessura de séries de estratos cruzados e das reconstruções de paleohidráulica do Membro Banzaê, da Formação Marizal, estimaram profundidades do canal entre 4 a 7 metros utilizando os valores de espessura médios e entre 25 a 60 m com os valores máximos e o método de (Leclair \& Bridge, 2001; Paola \& Borgman, 1991)

A estimativa da profundidade dos dados de paleohidráulica foi confrontada com a espessura preservada dos depósitos de canal. A seção B localizada entre duas superfícies erosivas apresenta uma sequência deposicional que englobam depósitos da base até 0 topo do canal, a partir da qual se estabelece uma profundidade mínima de $17 \mathrm{~m}$, correspondente à espessura do segmento. A espessura foi tomada do trabalho de Freitas (2014) que fez um levantamento estratigráfico nos paredões com equipamento de escala, proporcionando altíssima confiabilidade. Desta forma, a reconstituição de profundidade por espessura de séries é compatível com a espessura preservada de elementos de canal indicando um rio entrelaçado profundo.

A partir da distribuição espacial das medidas de paleocorrentes e considerando-se o erro ( $95 \%$ de confiança) de cada vetor médio obtido em relação a uma estação com 938 medidas (Ravina de Curralinho), foi possível reconstituir a geometria da sinuosidade dos 
canais na região de Banzaê. Estimou-se comprimento de onda de $9 \mathrm{~km}$ para a sinuosidade principal (maior que barras individuais ou rank 3 de Miall (1974) os depósitos do membro Banzaê nos três níveis estratigráficos estudados. Análise de alguns rios entrelaçados ativos com vazão conhecida mostra que o comprimento de onda da sinuosidade está diretamente relacionado à vazão, e se estima que os depósitos fluviais do Membro Banzaê são de grande porte, equiparáveis a rios de bacia de drenagem regional como o Irrawaddy (Mianmar) e o Brahmaputra (Índia-Bangladesh). Por tanto, se confirma as estimativas de Freitas interpretando os depósitos da Formação Marizal como o registro de um rio de grande porte.

O presente trabalho demonstra que a análise da distribuição espacial de grandes bases de dados de paleocorrentes, com estimativa de erro de vetores médios individuais e análise prévia do espaçamento ideal da malha de coleta para determinação do comprimento de onda da sinuosidade, é ferramenta com grande potencial para a interpretação do porte de sistemas fluviais antigos, podendo contribuir para uma das principais questões da geologia sedimentar fluvial: a identificação de rios de grande porte no registro geológico. 


\section{Referências}

Abdala, S. (2014). Comparação paleohidráulica entre as unidades basal (arenoconglomerática) e superior (areno-pelítica) da Formação Marizal (Aptiano), Bacia do Tucano (BA). Universidade de São Paulo.

Allen, J. R. L. (1966). On bed forms and palaeocurrents. Sedimentology, 6(3), 153-190

Allen, J. R. (1983). Studies in fluvial stile sedimentation: bars, bar complexes and sandstone sheets (low sinuosity braided streams) in the Brownstonews (L. Devonian), Welsh Borders. Sedimentary Geology, 33, 237-293.

Allen, P. A. (1970). Physical processes of sedimentation. American Elsevier Pub. Co.

Almeida, R. P., Freitas, B. T., Turra, B. B., Figueiredo, F. T., Marconato, A., \& Janikian, L. (2016). Reconstructing fluvial bar surfaces from compound cross-strata and the interpretation of bar accretion direction in large river deposits. Sedimentology.

Amaral, C. R. L., \& Brito, P. M. (2012). A new chanidae (Ostariophysii: Gonorynchiformes) from the cretaceous of Brazil with affinities to Laurasian gonorynchiforms from Spain. PLoS ONE, 7(5), 1-9.

Arai, M. (2014). Aptian/Albian (Early Cretaceous) paleogeography of the South Atlantic: a paleontological perspective. Brazilian Journal of Geology, 44(2), 339-350.

Ashley, G. M. (1990). Classification of large-scale subaqueous bedforms: a new look at an old problem-SEPM bedforms and bedding structures. Journal of Sedimentary Research, 60.

Ashworth, P. J., \& Lewin, J. (2012). How do big rivers come to be different? Earth-Science Reviews, 114(1-2), 84-107.

Assine, M. L. (1994). Paleocorrentes e paleogeografia na Bacia do Araripe, Nordeste do Brasil. Revista Brasileira de Geociências, 24(4), 223-232.

Barrett, P. J., \& Fitzgerald, P. G. (1985). Deposition of the lower Feather Conglomerate, a Permian braided river deposit in southern Victoria Land, Antarctica, with notes on the regional paleogeography. Sedimentary geology, 45(3-4), 189-208.

Bhattacharyya, P., Bhattacharya, J. P., \& Khan, S. D. (2015). Paleo-channel reconstruction and grain size variability in fluvial deposits, Ferron Sandstone, Notom Delta, Hanksville, Utah. Sedimentary Geology, 325, 17-25.

Best, J. L., Ashworth, P., Sarker, M. H., \& Roden, J. (2007). The Brahmaputra-Jamuna River, Bangladesh. In Large Rivers: Geomorphology and Management. (395-430).

Bill, P., Magi, M., \& Sagri, M. (1987). Coarse-grained low-sinuosity river deposits: example from Plio-Pleistocene Valdarno Basin, Italy.

Bizzi, L. A., Schobbenhaus, C., Vidotti, R. M., \& Gonçalves, J. (2003). Bacias Sedimentares da Margem Continental Brasileira. In Geologia, Tectônica e Recursos Minerais do Brasil (pp. 87-94). Brasilia: CPRM. 
Bradley, D. C., \& Hanson, L. S. (2002). Paleocurrent analysis of a deformed Devonian foreland basin in the Northern Appalachians, Maine, USA. Sedimentary Geology, 148(3), 425-447.

Bridge, J. S. (1993). Description and interpretation of fluvial deposits: a critical perspective. Sedimentology, 40.

Bridge, J. S. (2003). Rivers and floodplains: forms, processes, and sedimentary record. Blackwell, 491.

Brito, P. M., \& Alvarado-Ortega, J. (2008). A new species of Placidichthys (Halecomorphi: lonoscopiformes) from the Lower Cretaceous Marizal Formation, northeastern Brazil, with a review of the biogeographical distribution of the Ophiopsidae. Geological Society, London, Special Publications, 295(1), 145-154.

Caixeta, J. M., Bueno, G. V., Magnavita, L. P., \& Feijó, F. J. (1994). Bacias do Recôncavo, Tucano e Jatobá. Boletim de Geociências Da Petrobras, 8(1), 167-172.

Cant, D. J., \& Walker, R. G. (1978). Fluvial processes and facies sequences in the sandy braided South Saskatchewan River, Canada. Sedimentology, 25, 625-648.

Carling, P. A., Williams, J. J., Golz, E., \& Kelsey, A. D. (2000). The morphodynamics of fluvial sand dunes in the River Rhine, near Mainz, Germany. II. Hydrodynamics and sediment transport. Sedimentology, 47, 253.

Carrera, S. (2015). Arquitetura deposicional e proveniência da formação marizal nas subbacias Tucano Sul e Central, BA. Universidade de São Paulo.

Cesero, P., \& Ponte, F. C. (1997). Análise Comparativa Da Paleogeologia Dos Litorais Atlânticos Brasileiro E Africano Comparative. B. Geoci. Petrobras, 11, 1-18.

Chen, J., Wang, Z., Li, M., Wei, T., \& Chen, Z. (2012). Bedform characteristics during falling flood stage and morphodynamic interpretation of the middle-lower Changjiang (Yangtze) River channel, China. Geomorphology, 147-148,

Coleman, J. (1968). Brahamaputra River: channel processes and sedimentation. Elservier

Costa, I. P., Milhomem, P. da S., Bueno, G. V., Lima E Silva, H. S. R., \& Kosin, M. D. (2007a). Sub-bacias de Tucano Sul e Central. Boletim de Geociencias Da Petrobras, 15(2), 433-443.

Costa, I. P., Bueno, G. V., Milhomem, P. da S., Lima E Silva, H. S. R., \& Kosin, M. D. (2007b). Sub-bacia de Tucano Norte e Bacia de Jatobá. Boletim de Geociencias Da Petrobras, 15(2), 445-453.

Costa, P. R. C., Jardim De Sá, E. F., \& da Silva, F. C. A. (2005). Bandas de deformação na região de Jeremoabo ( BA ), Bacia do Tucano: implicações na compartimentação de reservatórios petrolíferos. In IBP (Ed.) (pp. 2-7). Salvador: $3^{\circ}$ Congresso Brasileiro de P\&D em Petróleo e Gás.

Costa, P. R. C., Jardim De Sá, E. F., Guedes, I. M. G., \& da Silva, F. C. A. (2003). Caracterização Estrutural Da Área Da Serra Do Letreiro, Oeste Da Cidade De Jeremoabo (NE Da Bahia). Revista de Geologia, 16(2), 49-60. 
Cupertino, J. A. (1990). Estágio exploratótio das Bacias do Tucano Centra, Norte e Jatobá. Boletim de Geociencias Da Petrobras, 4(1), 45-53.

Cupertino, J. A., \& Bueno, G. V. (2005). Arquitetura das seqüências estratigráficas desenvolvidas na fase de lago profundo no Rifte do Recôncavo. Boletim de Geociencias Da Petrobras, 13(2), 245-267.

Destro, N., Alkmim, F. F., Magnavita, L. P., \& Szatmari, P. (2003a). The Jeremoabo transpressional transfer fault, Recôncavo- Tucano Rift, NE Brazil. Journal of Structural Geology, 25, 1263-1279.

Destro, N., Szatmari, P., Alkmim, F. F., \& Magnavita, L. P. (2003b). Release faults, associated structures, and their control on petroleum trends in the Recôncavo rift, northeast Brazil. AAPG Bulletin, 87(7), 1123-1144.

Fielding, C. R. (2006). Upper flow regime sheets, lenses and scour fills: Extending the range of architectural elements for fluvial sediment bodies. Sedimentary Geology, 190, 227-240.

Figueiredo, F. T., Almeida, R. P., Freitas, B. T., Marconato, A., Carrera, S. C., \& Turra, B. B. (2016). Tectonic activation, source area stratigraphy and provenance changes in a rift basin: the Early Cretaceous Tucano Basin (NE-Brazil). Basin Research, 28(4), 433-445.

Freitas, B. T. (2014). A Formação Marizal (Aptiano) na Bacia do Tucano (BA): contribuições à análise da arquitetura de depósitos fluviais e inplicações palebiogeográficas. Universidade de São Paulo.

Harms, J. C., Southard, J. B., \& Walker, R. G. (1982). Fluvial deposits and facies models.

Julien, P. Y., \& Klaassen, G. J. (1995). Sand-dune geometry of large rivers during floods. Journal of Hydraulic Engineering, 121, 657-663.

Karim, F. (1999). Bed-form geometry in sand-bed flows. Journal of Hydraulic Engineering, $125,1253-1261$.

Knox, R. L., \& Latrubesse, E. M. (2016). A geomorphic approach to the analysis of bedload and bed morphology of the Lower Mississippi River near the Old River Control Structure. Geomorphology, 268, 35-47.

Kosin, M. D. (2008). O embasamento das bacias do Recôncavo, de Tucano e de Jatobá Uma visão a partir das cartas geológicas do Brasil ao milionésimo. Boletim de Geociencias Da Petrobras, 17(1), 89-108.

Kosuth, P., Callède, J., Laraque, A., Filizola, N., Guyot, J. L., Seyler, P., Guimarães, V. (2009). Sea-tide effects on flows in the lower reaches of the Amazon River. Hydrological Processes, 23(22), 3141-3150.

Kuchle, J., \& Dos Santos Scherer, C. M. (2010). Sismoestratigrafia de bacias rifte: Técnicas, métodos e sua aplicação o na Bacia do Recôncavo. Boletim de Geociencias Da Petrobras, 18(2), 179-206. 
Leclair, S. F., \& Bridge, J. S. (2001). Quantitative interpretation of sedimentary structures formed by river dunes. Journal of Sedimentary Research, 71(5), 713-716.

Lewin, J., \& Ashworth, P. J. (2014). Defining large river channel patterns: Alluvial exchange and plurality. Geomorphology, 215, 83-98.

Lima, C. C. U., \& Boas, G. da S. V. (1994). Mecanismos de transporte e deposição dos Conglomerados da Formação Marizal (Cretáceo Inferior) na Bacia do Recôncavo, Bahia, Brasil. Revista Brasileira de Geociências, 24(4), 240-246.

Magnavita, L. P. (1992). Geometry and kinematics of the Recôncavo-Tucano-Jatobá Rift, NE Brazil. Universidade de Oxford.

Magnavita, L. P., \& Cupertino, J. A. (1987). Concepção atual sobre as bacias do Tucano e Jatobá nordeste do Brasil. Boletim de Geociencias Da Petrobras, 1(2), 119-134.

Magnavita, L. P., Da Silva, R. R., \& Sanches, C. P. (2005). Roteiros geológicos - Guia de Campo da Bacia do Recôncavo, NE do Brasil. Boletim de Geociencias Da Petrobras, 13(2), 301-334.

Magnavita, L. P., Davison, I., \& Kusznir, N. J. (1994). Rifting, erosion, and uplift history of the Reconcavo-Tucano-Jatoba Rift, northeast Brazil. Tectonics, 13(2), 367-388.

Magnavita, L. P., Destro, N., Carvalho, M. S. S., Milhomem, P. da S., \& Souza-Lima, W. (2003). Bacias sedimentares brasileiras. Fundação Paleontológica Phoenix, 52, 1-9.

Maisey, J. G. (2000). Continental break up and the distribution of fishes of Western Gondwana during the early Cretaceous. Journal of African Earth Sciences, 33(2).

Miall, A. D. (1974). Paleocurrent analysis of alluvial sediments: a discussion of directional variance and vector magnitude. Journal of Sedimentary Research, 44.

Miall, A. D. (1985). Architectural-Element Analysis: A New Method of Facies Analysis Applied to Fluvial Deposits. Earth Science Reviews, 22, 261-308.

Miall, A. D. (1988). Architectural elements and bounding surfaces in fluvial deposits: anatomy of the Kayenta Formation (Lower Jurassic), southwest Colorado. Sedimentary Geology, 55(3-4).

Miall, A. D. (1996). Methods of architectural-element analysis. In The geology of fluvial deposits: sedimentary facies, basin analysis and petroleum geology. (75-98.). Springer-Verlag.

Miall, A. D. (2000). Principles of sedimentary basin analysis (3 ed). Springer-Verlag.

Miall, A. D. (2006). How do we identify big rivers? And how big is big? Sedimentary Geology, 186, 39-50.

Miall, A. D. (2016). Facies Models. In A Modern Synthesis (161-214). Springer International Publishing.

Milani, J. E., \& Davison, I. (1988). Basement control and transfer tectonics in the Recôncavo-Tucano- Jatobárift, Northeast Brazil. Tectonics, 154, 41-70. 
Milani, J. E., Lana, M. C., \& Szatmari, P. (1988). Mesozoic rift basins around the northeast Brazilian microplate (Recôncavo - Tucano - Jatobá, Sergipe - Alagoas). In TriassicJurassic rifiting: Continental Break up and the origin of the Atlantic Ocean and Passsive Margins (833-858).

Milani, J. E., Rangel, H. D., Bueno, G. V., Stica, J. M., Winter, W. R., Caixeta, J. M., \& Neto, O. da C. P. (2007). Bacias Sedimentares Brasileiras - Cartas Estratigráficas Introdução. Boletim de Geociencias Da Petrobras.

Oberg, K., Shelton, J. M., Gardiner, N., \& Jackson, P. R. (2009). Discharge and other hydraulic measurements for characterizing the hydraulics of Lower Congo River. The International Association for Hydraulic Research Congress, 1-8.

Payenberg, T. H., Sidi, F. H., \& Lang, S. C. (2003). Paleocurrents and reservoir orientation of Middle Miocene channel deposits in Mutiara field, Kutei Basin, East Kalimantan.

Paola, C., \& Borgman, L. (1991). Reconstructing random topography from preserved stratification. Sedimentology, 38, 553-565.

Ponte, F. C. (1978). Origem e acumulação de petróleo nas bacias sedimentares brasileras. In in. Congresso Brasileiro de petróleo. Rio de Janeiro: Instituto Brasileiro de Petróleo.

Potter, P. E., \& Pettijohn, F. J. (1977). Paleocurrents and basin analysis (2 ed). New York: Springer-Verlag.

Ranga Raju, K. G., \& Soni, J. P. (1976). Geometry of ripples and dunes in alluvial channels. Journal of. Hydraulic Research, 14, 241-249.

Reading, H. (1986). Facies. In In: Reading, H.G., (Ed.), Sedimentary Environments and Facies, 2nd edition. Blackwell.

Roden, J. E. (1998). The Sedimentology and Dynamics of Mega-Dunes, Jamuna by. University of Leeds.

Santos, C.C., Reis, C., Pedreira, A. J. (2010). Projeto Bacia do Tucano Central: Folha Ribeira do Pombal - SC.24-Z-A-IV; Folha Cícero Dantas - SC.24-Z-A-V. Estado da Bahia e Sergipe. salcador.

Sarker, M. H., Thorne, C. R., Aktar, M. N., \& Ferdous, M. R. (2014). Morpho-dynamics of the Brahmaputra-Jamuna River, Bangladesh. Geomorphology, 215, 45-59.

Selley, R. C. (1982). An introduction to sedimentology (2 da). London: Academic Press.

Tandon, S. K., \& Sinha, R. (2007). Geology of large rivers. In A. Gupta (Ed.), Large Rivers: Geology and Managment (7-28). John Wiley and Sons.

Ussami, N., Karner, G. D., \& Bott, M. H. P. (1986). Crustal detachment during South Atlantic rifting and formation of Tucano-Gabon basin system. Nature, 322, 629-632.

Viana, C. F., da Gama Junior, E. G., Simões, I. de A., Moura, J. A., Fonseca, J. dos R., \& Alves, R. J. (1971). Revisão estratigráfica da bacia recôncavo/tucano. Boltim Técnico Da Petrobrás, 14, 157-192. 
Walker, R. G. (1992). Facies, facies models and modern stratigraphic concepts. In In: R.G. Walker \& N.P. James (Eds.), Facies Models and Response to Sea-level Change ( $p$. 1-14.). Geological Association of Canada.

Wilbers, A. W. E., \& Ten Brinke, W. B. M. (2003). The response of subaqueous dunes to floods in sand and gravel bed reaches of the Dutch Rhine. Sedimentology, 50(6), 1013-1034.

Wu, C., Bhattacharya, J. P., \& Ullah, M. S. (2015). Paleohydrology and 3D facies architecture of ancient point bars, Ferron Sandstone, Notom Delta, south-central Utah, USA. Journal of Sedimentary Research, 85(4), 399-418.

Yalin, M. S. (1964). Geometrical properties of sand wave. Journal of the Hydraulics Division, 90(5), 105-119. 
Anexos 
Anexo 1. Resultado gráfico das análises de reconstrução de superfícies barra. Curralinho
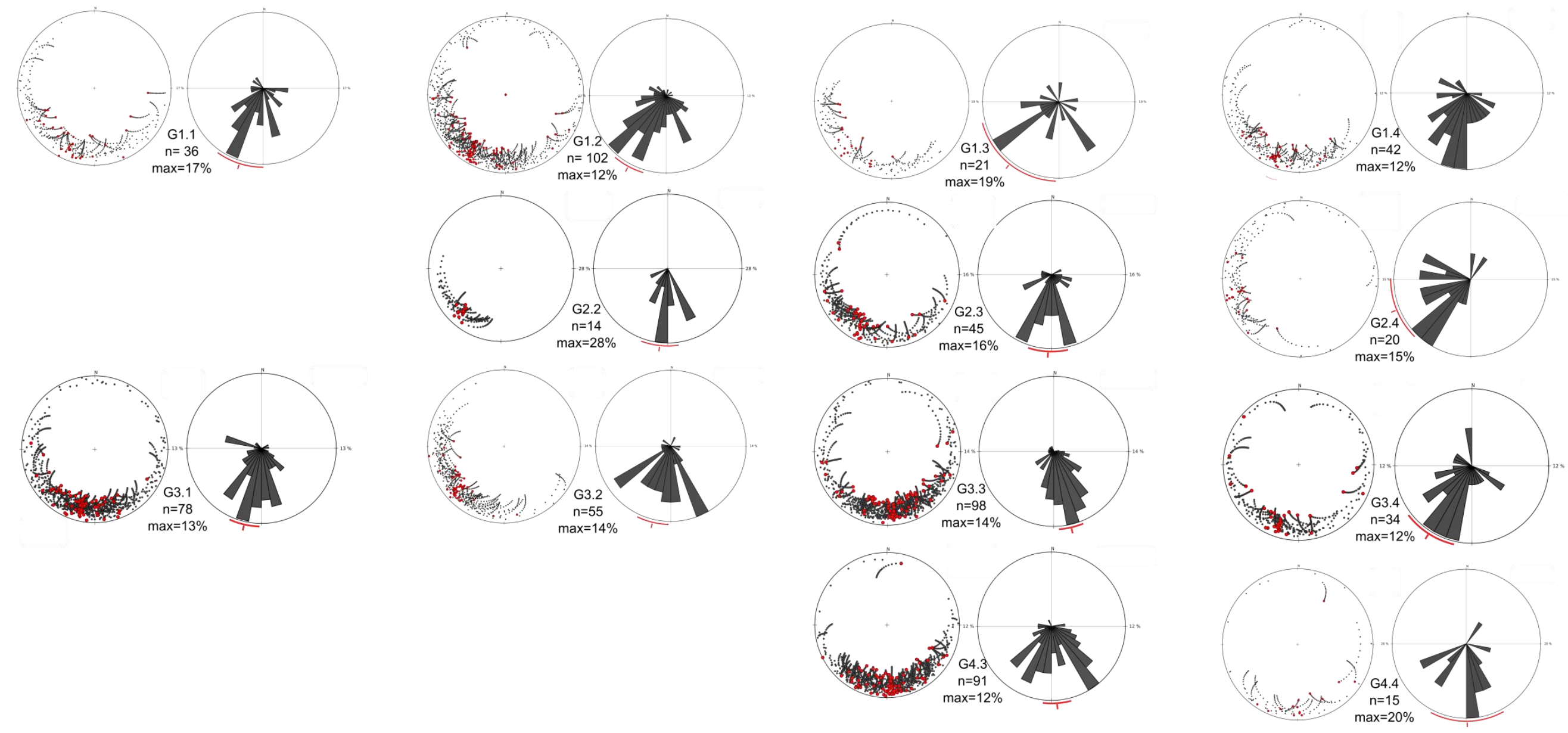
Anexo 2. Resultado gráfico das análises de reconstrução de superfícies barra, Banzaê , mapa $A$.
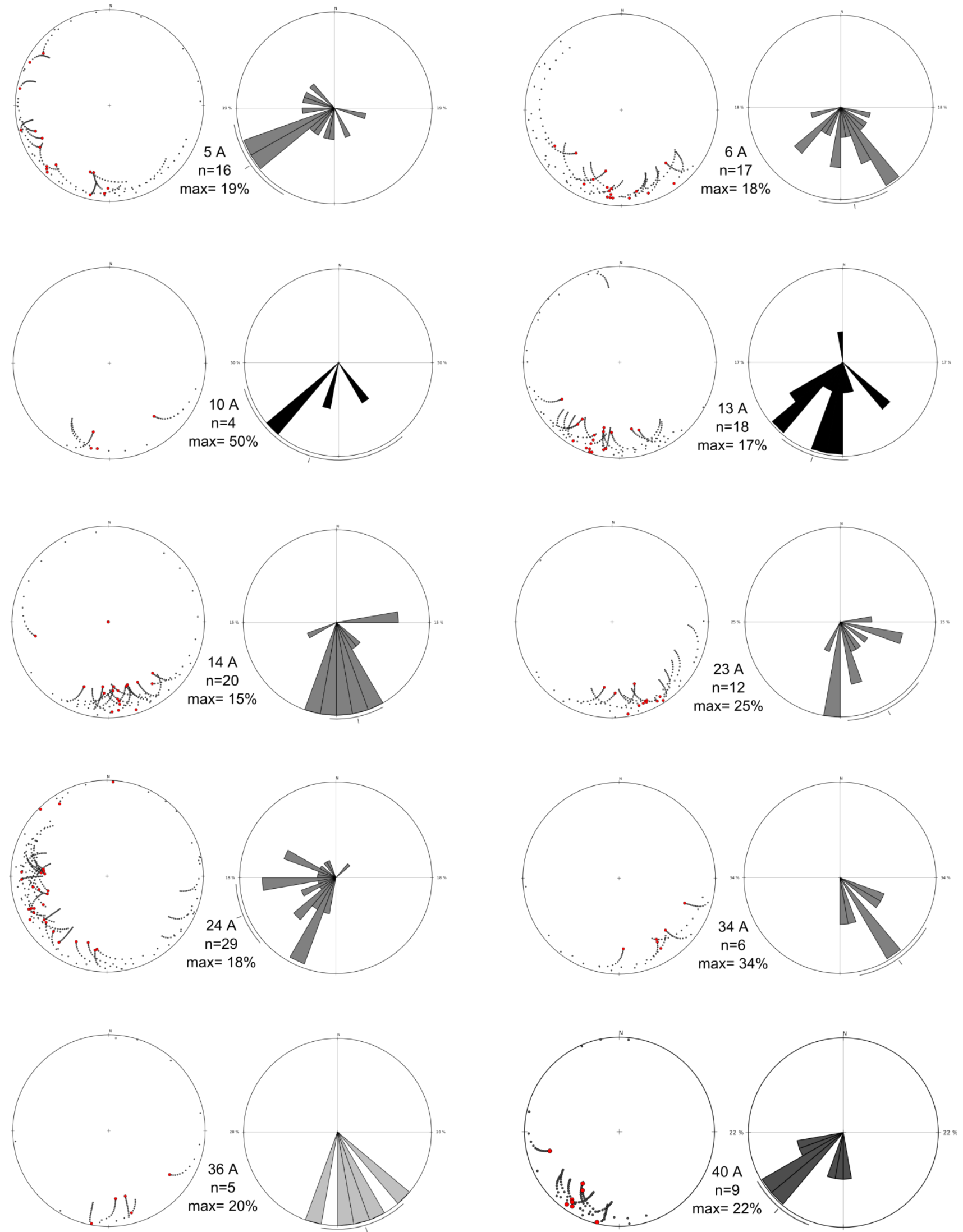
Anexo 3. Resultado gráfico das análises de reconstrução de superfícies barra, Banzaê , mapa B.
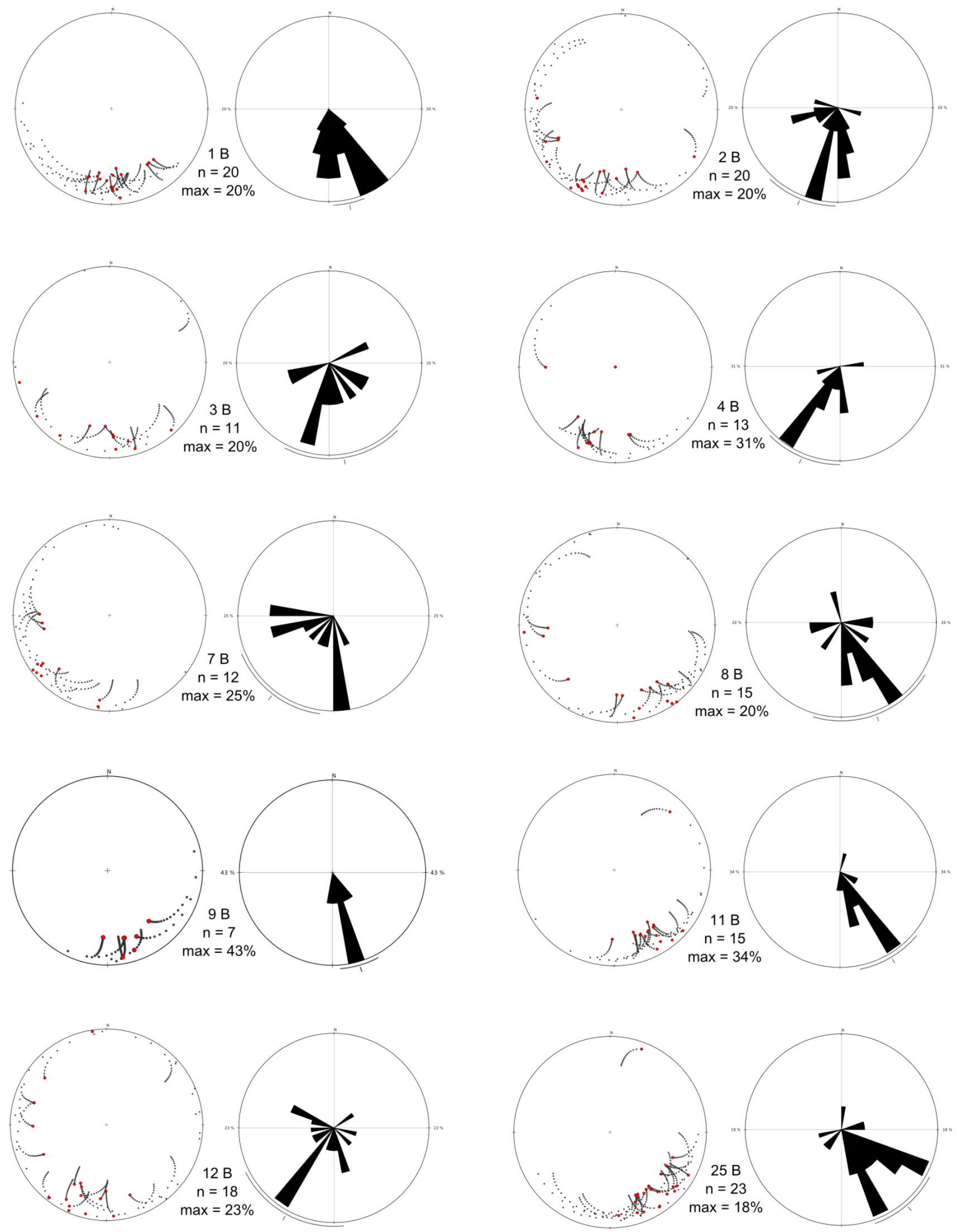
Continuação
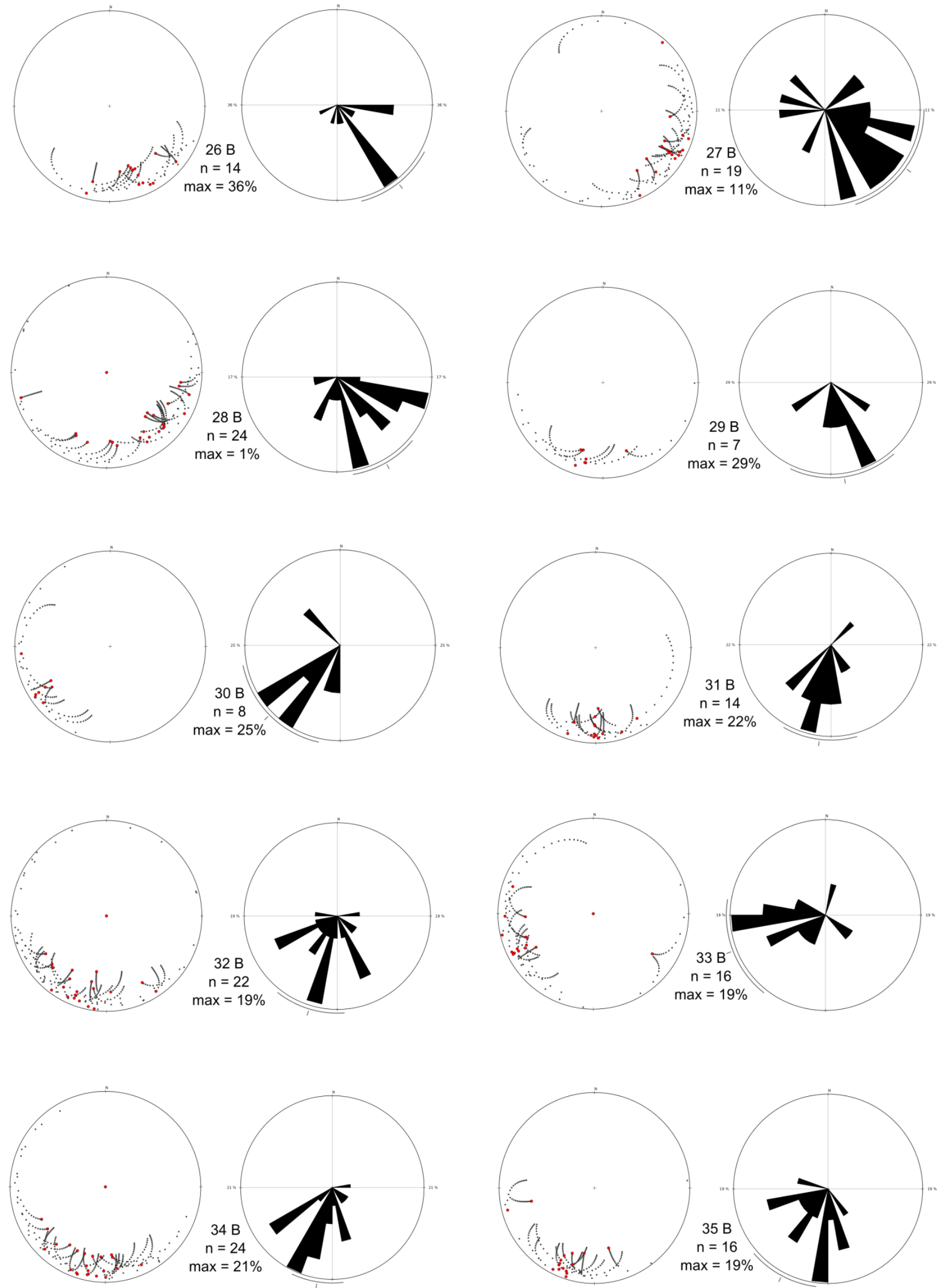

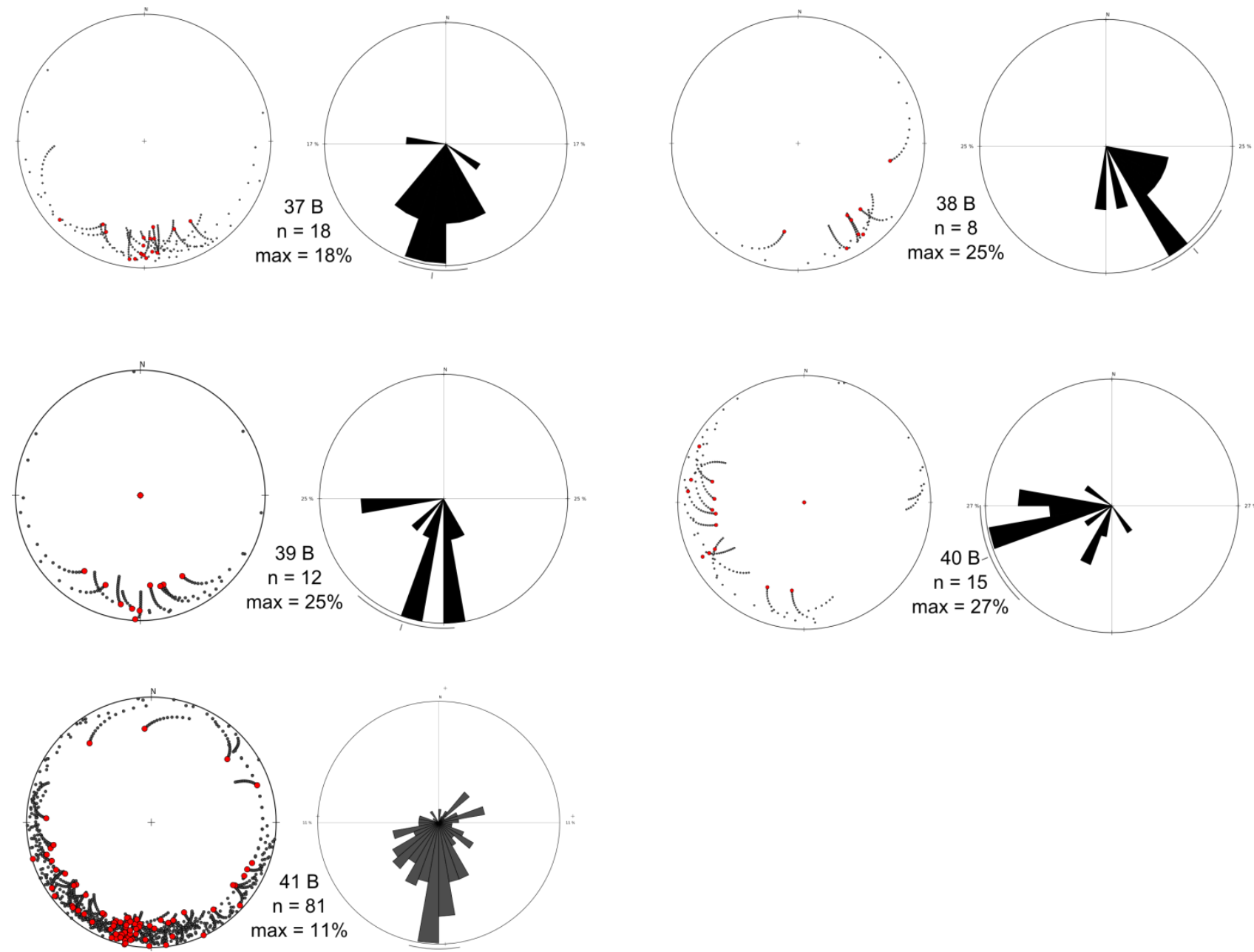
Anexo 4. Resultado gráfico das análises de reconstrução de superfícies barra, Banzaê , mapa C.
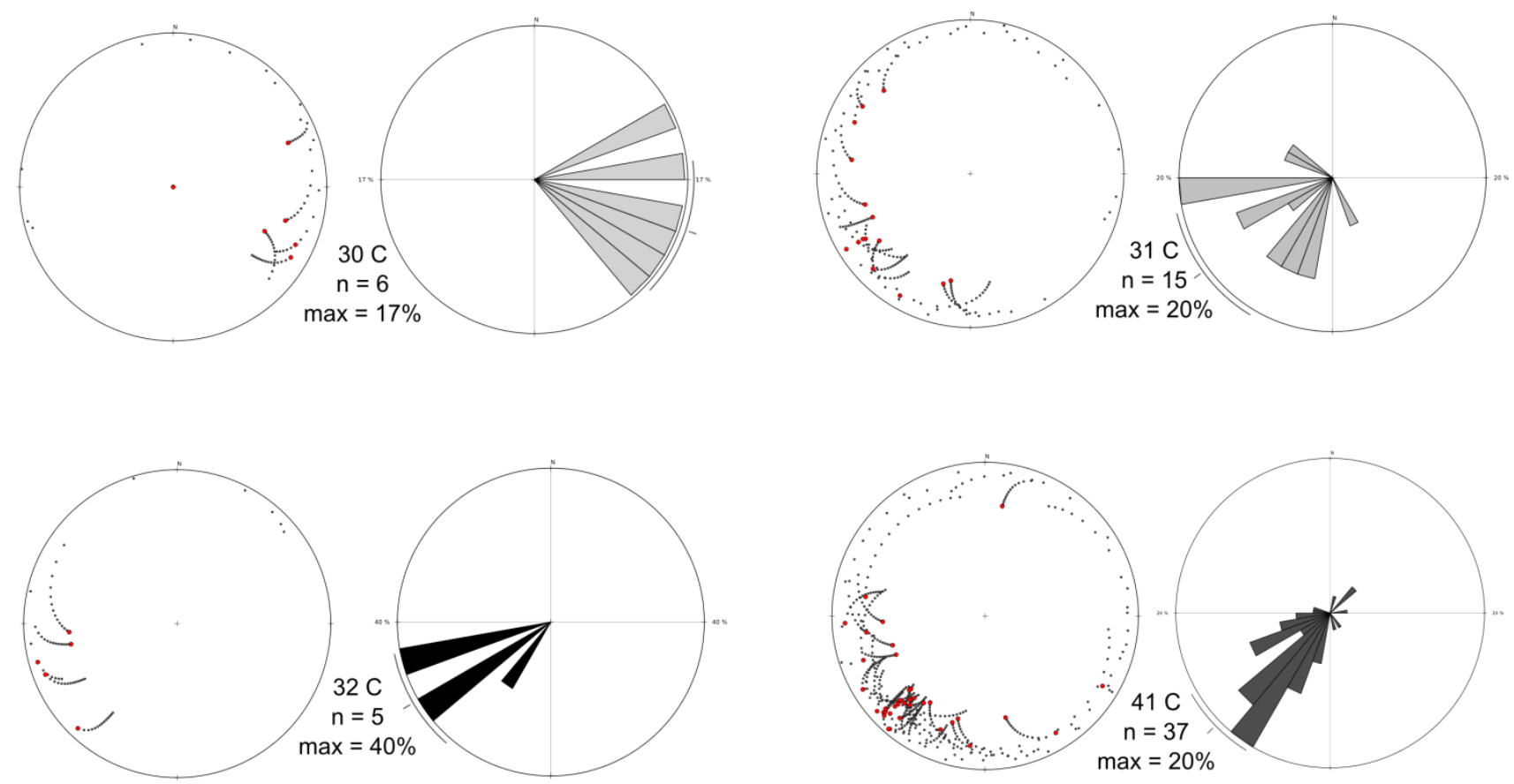